\title{
WestVirginiaUniversity
}

THE RESEARCH REPOSITORY @ WVU

Graduate Theses, Dissertations, and Problem Reports

2004

\section{Predictability of equity returns and conditional asset pricing}

$\mathrm{Ou} \mathrm{Hu}$

West Virginia University

Follow this and additional works at: https://researchrepository.wvu.edu/etd

\section{Recommended Citation}

$\mathrm{Hu}, \mathrm{Ou}$, "Predictability of equity returns and conditional asset pricing" (2004). Graduate Theses, Dissertations, and Problem Reports. 2113.

https://researchrepository.wvu.edu/etd/2113

This Dissertation is protected by copyright and/or related rights. It has been brought to you by the The Research Repository @ WVU with permission from the rights-holder(s). You are free to use this Dissertation in any way that is permitted by the copyright and related rights legislation that applies to your use. For other uses you must obtain permission from the rights-holder(s) directly, unless additional rights are indicated by a Creative Commons license in the record and/ or on the work itself. This Dissertation has been accepted for inclusion in WVU Graduate Theses, Dissertations, and Problem Reports collection by an authorized administrator of The Research Repository @ WVU.

For more information, please contact researchrepository@mail.wvu.edu. 


\title{
Predictability of Equity Returns and \\ Conditional Asset Pricing
}

\author{
$\mathrm{Ou} \mathrm{Hu}$ \\ Dissertation submitted to the \\ College of Business and Economics \\ at West Virginia University \\ in partial fulfillment of the requirements \\ for the degree of \\ Doctor of Philosophy \\ In \\ Economics \\ Ronald J. Balvers, Ph.D., Chair \\ Ashok B. Abbott, Ph.D. \\ Victor K. Chow, Ph.D. \\ Stratford M. Douglas, Ph.D. \\ Kern Kymn, Ph.D. \\ Department of Economics \\ Morgantown, West Virginia \\ 2004
}

Keywords: Asset Pricing, Stock Price Predictablity, Trading Strategies, Kalman Filter

Copyright (C) $2004 \mathrm{Ou} \mathrm{Hu}$ 


\section{ABSTRACT \\ Predictability of Equity Returns \\ And \\ Conditional Asset Pricing}

$\mathrm{Ou} \mathrm{Hu}$

In this dissertation, I investigate the applicability of some asset-pricing models by exploiting the predictive power of structural variables and accommodate the characteristic of predictability of stock returns in a theoretical conditional asset-pricing framework.

In the first chapter of the dissertation, I briefly review the relevant literature on the predictability of stock returns, and discuss the motivations for my research, and finally present my contributions to the existing literature while providing some discussions for future research. Chapter 2 examines the ability of the Fama-French three-factor model and the CAPM in estimating portfolios' returns. Instead of using historical average of risk premiums as a proxy for the estimated risk premiums, I propose that the estimation of risk premiums is conditioned on structural variables. The out-of-sample results from a simple trading strategy show that at least in the short-run, the structural variables generate better estimates of risk premiums than the historical averages of risk premiums, and the Fama-French three-factor model outperforms the CAPM in estimating portfolios' returns. Chapter 3 of the dissertation investigates the common and country-specific components in national stock price indices. The proposed general dynamic state-space model not only incorporates the feature of predictability of stock returns by modeling the price index as the combination of a permanent component and a transitory component, but also allows distinguishing the common shocks shared by each country from the country-specific shocks. It is found that for the G7 countries, there exist country-specific permanent and transitory components, which implies that the price indices of these countries are not only predictable, but also they are not cointegrated around one stochastic trend. Therefore, there exist potential long-run international diversification benefits. In light of the predictability of stock returns, Chapter 4 proposes a conditional two-beta intertemporal asset pricing model to investigate how the permanent shock and the transitory shock to market return are priced. Two decomposition methods are employed: the HodrickPrescott approach and the unobserved component method with Markov-Switching disturbances. The traditional two-pass evaluation indicates that this two-beta model outperforms the CAPM, but it is not as good as the Fama-French three-factor model in explaining stock returns. 


\section{ACKNOWLEDGEMENTS}

This work can not have been done without contributions from a large group of people. With honor, I wish to express my sincere appreciation and gratitude to all.

Especially, I would like to thank my advisor, Ronald Balvers, for his remarkable patience and dedication in guiding me through this work and for his inspiration for my research. A great teacher can influence one's whole life. Not only has he exemplified what a great mentor is, but he has also showed us what constitutes a real researcher: rigorous attitude, hard work, and unfailing pursuit of truth. I would also like to thank my dissertation committee members who have influenced and shaped my perception of this research: Ashok Abbot, K. Victor Chow, Stratford Douglas, and Kern Kymn.

My work has benefited from discussions with an outstanding group of professors and fellow graduate students. Therefore, I would like to thank Jon Vilassuso, Arabinda Basistha, Alexei Egorov, Ding Du, Dayong Huang, and Zhaodan Huang. Special thanks to Barbara Michniak for her incomparable help. To Samia Islam, words just can not express how grateful I am to have had such a wonderful friend as you, best luck on your journey.

Finally, I would like to express my great indebtedness to my parents and my dear sister. Without your unconditional love, support and faith, I could never have accomplished this work. To them, I wish good health and happiness.

To All: Where there is a will, there is a way. 


\section{TABLE OF CONTENTS}

NOTICE OF COPYRIGHT....................................................................................

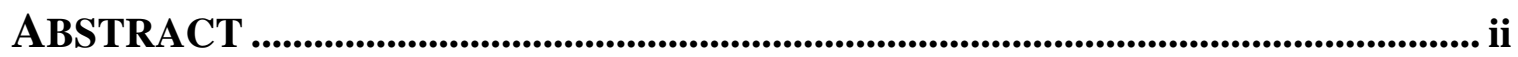

ACKNOWLEGEMENTS .................................................................................................. iii

TABLE OF CONTENTS _........................................................................................ iv

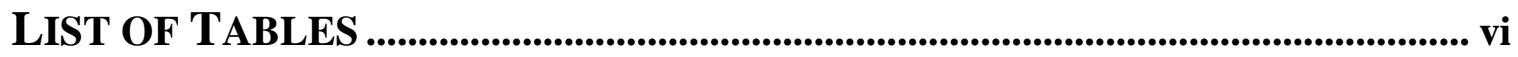

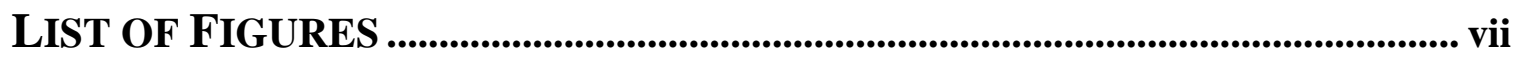

\section{CHAPTER 1:}

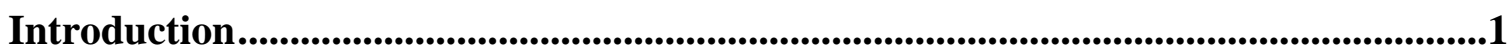

\section{CHAPTER 2:}

Applicability of the Fama-French three-factor model and the CAPM in estimating portfolio returns ......................................................................................................................7

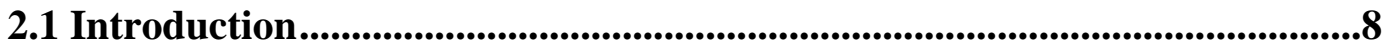

2.2 The Fama and French three-factor model.....................................................12

2.3 Data and Methodology ...........................................................................................13

2.4 In-sample estimation.........................................................................................17

2.5 Out of sample performance of a simple trading strategy ..............................19

2.5.1 One month ahead forecast...............................................................19

2.5.2 3 months ahead up to 4 years ahead forecasts................................22

2.5.3 Two more comparable cases ..............................................................24

2.5.4 A further evaluation on the correctness of the test models ..........25

2.6 Testing for stochastic dominance ....................................................................26

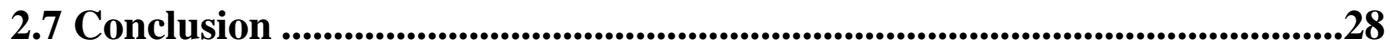




\section{CHAPTER 3:}

Common and country-specific components in national stock prices .............................42

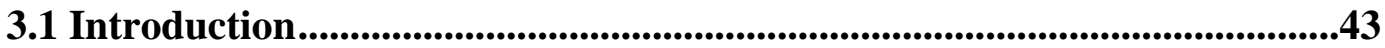

3.2 Review of previous studies .......................................................................................46

3.3 Mean reversion in control of cointegrating vector..............................................48

3.4 A general dynamic factor model in consideration of common and country-specific components in national stock prices ...........................................53

3.5 Conclusion ......................................................................................................................59

\section{CHAPTER 4:}

Pricing permanent and transitory betas .............................................................................65

4.1 Introduction.....................................................................................................66

4.2 Decomposition of market returns...............................................................................70

4.2.1 Hodrick and Prescott decomposition (H-P) ........................................71

4.2.2 The unobserved component (UC) approach ......................................73

4.3 Model shocks to market return in a dynamic asset-pricing model .............77

4.4 Evaluation of an asset-pricing model ...........................................................80

4.5 A conditional multivariable asset-pricing model ................................................85

4.6 Conclusion ..........................................................................................................................88

\section{APPENDIX:}

State-space model and Kalman Filter estimation procedure..........................................106

REFERENCES ........................................................................................................111 


\section{LIST OF TABLES}

Table 2.1 - Summary statistics of 17 equal-weighted industry portfolios and other predictive variables: monthly data from 1953:04 to 2001:10.

Table 2.2 - In-sample estimation of Fama and French three factors .......................................................31

Table 2.3 - In-sample estimation of factor loadings...........................................................................32

Table 2.4 - Out of sample trading strategy performance of F\&F three-factor model based on common practice

Table 2.5 - Out of sample trading strategy performance of the F\&F three-factor model based on the estimation procedures described in section IV

Table 2.6 - Out of sample trading strategy performance of CAPM based on the estimation procedures described in section IV.

Table 2.7 - Out-of-sample performance for five different means of in-sample selection over seven different horizons

Table 2.8 - Out-of-sample performance for more comparable cases ......................................................38

Table 2.9 - Test for the difference between actual excess return and expected excess return ..............40

Table 2.10 - Conditional Mean Dominance for the out-of-sample performance for four different methods of in-sample selection.

Table 3.1 - Augmented Dickey-Fuller unit root test for the difference between a country's price index and the world index $\left(P_{t}^{i}-P_{t}^{w}\right)$

Table 3.2 - Mean reversion in control of the cointegration relationship between national stock price indices and the world price index

Table 3.3 - Out-of-sample performance of a parametric contrarian trading strategy

Parameters are estimated for two different state space models.

Table 3.4 - Out-of-sample performance of a parametric contrarian trading strategy

Parameters are estimated for two different state space models.

Table 3.5 - Drifts and AR(1) coefficients estimates for the state space model........................................56

Table 3.6 - Estimation of the share of common trend and country-specific trend.................................57

Table 3.7 - Estimation of the share of common cycle and country-specific cycle ...................................57

Table 4.1 - Descriptive statistics for real stock market returns

Table 4.2 - The correlation of permanent and transitory shocks for the market price from H-P decomposition

Table 4.3 - Estimates of the state space model of real stock market returns (1926:07-2003:12) $\quad$.........94

Table 4.4 - Estimates of the state space model of real stock market returns (1926:07-2003:12) with Markov-switching variances

Table 4.5 - The correlation of permanent and transitory shocks for the market price from the UCMS decomposition.

Table 4.6 - Permanent and transitory $\beta$ s for the $25 \mathrm{ME}$ and BE/ME portfolios ...............................98

Table 4.7 - Permanent and transitory $\beta$ s for the $25 \mathrm{ME}$ and BE/ME portfolios ...............................100

Table 4.8 - Asset pricing tests with a cross-sectional regression on mean return ..............................102

Table 4.9 - Asset pricing tests with Fama-MacBeth procedure .............................................................103

Table 4.10 - Evaluation of a six-beta asset-pricing model ........................................................................105 


\section{LIST OF FIGURES}

Figure 2.1 - Out-of-sample performance (Max1-Min1) for five different means of insample selection over seven different horizons

Figure 2.2 - Out-of-sample performance (Max1-Min1) for four different comparable cases.

Figure 4.1 - U.S. real stock market price and the Hodrick-Prescott trend Monthly, 1926:07-2003:12

Figure 4.2 - The Hodrick-Prescott cycle for the U.S. real stock market price Monthly, 1926:07-2003:12

Figure 4.3 - U.S. real stock market price and the Hodrick-Prescott trend Quarterly, 1926: III-2003: IV

Figure 4.4 - The Hodrick-Prescott cycle for the U.S. real stock market price Quarterly, 1926: III-2003: IV

Figure 4.5 - U.S. real stock market price and the Hodrick-Prescott trend Annually, 1926-2003

Figure 4.6 - The Hodrick-Prescott cycle for the U.S. real stock market price Annually, 1926-2003

Figure 4.7 - U.S. real stock market price and the UC-MS trend Monthly, 1926:072003:12

Figure 4.8 - The UC-MS cycle for the U.S. real stock market price Monthly, 1926:07-2003:12.

Figure 4.9 - U.S. real stock market price and the UC-MS trend Quarterly, 1926: III2003: IV

Figure 4.10 - The UC-MS cycle for the U.S. real stock market price Quarterly, 1926: III-2003: IV

Figure 4.11 - U.S. real stock market price and the UC-MS trend Annual, 1926-2003

Figure 4.12 - The UC-MS cycle for the U.S. real stock market price Annual, 1926- 
CHAPTER 1

Introduction 


\section{Chapter 1}

\section{Introduction}

A large literature has documented the predictability of stock returns. Substantial evidence supports the positive autocorrelation of stock returns in the short-run and the negative autocorrelation in the long-run. Poterba and Summers (1988) and Fama and French (1988) find evidence of mean reversion by assuming stock price as the sum of a trend component and a cyclical component. The work of DeBondt and Thaler (1985, 1987), Chopra, Lakonishok, and Ritter (1992), Richards (1997) among others finds that a contrarian strategy of holding portfolios with the lowest previous returns and shorting those with the highest previous returns generates positive excess returns. On the other hand, the work of Jegadeesh and Titman (1993, 2001), Chan, Jegadeesh, and Lakonishok (1996), Rouwenhorst (1998), Chan, Hameed and Tong (2000), Grundy and Martin (2001), and others discovers that a momentum strategy of holding portfolios with the highest previous returns and shorting those with the lowest previous returns generates positive excess returns. These two strategies are not contradicting each other since the contrarian strategies work for a sorting period ranging from 3 to 5 years prior and a similar 3 to 5 years holding period, whereas momentum strategies work for a shorter period from 1 month (or more commonly 3 months) to 12 month. In additional to the findings that the predictability of stock returns is implied in the patterns of the autocorrelation of stock returns, some studies also find that stock returns can be predicted by other variables. Campbell (1987), Fama and French (1989), Ferson and Harvey, and Cooper, Gulen and Vassalou, among many others, find that macrovariables such as the 
dividend yield, the default premium, the term premium, and the short-term interest rate forecast excess stock market returns. The mean reversion and the momentum in stock returns defy a simple explanation. Balvers and Wu (2003) formulate a parametric approach which combines mean reversion and momentum. They find that standard risk factors do not account for any of the profitability of the combination strategies: even the Fama-French three factor model can not explain the excess returns. However, their findings support a behavior overreaction perspective. Few studies find theoretical explanations for the non-randomness in stock returns in a general equilibrium framework, except Campbell and Vuolteenaho (2003)'s two-factor intertemporal model, they interpret the two components (cash flow news and discount rate news) as permanent and transitory shocks to wealth.

In this dissertation, I attempt to accommodate the characteristic of predictability of stock returns in a theoretical conditional asset-pricing framework by directly modeling the permanent and transitory shocks to stock returns and I also investigate the applicability of some asset-pricing models by exploiting the predictive power of structural variables.

In the model-based estimation of the cost of equity capital, the common practice uses the average historical factor premiums as a proxy for the estimated factor premiums. But evidence shows that the common practice generates very inaccurate estimates. Therefore, in the second chapter of this dissertation, I propose an alternative way to estimate factor premiums by using structural variables that have been shown to be important predictors of future asset returns. Therefore, the estimation of future risk premiums is conditioned 
on the historical value of some structural variables. Based on the out-of-sample results from a simple trading strategy, my estimation procedure beats the common practice for both the Fama- French three-factor model and the CAPM. Also, the Fama and French three-factor model performs better than the CAPM, at least in the short run. Moreover, a conditional mean dominance (CMD) criterion confirms the better performance of the Fama and French three-factor model under all market situations. However, in the long run, neither asset-pricing model, using either estimation procedure, has good performance. As a result, at least in the short run, the Fama and French three-factor model with factor premiums estimated from structural variables should be recommended for calculating the cost of equity capital. For further studies, the robustness of the trading strategies can be examined to different sets of portfolios, and instead of fixed in-sample model method, the selection of the in-sample model can be endogenized based on some methods like adjusted $R^{2}$ or terminal wealth.

Previous studies on the cointegration among national stock markets give inconsistent implications on the international diversification benefits. Chapter 3 of this dissertation designs a general dynamic state space model which investigates the importance of common world-wide components and country specific components in national stock market indices. It is found that for the G7 countries, there exist country-specific permanent and transitory components. Based on a variance decomposition analysis, Germany, Italy and Japan’s country-specific permanent shock accounts for about half of their total permanent shock. Most of France, Germany and the United Kingdom's transitory shocks are found to be country-specific. Therefore, the G7 countries seem not 
to cointegrate around one common stochastic trend, and potential long-run international diversification benefits exist. A potential extension of this study is to look at other countries and I expect that for developing countries or less open-economic countries, they probably share less common shocks and their stock markets is more likely affected by their own country-specific shocks.

Chapter 4 makes an attempt to propose a conditional two-beta intertemporal asset pricing model to investigate how the two betas - permanent and transitory will be priced by risk-averse investors. The Hodrick-Prescott (HP) approach and the unobserved components method with Markov-switching disturbances are applied to decompose the real returns for the U.S. stock market. Empirically, we find that small-firm stocks and value stocks have higher permanent betas than large-firm stocks and growth stocks. However, our model in a traditional two-pass evaluation framework only outperforms the CAPM with an inconsiderable margin. The Fama and French three-factor model performs best among all the models involved. The problem could lie in the fact that so far there is no perfect decomposition method. A more sophisticated model would probably only sacrifice the precision in estimation and the computation time. A feasible further trial can consider switching regimes in the drift (the unconditional expected market return) in the permanent component. Besides, the whole sample can be divided into different periods. As Campbell and Vuolteenaho (2003) suggests, the sample can be split at 1963:07, because that is when COMPUSTAT data become reliable and because most of the evidence on the book-to-market anomaly is obtained from the post-1963:07 period. Another possible break point is 1952:01, since Campbell (1991) and Hodrick (1992) 
found a structural change in the dividend process after this date. In this chapter we also derive a six-beta model based on a stochastic discount factor. The Fama-MacBeth evaluation method shows that the six-beta model performs as well as the Fama-French three-factor model in explaining the returns of the 25 book-to-market and size portfolios.

In conclusion, this dissertation contributes to the predictability of asset returns and the conditional asset pricing literatures. It is found that in the application of an asset-pricing model in estimating portfolio returns, the historical average of a risk premium is not a good estimate for its future value, and using structural variables instead might be a better alternative. It is also found that the market return seems to contain two different kinds of information - permanent and transitory - which are both priced in a conditional asset pricing framework. What is so significant is that the conditional asset pricing model is intended to provide a risk-based explanation for the predictability of portfolio returns. This is the first attempt in theoretically incorporating the predictability of portfolio returns in an equilibrium asset pricing model. Further efforts would be made to improve the model's performance in explaining portfolio returns. 


\section{CHAPTER 2}

Applicability of the Fama-French three-factor model and the CAPM in estimating portfolio returns 


\section{Chapter 2}

\section{Applicability of the Fama-French three-factor model and the CAPM in estimating portfolio returns}

\subsection{Introduction}

To evaluate the profitability of a project, most practitioners rely on an asset-pricing model to estimate the cost of capital ${ }^{1}$. As is well known, project managers in project valuation have employed the Capital Asset Pricing Model (CAPM) since its origination in the $1960 s^{2}$. In practice, to obtain an estimate of the cost of equity capital, practitioners first estimate the risk loadings by regressing historical asset returns (usually the most recent five years) on risk factors and then estimate risk premiums by averaging the long term historical risk premiums. However, there is clear evidence ${ }^{3}$ that the historical average market excess return is much higher than the actual market risk premium so that the estimate of equity returns substantially overstates what rational investors would have expected to earn. The poor performance of this common practice has made asset-pricing models untrustworthy.

Furthermore, the fact that a particular asset-pricing model can perform well in explaining asset returns does not mean it has the same power for forecasting asset returns. As Fama and French (1997) demonstrate, the imprecision in estimating equity returns comes from two sources: one is the estimation error of the risk loadings (risk sensitivity or

\footnotetext{
${ }^{1}$ In the financial literature, Net Present Value (NPV) is one of the evaluation criteria of a project's profitability. A key input to computing the NPV is the project's cost of capital, which serves as a discount rate for estimated future cash flows.

${ }^{2}$ Some surveys about how prevalent the application of CAPM in the industry can be found in Gitman and Mercurio (1982), Bruner, Eades, Harris and Higgins (1998), Graham and Harvey (2001).

${ }^{3}$ For references, see Blanchard (1993), Wadhwani (1999), Jagannathan, McGrattan and Scherbina (2001), and Fama and French (2001).
} 
exposure) and the other is the estimation error of the risk premiums (price of risk); and between these two, the uncertainty about risk premiums is responsible for a larger part of the problem in estimating the cost of capital. Ferson and Locke (1998), analyzing the sources of errors in CAPM-based estimates of expected returns on industry portfolios, reach a similar conclusion that errors in estimating betas (factor loadings) probably do not matter as much as errors in estimating market premium. Pastor and Stambaugh (1999) examine the estimation of costs of equity for individual firms by using a Bayesian approach and comparing estimates of three factor-based pricing models. They find that model uncertainty is less important than parameter uncertainty within any given model; and without mispricing uncertainty, estimation errors of factor premiums are likely to account for more of the uncertainty about the cost of capital.

Merton (1980) investigates the problem of estimating market excess return and presents three models, all of which explicitly relate excess return to its variance; and performance of those models mostly depends on how accurate the variance of market excess returns can be estimated. In this chapter, I do not intend to invent a model to estimate the variancecovariance in returns ${ }^{4}$, but out of the concern about the prevailing discredit on the popular use of the CAPM in practice, I attempt to assess the usefulness of standard asset pricing models in predicting future returns. Following the spirit of Elton $(1999)^{5}$, I design an alternative way to estimate factor premiums. Then I examine empirically the ability of the F\&F three-factor model and the CAPM in forecasting asset returns. The approach

\footnotetext{
${ }^{4}$ Although fundamentally different in approach, my results are analogous to Chan, Karceski and Lakonishok's (1999). They also find that factor-based models generate some improvement in their ability to predict future covariances compared with forecasts based on historical covariances.

${ }^{5}$ While arguing that the average realized returns are poor proxies for expected returns, Elton (1999) proposes some alternative ways to estimate expected returns.
} 
employed in this chapter is a simple trading strategy ${ }^{6}$, by which I can examine relatively clearly the economic significance of the predictability of excess returns so as to assess the forecasting ability of a particular asset-pricing model. As has been widely accepted', 'the major determinant of price movements on the stock exchange is the business cycle' [Angas (1936)]. Therefore, I first estimates the three factor premiums by using their own lags and some standard structural variables (such as term premium, default risk premium, dividend yield, industrial production growth rate and short interest rate) and then risk loadings are estimated by regressing historical returns of 17 U.S. industries ${ }^{8}$ on historical factor returns. Accordingly, the estimated next-period excess returns for the 17 industry portfolios can be calculated. It is noteworthy that the methodology applied in this chapter is fundamentally different from what previous studies used. For instances, Ferson and Harvey (1999) allow factor loadings to be conditional on some predetermined variables to test the Fama-French three-factor model for the cross section of stock returns; and Cooper, Gulen and Vassalou(2001) directly use business cycle variables and macroeconomic variables to predict asset future returns and find some evidence to support that the size factor and bookto-market factor are representative of fundamental economic risks. However, those studies have not looked at the applicability of any particular asset pricing model.

After expected returns are calculated, a trading strategy is applied to hold the portfolio(s) with the highest expected excess return and (short) sell the one(s) with the

\footnotetext{
${ }^{6}$ The trading strategy adopted in this chapter follows the spirit in Fama and Schwert (1977), Jegadeesh (1990), Pesaran and Timmermann (1995, 2000), and Balvers, Wu, and Gilliland (2000), among others. ${ }^{7}$ See, for instance, the articles by Campbell (1987), Balvers, Cosimano, and McDonald (1990), Cochrane (1991), Ferson and Harvey (1993), Pesaran and Timmermann (1995), Cooper, Gulen and Vassalou (2001). ${ }^{8}$ See the industry definition on Kenneth French's website: http://mba.tuck.dartmouth.edu/pages/faculty/ken.french/
} 
lowest expected excess return. Finally, I can calculate the realized excess returns for long and short positions and the excess profits for a zero-investment strategy (combining long and short positions). Based on the empirical results, it is impressive to see that, for the forecasting horizons from 1 month ahead to 2 years ahead, the estimation procedure adopted in this chapter gets the better of the common practice and the conditional mean dominance (CMD) also confirms this result; however, for a longer period forecast (3 years up to 4 years), the F\&F three-factor model loses its power in forecasting asset excess returns no matter which estimation procedure is applied. Moreover, the F\&F three-factor model evidently outperforms the CAPM for 1 month up to 2 years ahead forecasting. For 3 years up to 4 years ahead forecasting, both F\&F three-factor model and CAPM seem unable to predict excess returns. Therefore, consistent with previous studies, some evidence is provided here against the common practice of estimating the cost of capital, but at the same time provides some support for the application of an alternative estimation procedure in capital budgeting decisions. Meanwhile, the difference in out-of-sample performance between the F\&F three-factor model and the CAPM implies support for the risk-based explanation of the size factor (SMB) and the book-to-market factor (HML). The next section briefly lays out the F\&F three-factor model. Section 2.3 gives the details of data and methodology. Section 2.4 reports the in-sample estimation of factor risk premiums and risk loadings. Out-of-sample performance of trading strategies is presented in Section 2.5. Section 2.6 provides a conditional mean dominance test for the out-of-sample performance of four different zero-investment strategies. Section 2.7 concludes the chapter. 


\subsection{The Fama and French three-factor model}

Fama and French (1992) find that besides beta two additional factors - firm size and book-to-market ratio play an important role in explaining the cross section of expected stock returns and overcoming the inability of the CAPM in explaining size effect, value effect, and other apparent anomalies. Their findings have ever since been challenged as the subject of a series of chapters. The arguments around the Fama and French threefactor model could be classified as follows: 1. its explanatory power is an illusion arising from survivorship bias in the data [Lo and MacKinlay (1990b), Black (1993), Breen and Korajczyk (1995), Kothari, Shanken and Sloan (1995), Forster, Smith, and Whaley (1997)]; 2. data mining is the reason and the size effect is simply a sample period effect; 3. the model is a particular form of APT or ICAPM, and size and book-to-market factors represent fundamental risks [Fama and French $(1993,1995,1996)$, Liew and Vassalou (2000), Vassalou (2001)]. While the debate on its validation is on-going, the strong performance of this model in describing asset returns - not only for U.S. data, but also for international data [Fama and French (1998)] brings about more and more application of it in the real world. The F\&F three-factor model is as follows:

$r_{i t}-r_{f t}=b_{i}\left(r_{m t}-r_{f t}\right)+s_{i} r_{s m b, t}+h_{i} r_{h m l, t}+e_{i t}$

$r_{i t}$ : return on stock $i$ at time $t$

$r_{f t}$ : return on the risk-free asset at time $t$

$r_{s m b, t}:$ return on the size factor at time $t$

$r_{h m l, t}:$ return on the book-to-market factor at time $t$ 
$e_{i t}:$ mean-zero regression disturbance

The size factor, $r_{s m b, t}$ is the return on a zero-investment portfolio that is long on small size stocks (size is measured by multiplying market price with total number of outstanding stocks) and short on big size stocks; the book-to-market (B/M) factor, $r_{h m l, t}$ is the return on a zero - investment portfolio that is long on high B/M stocks and short on low B/M stocks ${ }^{9} . b_{i}, s_{i}$ and $h_{i}$ are factor loadings. Fama and French (1992) generate 25 portfolios sorted by size and book-to-market factors. For each of the 25 regressions in the form of equation (2.1), the typical $R^{2}$ is above 0.9 . The same regression is used by Fama and French (1997) on 48 industries and the average $R^{2}(0.68)$ is slightly higher than that (0.63) of the CAPM. The above evidence, among others, is supportive of the power of the F\&F three-factor model in explaining asset returns. However, in order to investigate its forecasting ability, equation (2.2) needs to be rewritten in a conditional form:

$r_{i t}-r_{f t}=b_{i} E_{t-1}\left(r_{m t}-r_{f t}\right)+s_{i} E_{t-1}\left(r_{s m b, t}\right)+h_{i} E_{t-1}\left(r_{h m l, t}\right)+\varepsilon_{i t}$

As equation (2.2) indicates, all the three factor premiums at time $t$ need to be estimated by means of historical available information up to time $t-1$. And the factor loadings can be estimated from the time-series regression (2.2).

\subsection{Data and Methodology}

All the variables are measured at monthly frequencies over the period from 1953:04 to $2001: 10^{10}$. 17 equal-weighted industry portfolios defined by Fama and French are

\footnotetext{
${ }^{9}$ Details about how to construct the SMB and HML factors are available on Kenneth French's Website.

10 The starting and ending points are determined by the data availability.
} 
examined in the test. The data are available on Kenneth French's website. They form the 17 industry portfolios by assigning each NYSE, AMEX, and NASDAQ stock to an industry group at the end of June of year $t$ based on its four-digit SIC code at that time and then compute returns from July of year $t$ to June of year $t+1$. Since in the F\&F three-factor model, excess returns are used as dependent variables, a risk free rate should be subtracted from actual returns. The one-month Treasury bill rate is used as the risk free rate. The Fama and French three factors -- the market excess return (mktexrt), the size factor (SMB) and the book-to-market (B/M) factor (HML) are obtained from Kenneth French's website. SMB is the excess return from a zero-investment strategy of buying small size portfolios and selling large size portfolios. HML is the excess return from a zero-investment strategy of buying value portfolios (high B/M ratio) and selling growth portfolios (low $\mathrm{B} / \mathrm{M}$ ratio). To predict the three factor premiums, the following variables are used in the test: dividend yield (DIV, the difference between market return with dividend and market return without dividend), the nominal one-month T-bill rate (TB), the industrial production growth rate (IP), the term premium (TERM, the difference between 10-year and 3-month Treasury yields) and the default risk premium (DEFP, the spread between Moody’s Bbb and Aaa corporate bond yields). DIV is obtained from the Center for Research in Security Prices (CRSP). TB is obtained from Ibbotson and Associates. IP, TERM and DEFP are all acquired from the Federal Reserve Bank of St.Louis. However, since I am looking at the forecasting ability of the F\&F three-factor model, what is different from previous studies is that these predictive variables are not used to directly predict stock returns ${ }^{11}$, but to predict the Fama and French factors (in the

\footnotetext{
${ }^{11}$ In Section V, part C, when all these predictive variables are directly used to predict the returns of
} 
test, the independent variables also include the lags of these three factors $)^{12}$. Then, the predicted (conditional) factor premiums are plugged into equation (2.2) to estimate the excess returns of the industry portfolios.

Table 2.1 reports the summary statistics of the 17 industry portfolios and the predictive variables. As shown, no obvious patterns can be detected across the means and the standard deviations of the 17 industries, because unlike the portfolios formed on size or $\mathrm{B} / \mathrm{M}$ ratio, the 17 industries were formed according to the characteristics and activities (indicated by SIC code) of individual firms. Therefore, the advantage of examining 17 industries instead of the commonly used size or $\mathrm{B} / \mathrm{M}$ decile portfolios is to avoid the suspicious inherent relationship between the two factors (SMB and HML) and the size or B/M decile portfolios.

Significant positive first-order autocorrelation exists over the 17 industries with all Pvalues less than 0.05. This is not surprising based on the finding that a strong and prevalent momentum exists in industries ${ }^{13}$. Autocorrelations of market excess returns (MKTEXRT) are very weak. In contrast, SMB and HML both exhibit stronger first order autocorrelation with P-values of 0.065 and 0.001 respectively. So, it is advisable to use lags of SMB and HML as predictors for next period SMB and HML. As for the other explanatory variables--TB, IP, TERM, DEFP and DIV-- they exhibit strikingly significant autocorrelations over almost all the time intervals (from 1 month to 36

industry portfolios, the out-of-sample performance is similar to the one by using the F\&F three-factor model with risk premiums estimated by these predictive variables.

${ }^{12}$ Liew and Vassalou (2000) show that HML and SMB can also predict future economic growth. And

Cooper, Gulen and Vassalou (2001) treat market excess return, HML and SMB as business cycle variables.

${ }^{13}$ See Moskowitz and Grinblatt (1999): ‘Do industries explain momentum?’. 
months) and the magnitude of autocorrelations tends to get less as the time interval gets longer.

As for the methodology, a recursive trading strategy starting from the first ten-year period 1953:04 to 1963:03 is formulated. First, in-sample estimation is conducted to predict the three factor premiums - MKTEXRT, SMB, and HML over all the historical data from 1953:04 to 1963:03 and using the following regression:

$F_{t}=\alpha+\sum_{k=1}^{n} \phi_{k}(L) \beta_{k} X_{t}+e_{t}$

where $F_{t}$ (the factor) can be $r_{m t}-r_{f t}$, or $r_{s m b, t}$, or $r_{h m l, t} \cdot \alpha$ is the intercept, $e_{t}$ is the error term, $\phi_{k}(L)$ is a $k^{\text {th }}$ lag operator, $\beta_{k}$ is a vector of regression coefficients for lag $k$, and $X_{t}$ is a vector of predetermined variables, which include $r_{m}-r_{f}, r_{s m b}, r_{h m l, t}$, TB, IP, TERM, DEFP and DIV. Then the coefficients' estimates from (2.3) are used to predict one-month forward factor premiums (referring to 1963:04), that is:

$\hat{F}_{t}=\hat{\alpha}+\sum_{k=1}^{n} \phi_{k}(L) \hat{\beta}_{k} X_{t}$

Secondly, besides the estimates of factor premiums, the estimates of factor loadings need to be obtained before calculating the expected excess returns of industry portfolios. Applying equation (2.1), we regress all the historical excess returns on the historical factor premiums to obtain the estimates of factor loadings $\hat{b}_{i}, \hat{s}_{i}, \hat{h}_{i}$ and then by way of equation (2.2), we multiply the estimates of factor loadings with their corresponding predicted factor premiums $\hat{F}_{t}$ to calculate the expected excess returns of industry portfolios. The third step is that, based on the sorted expected excess returns, a simple trading strategy is constructed, that is to hold the industry with the highest expected 
excess return and to short-sell the industry with the lowest expected return, and then to record the realized returns of the long position, short position and a zero-investment strategy (the difference between the long position and the short position) for the period 1963:04. Moving one month forward, I repeat the same steps 463 times until reaching the end of the entire period, 2001:10 and finally calculate the average realized excess returns and compare those with the average expected excess returns. As for 3-month up to 4-year ahead forecasts, a similar estimation procedure and trading strategy will be applied with the only difference that I use overlapping data ${ }^{14}$, because if I use non-overlapping cumulated returns for longer horizons, I will end up with a small number of observations and this will render the statistic inference unconvincing. One thing which is noteworthy is that even though overlapping data introduce serial correlation which renders the estimated standard errors inaccurate, as long as the ordinary least squares (OLS) estimators of coefficients are consistent, the in-sample estimation of factor premiums would be still valid since I only need the estimates of the coefficients to do out-of-sample estimation [Hansen and Hodrick (1980)].

\subsection{In-Sample Estimation}

This chapter follows the spirit of the F\&F three-factor model that if the three factors are indeed the representatives of fundamental economic risks faced by all the firms, then the conditional form of this model can be used to predict asset returns, as specified by equation (2.2). Table 2.2 presents the monthly in-sample estimation of the Fama and French three factors over the full time period 1953:04 to 2001:10. As indicated by the P

\footnotetext{
${ }^{14}$ Overlapping data are created based on monthly returns.
} 
values, among all the predictive variables, twelve-month lagged value of TERM, both the one-month and twelve-month lagged values of DEFP, the twelve-month lagged value of DIV and the one-month lagged value of TB seem important in predicting market excess returns. In contrast, only the one-month lagged value of MKTEXRT and the twelvemonth lagged value of TERM play a significant role in predicting the size factor, SMB. As for predicting the future value of HML, the important variables include the one-month lagged values of MKTEXRT, HML, TERM and DEFP and the twelve-month lagged values of DEFP and DIV. It is interesting to note that the adjusted R-squares for the three regressions are about the same value of 0.04 , which indicates that over the entire period, the overall predictabilities of the three factors are about the same by way of all the explanatory variables used in the test. What is worthwhile to check is to compare the overall adjusted R-squares with the in-sample rolling regressions' average adjusted Rsquares, which includes 463 results from 463 regressions. The average in-sample adjusted R-square for MKTEXRT is 0.036 with $\sigma$ (standard deviation) of 0.015 ; for $\mathrm{SMB}$, it is 0.08 with $\sigma$ of 0.025 ; for $\mathrm{HMB}$, it is 0.07 with $\sigma$ of 0.016 , which indicates that sometimes the monthly in-sample estimation is twice as much as the overall estimation. It is also interesting to check how the predicted values of the three factor premiums change over time. As for MKTEXRT, the average monthly predicted value is $0.26 \%$ with $\sigma$ of $1.28 \%$; for SMB, it is $0.23 \%$ with $\sigma$ of $1.14 \%$; for HML, it is $0.31 \%$ with $\sigma$ of $0.84 \%$. Evidently, the values of the predicted factor premiums $\left(\hat{F}_{t}\right)$ bear a significant level of volatility. 
The second part of the in-sample estimation is designed to obtain the factor loadings $\hat{b}_{i}, \hat{s}_{i}, \hat{h}_{i}$. Specifically, it is to regress the excess returns of industry portfolios on the historical factor premiums. Table 2.3 reports the results for the 17 industries. Based on equation (2.1):

$r_{i t}-r_{f t}=b_{i}\left(r_{m t}-r_{f t}\right)+s_{i} r_{s m b, t}+h_{i} r_{h m l, t}+e_{i t}$, monthly excess returns for each of the equally-weighted 17 industry portfolios are regressed on the historical values of the three factors: MKTEXRT, SMB, HML. Presented in Table 2.3 are the estimates of the factor loadings and the adjusted R-squares for the 17 industries over the whole sample period 1953:04-2001:10. As shown, the explicability of excess returns is fairly similar over the 17 industries with average adjusted R-squares over 70\%. The least explainable are Mines, Oil and Utility industries with average adjusted R-squares about 52\%. This result confirms that the F\&F three-factor model has significant power in explaining the 17 industries’ excess returns.

\subsection{Out of sample performance of a simple trading strategy}

\subsubsection{One month ahead forecast}

In the financial literature, a commonly used approach to evaluate the predictability of asset returns is to formulate an investment strategy and to see whether an economically significant profit can be generated. A simple trading strategy ${ }^{10}$ adopted in this chapter is described as follows: for the starting in-sample period 1953:04 to 1963:03, the estimates

\footnotetext{
${ }^{10}$ The trading strategy implemented here is similar in spirit to approaches employed previously by Fama and Schwert (1977), Breen, Glosten, and Jagannathan (1989), Pesaran and Timmerman (1995), and Balvers, Wu and Gilliland (2000), among others.
} 
of factor premiums and factor loadings for next month 1963:04 (out of sample) can be obtained from the estimation procedures in section 2.4, then the expected excess returns for the 17 industry portfolios can be calculated by equation (2.2); next, hold (long) the portfolio with the highest expected excess return and sell (short) the portfolio with the lowest expected excess return - referred to as 'Max1-Min1' ( or hold the three portfolios with the highest expected excess returns and sell three portfolios with the lowest expected excess returns, which is referred to as 'Max3-Min3'); after that, record the realized excess returns for the long and short positions and the difference between them (the zeroinvestment strategy) for 1963:04; then expand the sample period one month forward and repeat the steps until the last period, i.e. 2001:09; finally, compare the average realized excess returns with the average expected excess returns.

As pointed out in the introduction, estimation of the cost of capital from common practice has proven very inaccurate. Therefore, it is necessary to check the trading strategy performance of the F\&F three-factor model based on common practice. Table 2.4 shows that the out of sample performance of the common practice is poor indeed: for Max1-Min1, the difference (1_s_ac=0.195\%) between the average realized monthly return (0.704\%) of the long position (long_ac) and the average realized return (0.509\%) of the short position (short_ac) is insignificantly different from 0 with a t-statistic of 0.767, which contravenes the spirit of the trading strategy where long_ac is expected to be significantly greater than short_ac. Moreover, if the market excess return (MKTEXRT) is treated as a benchmark, it is also expected that long_ac is significantly greater than MKTEXRT and short_ac is significantly lower than MKTEXRT. However, 
for the common practice, not only are long_ac and short_ac similar but they are not statistically different from MKTEXRT (0.459\%). A similar result stands for Max3-Min3, where the profit (l_s_ac) from the zero-investment portfolio turns out to be insignificant. In conclusion, this simple trading strategy provides evidence against the application of the common practice.

In contrast, Table 2.5 presents a strikingly different result for the performance of the F\&F three-factor model based on the estimation procedures described in section IV. In the case of Max1-Min1, the average long_ac is $1.037 \%$, which is not only significantly different from zero (with a t-statistic of 3.827) but is also significantly different from the benchmark (with average long-mkt of 0.578 and t-statistic of 3.179); as for the short position, the average short_ac is $0.086 \%$, which is not statistically different from zero (with t-statistic of 0.303) and compared with the benchmark, the average return from the short position is significantly lower than average market excess return (with average short-mkt of -0.373 and t-statistic of -1.769 ). Consequently, the realized profit $0.951 \%$ from zero-investment portfolio is also economically significant (with t_statistic of 3.479). This outcome indicates that, at least, the relative directions of excess returns can be correctly forecasted by the estimation procedure adopted in this chapter. Meanwhile, it is not surprising to see that actual excess returns are much more volatile than expected excess returns. Finally, a similar conclusion is reached for the case Max3-Min3.

It is worthwhile to compare the performance of the F\&F three-factor model with the performance of the CAPM in order to investigate whether the other two factors - SMB and HML reveal any more information about the future excess returns. Table 2.6 presents 
the out of sample trading strategy performance of the CAPM based on the estimation procedures described in section 2.4. As shown in the case Max1-Min1, the realized return of the long position is not significantly higher than market excess return and the realized return of the short position is not significantly lower than the market excess return. In fact, the discrepancy between the long and short position (1_s_ac) is only $0.289 \%$ and is not significantly different from zero. Comparing Tables 5 and 6, long_ac for the F\&F three-factor model is actually significantly higher than that for the CAPM, with a difference of $0.338 \%$ and t-statistic of 1.68 ; and short_ac for the F\&F three-factor model is significantly lower than that for the CAPM, with a difference of $-0.324 \%$ and t_statistic of -1.608; consequently, the return of the zero-investment portfolio (1_s_ac) for the F\&F three-factor model is statistically and economically greater than that for the CAPM, with a difference of $0.662 \%$ and t-statistic of 1.897 . The same analyses can be conducted for the case Max3-Min3 and the conclusion can only be drawn that the out of sample performance of the F\&F three-factor model is better than that of the CAPM. As a result, this finding provides indirect evidence in support of the view that after controlling for the market factor, the size factor SMB and the book-to-market factor HML contain some exclusive information about asset returns. This evidence also suggestes the application of the F\&F three-factor model in capital budget decisions over that of the CAPM.

\subsubsection{3 months ahead up to 4 years ahead forecasts}

Usually, in capital budgeting, project managers are more concerned about the longrun expected cost of capital since a project's economic life normally lasts for years. In 
light of this fact, in this section, I implement the same trading strategy to evaluate the predictability of excess returns for 3-month up to 4- year horizons. As is shown in section A, the most manifest appraisal of the performance of a trading strategy is to look at the return from a zero-investment portfolio. Table 2.7 reports the out-of-sample results for time horizons of 1 month, 3 months, 6 months, 1 year, 2 years, 3 years and 4 years for five different methods of in-sample portfolio selection: the F\&F three-factor model with factor premiums estimated from business cycle variables; the F\&F three-factor model with factor premiums estimated by common practice; the CAPM with market excess return estimated from business cycle variables; the CAPM with market excess returns estimated by common practice; a naïve estimation ${ }^{15}$ of 17 industries' excess returns by averaging their historical returns. Also, Figure 2.1 depicts the comparison of the actual returns of the zero-investment strategy for these five different methods of portfolio selection over seven different time horizons. It is plain to see that among the five different methods of in-sample selection, the common practice, no matter whether it is applied to the F\&F three-factor model or the CAPM, has worst performance. Meanwhile, in the short run, from 1 month to 2 years, the F\&F three-factor model with factor premiums estimated from business cycle variables dominates the other four methods as its out-of-sample returns of the zero-investment strategy are statistically higher than those from the other four methods. However, for time horizons over 3 years, none of the five methods seems useful in estimating excess returns. Moreover, from Figure 2.1, a clear trend in the returns of zero-investment strategy is revealed that as time horizon expands

\footnotetext{
${ }^{15}$ The naïve in-sample portfolio selection is based on the average historical returns for the 17 industry portfolios: simply sort the in-sample average returns over the 17 industry portfolios, then hold the one with the highest average historical return and sell the one with the lowest average historical return.
} 
the magnitude of returns decreases, which implies that the economic significance of the predictability of excess returns becomes worse with the length of the forecast period.

\subsubsection{Two more comparable cases}

If the F\&F three factors truly represent fundamental economic risks, they should contain all the information implied in the business cycle variables and then are supposed to at least possess the same forecasting ability as do the business cycle variables ${ }^{16}$. Therefore, it is worthwhile to find out the out-of-sample performance when the business cycle variables are used directly to estimate portfolios' returns. As is shown in Table 2.8 and Figure 2.2, the F\&F three-factor model with factor premiums estimated from business cycle variables has statistically similar out-of-sample performance as the business cycle variables by themselves. For instance, the annualized return for the zeroinvestment strategy is $14 \%$ for the case of Max1-Min1 when estimation is conducted by using business cycle variables directly, which is not significantly different from the $12 \%$ annualized return from the F\&F three-factor mode ${ }^{17}$. So, this result provides direct support for the risk-based explanation of the F\&F three factors.

Another case is to compare the out-of-sample performance of the F\&F three-factor model with risk premiums estimated by business cycle variables to the one with risk premiums assumed as already known, i.e. with risk premiums ‘perfectly’ estimated. From Table 2.8 and Figure 2.2, it is not surprising to see that the return of a zero-investment

\footnotetext{
${ }^{16}$ Since the number of business cycle variables is larger than the number of Fama and French factors, the in-sample performance of business cycle variables is expected to perform better than Fama and French three factors. However, as for out-of-sample performance, if Fama and French three factors are the only risk factors, their estimates should be more efficient in predicting asset returns and should perform better than the business cycle variables do, given that the risk loadings are correctly estimated.

${ }^{17}$ When the two series of out-of-sample returns of the zero-investment strategy are treated as paired samples, the t-statistic for the null hypothesis that they have the same mean is 0.368 .
} 
portfolio when risk premiums are presupposed as known is much higher than when risk premiums are partially estimated. For instance, an annualized return of $57.7 \%$ for the case Max1-Min1 ${ }^{18}$ can be generated when market excess return, HML and SMB are 'perfectly' estimated, compared with the $12 \%$ when the three factor premiums are estimated by the business cycle variables. As for the one-factor model, CAPM, a similar result can be obtained. Moreover, if we compare F\&F three-factor model and CAPM, the three-factor model still earns higher returns. Consequently, HML and SMB do contain some useful economic information about the variation in portfolio returns.

\subsubsection{A further evaluation on the correctness of test models}

So far, the null hypothesis in the out-of-sample test is that the actual excess return from the zero-trading strategy is zero. Our argument for this test is that if our in-sample selection is correct, the out-of-sample performance of the zero-trading strategy should provide some evidence to show the success in distinguishing portfolios with high return from portfolios with low return. However, the fact that the actual excess return is significantly different from zero is not sufficient to judge which model is correct. Therefore, a further evaluation can be a test on how different the actual excess return is from the expected excess return. In other words, we test how much of the expected riskadjusted excess return $\sum_{i=1}^{n}\left(\hat{\beta}_{H}^{i}-\hat{\beta}_{L}^{i}\right) \hat{F}^{i}$ can be realized. Table 2.10 reports the test result. Not surprisingly, the mean difference between actual excess return and expected excess return is negative for all the in-sample selections. For the time horizons over 1 year, the mean difference is significantly negative for all the cases. However, for the 1-month case,

\footnotetext{
${ }^{18}$ Similar results are obtained for the case Max3-Min3
} 
the mean difference is statistically significantly negative only for the FF 3-factor model (BC). Hence, this test result seems to show that even though a model can predict the difference among the portfolios with different mean returns, it might be wrong on the estimation of the magnitude of the difference.

\subsection{Testing for stochastic dominance}

In the previous section, I compare the out-of-sample performance for different insample selection methods and I look at the difference in the unconditional means (i.e. the overall average means of the returns of a zero-investment trading strategy). However, as argued in Chow and $\mathrm{Hu}$ (2003), unconditional mean dominance is necessary but insufficient to ensure that all rise-averse investors prefer the same portfolio reallocation, i.e. unconditionally, $\mu_{k}-\mu_{j} \geq 0$ is not sufficient to make sure that all the risk-averse investors prefer portfolio $k$ to portfolio $j$ in a sense that by holding more of portfolio $k$ and less of portfolio $j$, all investors expect to increase their utility. Therefore, the conditional mean dominance (CMD) criterion can be applied in this case where I can check whether, under any market situation, all investors prefer the F\&F three-factor model to the CAPM in capital budgeting or whether they prefer using business cycle variables to estimate the risk premiums to using the historical averages.

From conventional portfolio theory, Chow and Hu (2003) formally identify a criterion to ensure that an asset re-allocation increases expected utility of any risk-averse investor. Given the existing market portfolio, the following condition ensures that investors prefer to increase holding portfolio $k$ and decreasing holding portfolio $j$ : 
$\frac{d}{d w_{k}} E(U(W))=E U^{\prime}(W)\left(r_{k}-r_{j}\right) \geq 0$, where $W=1+\sum_{i=1}^{n} w_{i} r_{i}$

Chow and $\mathrm{Hu}$ (2003) demonstrate that conditional mean dominance (CMD) is the necessary and sufficient condition for the marginal increase in expected utility as shown in (2.4). For all risk-averse investors, the inequality (2.4) holds if and only if

$\int_{-\infty}^{\tau_{p}^{m}} \int_{-\infty}^{\infty} r_{k} f\left(r_{k}, r_{m}\right) d r_{m} d r_{k} \geq \int_{-\infty}^{\tau_{p}^{m}} \int_{-\infty}^{\infty} r_{j} f\left(r_{j}, r_{m}\right) d r_{m} d r_{j}$

or $E\left(r_{k}-r_{j} \mid r_{m} \leq \tau_{p}^{m}\right) \geq 0$, for all $p$, where $0 \leq p \leq 1$

$E$ is the expectation operator, and $\tau_{p}^{m}=F_{m}^{-1}(p) . \quad F_{m}=p$ is the cumulative density function of $r_{m}$.

To apply the CMD rule to the returns from the zero-investment trading strategy, I select a set of finite target returns, $\left\{\tau_{t} \mid t=1,2, \ldots, 10\right\}$ corresponding to a set of quantiles of the market portfolio return distribution. Let $I_{m}^{\tau_{t}}$ be an indicator variable such that $I_{m}^{\tau_{t}}=1$, if $r_{m} \leq \tau_{t}$, and, $I_{m}^{\tau_{t}}=0$ otherwise. Then, the CMD rule of inequality (2.5) can be written as $\mu_{k-j}^{m}\left(\tau_{t}\right)=E\left\{\left(r_{k}-r_{j}\right) I_{m}^{\tau_{t}}\right\}$, for all $\tau_{t}$ $\mu_{k-j}^{m}\left(\tau_{t}\right)$ can be characterized as the conditional expected premium between for all corresponding market returns below the target $\tau_{t}$. And here, $r_{k}-r_{j}$ is just the return of the zero-investment trading strategy. Therefore, if all risk-averse investors prefer portfolio $k$ to $j, \mu_{k-j}^{m}\left(\tau_{t}\right) \geq 0$ should stand for all $\tau_{t}$, with at least one strong inequality ${ }^{19}$.

\footnotetext{
${ }^{19}$ See Chow and Hu (2003) for the statistical inference for CMD.
} 
I test conditional mean dominance (CMD) for four different methods of in-sample selection: the Fama \& French three-factor model with factor premiums estimated by business cycle variables, the CAPM with factor premiums estimated by business cycle variables, the Fama \& French three-factor model with factor premiums estimated by averaging the historical factor premiums, and CAPM with factor premiums estimated by averaging the historical factor premiums. And I use the one-month holding period as an illustration. Table 2.9 reports the CMD ordinates and the corresponding statistics ${ }^{20}$. As shown, the Fama \& French three-factor model with factor premiums estimated by business cycle variables stands the CMD test, which means that all the risk-averse investors, under any market situation, would agree on this method of in-sample selection in deciding what portfolios to hold out of sample. As for the CAPM with factor premiums estimated by business cycle variables, there is evidently no dominance under any circumstance, which means that this method has no power in estimating the portfolio returns. As for the last two methods, no matter which asset pricing model is used and no matter how the factor premiums are estimated, the negative Z-Scores show that they consistently and statistically significantly yield incorrect forecasts, especially when the market return is below average. Hence, the CMD test strongly confirms the results obtained from the previous section.

\subsection{Conclusion}

Motivated by the serious problems caused by the common practice in the estimation of the equity cost of capital, I propose an alternative set of estimation procedures and

${ }^{20}$ See Chow (2001) for reference. 
implement a simple trading strategy to evaluate the forecasting ability of the F\&F threefactor model and the CAPM. Based on the empirical results, it is impressive to see that, for either factor-based model, the estimation procedures applied in this chapter are preferred to the common practice in the sense that the out-of-sample performance is significantly better with the alternative estimation procedures using structural variables. Furthermore, with the proposed estimation procedure, the out-of-sample performance of the F\&F three-factor model is superior to that of the CAPM. Specifically, in the short run from 1 month to 2 years, the F\&F three-factor model with factor premiums estimated from structural variables significantly outperforms the other methods of in-sample portfolio selection, to which the conditional mean dominance (CMD) test gives a strong support, while in the longer run over 3 years, all the methods have very poor performance. Moreover, a test also shows that a model which can predict the difference between portfolios in their returns might not have the same ability to predict the magnitude of the difference. As a result, I conclude that at least in the short run, the F\&F three-factor model with factor premiums estimated from business cycle variables is more reliable in estimating the equity cost of capital. 
Table 2.1: Summary statistics of 17 equal-weighted industry portfolios and other predictive variables: monthly data from 1953:04 to 2001:10

Data and definitions of 17 industries are available on French's website. MKTEXRT stands for the excess return of market portfolio over the risk free rate. SMB is the excess return from a zero-investment strategy of buying small size portfolios and selling large size portfolios. HML is the excess return from a zeroinvestment strategy of buying value portfolios (high $\mathrm{B} / \mathrm{M}$ ratio) and selling growth portfolios (low $\mathrm{B} / \mathrm{M}$ ratio). TB refers to the nominal one-month T-bill rate. Industrial production growth rate is denoted by IP, TERM represents term premium defined as the difference between 10-year and 3-month Treasury yields. The spread between Moody's Bbb and Aaa corporate bond yields, i.e. default risk premium, is referred to as DEFP, DIV represents dividend yield, the difference between market return with dividend and market return without dividend, TB, IP, TERM and DEFP are all obtained from Federal Reserve Bank of St.Louis. DIV is obtained from the Center for Research in Security Prices (CRSP) tapes. $\rho_{i}$ represents the autocorrelation coefficient over the time interval $i$ month(s). Enclosed in parentheses are the P-values.

\begin{tabular}{|c|c|c|c|c|c|c|c|}
\hline $\begin{array}{l}\text { Industry } \\
\text { Portfolio }\end{array}$ & Mean & Stdev & $\rho_{1}$ & $\rho_{3}$ & $\rho_{6}$ & $\rho_{12}$ & $\rho_{36}$ \\
\hline Food & 1.14 & 4.40 & $0.198(0.000)$ & $-0.017(0.677)$ & $-0.027(0.512)$ & $0.116(0.006)$ & $0.070(0.104)$ \\
\hline Mines & 1.22 & 6.58 & $0.128(0.002)$ & $0.002(0.970)$ & $0.012(0.777)$ & $0.080(0.062)$ & $0.181(0.000)$ \\
\hline Oil & 1.32 & 6.60 & $0.142(0.001)$ & $0.061(0.145)$ & $0.022(0.596)$ & $0.091(0.032)$ & $0.076(0.091)$ \\
\hline Clths & 1.00 & 6.03 & $0.245(0.000)$ & $-0.008(0.840)$ & $0.014(0.747)$ & $0.126(0.003)$ & $0.106(0.016)$ \\
\hline Durbl & 1.14 & 6.17 & $0.218(0.000)$ & $-0.019(0.645)$ & $-0.038(0.361)$ & $0.112(0.009)$ & $0.065(0.143)$ \\
\hline Chems & 1.23 & 5.27 & $0.152(0.000)$ & $-0.034(0.416)$ & $-0.040(0.341)$ & $0.076(0.072)$ & $0.085(0.051)$ \\
\hline Cnsum & 1.57 & 6.57 & $0.181(0.000)$ & $-0.051(0.219)$ & $-0.016(0.702)$ & $0.024(0.585)$ & $0.047(0.345)$ \\
\hline Cnstr & 1.21 & 5.91 & $0.224(0.000)$ & $-0.035(0.403)$ & $-0.025(0.553)$ & $0.1270 .003)$ & $0.089(0.042)$ \\
\hline Steel & 1.08 & 6.16 & $0.142(0.001)$ & $-0.041(0.327)$ & $-0.013(0.759)$ & $0.035(0.409)$ & $0.075(0.091)$ \\
\hline FabPr & 1.21 & 5.62 & $0.187(0.000)$ & $-0.053(0.204)$ & $-0.006(0.894)$ & $0.117(0.006)$ & $0.088(0.043)$ \\
\hline Machn & 1.39 & 6.91 & $0.206(0.000)$ & $-0.035(0.410)$ & $-0.004(0.930)$ & $0.045(0.303)$ & $0.071(0.133)$ \\
\hline Cars & 1.15 & 6.06 & $0.206(0.000)$ & $0.003(0.938)$ & $0.018(0.666)$ & $0.101(0.018)$ & $0.074(0.090)$ \\
\hline Trans & 1.16 & 5.80 & $0.195(0.000)$ & $-0.029(0.487)$ & $0.040(0.342)$ & $0.100(0.019)$ & $0.074(0.089)$ \\
\hline Utils & 1.07 & 3.36 & $0.085(0.040)$ & $0.018(0.662)$ & $-0.015(0.719)$ & $0.042(0.322)$ & $0.044(0.320)$ \\
\hline Rtail & 1.09 & 5.71 & $0.254(0.000)$ & $-0.019(0.645)$ & $-0.014(0.740)$ & $0.087(0.044)$ & $0.080(0.074)$ \\
\hline Finan & 1.25 & 4.87 & $0.247(0.000)$ & $0.015(0.711)$ & $0.036(0.389)$ & $0.129(0.002)$ & $0.050(0.239)$ \\
\hline Other & 1.31 & 6.43 & $0.205(0.000)$ & $-0.030(0.477)$ & $-0.013(0.755)$ & $0.056(0.205)$ & $0.074(0.119)$ \\
\hline \multicolumn{8}{|l|}{$\begin{array}{l}\text { Explanatory } \\
\text { Variables }\end{array}$} \\
\hline MKTEXRT & 0.57 & 4.31 & $0.061(0.140)$ & $0.012(0.771)$ & $-0.028(0.503)$ & $0.027(0.525)$ & $-0.014(0.749)$ \\
\hline SMB & 0.13 & 3.02 & $0.077(0.065)$ & $-0.099(0.018)$ & $0.062(0.146)$ & $0.145(0.001)$ & $0.075(0.136)$ \\
\hline HML & 0.38 & 2.80 & $0.139(0.001)$ & $0.042(0.314)$ & $0.078(0.063)$ & $0.040(0.372)$ & $0.038(0.450)$ \\
\hline TB & 0.44 & 0.23 & $0.955(0.000)$ & $0.908(0.000)$ & $0.855(0.000)$ & $0.762(0.000)$ & $0.457(0.000)$ \\
\hline IP & 0.25 & 0.92 & $0.419(0.000)$ & $0.193(0.000)$ & $0.026(0.536)$ & $-0.150(0.000)$ & $-0.044(0.282)$ \\
\hline TERM & 0.11 & 0.10 & $0.949(0.000)$ & $0.811(0.000)$ & $0.648(0.000)$ & $0.433(0.000)$ & $-0.093(0.032)$ \\
\hline DEFP & 0.08 & 0.04 & $0.972(0.000)$ & $0.905(0.000)$ & $0.829(0.000)$ & $0.686(0.000)$ & $0.353(0.000)$ \\
\hline DIV & 0.29 & 0.18 & $-0.133(0.001)$ & $0.939(0.000)$ & $0.923(0.000)$ & $0.919(0.000)$ & $0.843(0.000)$ \\
\hline
\end{tabular}


Table 2.2: In-sample estimation of Fama and French three factors

Over the entire period 1953:04 to 2001:10, monthly returns of Fama and French three factors are regressed on the following explanatory variables: onemonth lags of three factors themselves: market excess return (MKTEXRT), size factor (SMB), and book-to-market factor (HML);one-month lags of the business cycle related variables: growth rate of industrial production (IP), the difference between 10-year and 3-month Treasury yields (TERM), the spread between Moody's Bbb and Aaa corporate bond yields (DEFP), dividend yield - the difference between market return with dividend and market return without dividend (DIV), and the nominal one-month T-bill rate (TB); and 12-month lags of IP, TERM, DEFP, and DIV. Enclosed in parentheses are the P-values. The R-squares are corrected for degrees of freedom.

\begin{tabular}{|c|c|c|c|c|c|c|c|c|c|c|c|c|c|c|}
\hline Factor & Intercept & MKTEXRT(-1) & HML(-1) & $\operatorname{SMB}(-1)$ & $\operatorname{IP}(-1)$ & $\mathrm{IP}(-12)$ & $\operatorname{TERM}(-1)$ & TERM(-12) & DEFP(-1) & $\operatorname{DEFP}(-12)$ & $\operatorname{DIV}(-1)$ & $\operatorname{DIV}(-12)$ & $\mathrm{TB}(-1)$ & $\mathrm{R}^{2}$ \\
\hline MKTEXRT & $\begin{array}{l}-0.2024 \\
(0.7530)\end{array}$ & $\begin{array}{l}-0.0225 \\
(0.6313)\end{array}$ & $\begin{array}{l}-0.0552 \\
(0.4397)\end{array}$ & $\begin{array}{c}0.0651 \\
(0.2955)\end{array}$ & $\begin{array}{c}0.0304 \\
(0.8864)\end{array}$ & $\begin{array}{l}-0.2190 \\
(0.2876)\end{array}$ & $\begin{array}{c}1.7546 \\
(0.5423)\end{array}$ & $\begin{array}{c}5.1958 \\
(0.0356)\end{array}$ & $\begin{array}{l}37.0074 \\
(0.0003)\end{array}$ & $\begin{array}{l}-28.2458 \\
(0.0022)\end{array}$ & $\begin{array}{c}0.1341 \\
(0.9000)\end{array}$ & $\begin{array}{c}1.6765 \\
(0.1061)\end{array}$ & $\begin{array}{l}-2.5567 \\
(0.0578)\end{array}$ & 0.038 \\
\hline SMB & $\begin{array}{l}-0.0008 \\
(0.9986)\end{array}$ & $\begin{array}{c}0.1594 \\
(0.0000)\end{array}$ & $\begin{array}{c}0.0776 \\
(0.1222)\end{array}$ & $\begin{array}{c}0.0265 \\
(0.5448)\end{array}$ & $\begin{array}{l}-0.0262 \\
(0.8611)\end{array}$ & $\begin{array}{c}0.0297 \\
(0.8374)\end{array}$ & $\begin{array}{c}0.4391 \\
(0.8282)\end{array}$ & $\begin{array}{l}-3.1706 \\
(0.0678)\end{array}$ & $\begin{array}{c}4.1025 \\
(0.5631)\end{array}$ & $\begin{array}{c}2.5082 \\
(0.6979)\end{array}$ & $\begin{array}{c}0.0297 \\
(0.9684)\end{array}$ & $\begin{array}{l}-0.0826 \\
(0.9096)\end{array}$ & $\begin{array}{l}-0.4189 \\
(0.6577)\end{array}$ & 0.040 \\
\hline HML & $\begin{array}{c}0.5798 \\
(0.1658)\end{array}$ & $\begin{array}{c}0.0513 \\
(0.0930)\end{array}$ & $\begin{array}{c}0.1494 \\
(0.0014)\end{array}$ & $\begin{array}{l}-0.0022 \\
(0.9571)\end{array}$ & $\begin{array}{l}-0.0075 \\
(0.9570)\end{array}$ & $\begin{array}{l}-0.0554 \\
(0.6791)\end{array}$ & $\begin{array}{l}-3.2575 \\
(0.0822)\end{array}$ & $\begin{array}{c}0.5243 \\
(0.7438)\end{array}$ & $\begin{array}{c}-10.8785 \\
(0.0979)\end{array}$ & $\begin{array}{l}20.3555 \\
(0.0007)\end{array}$ & $\begin{array}{l}-0.5354 \\
(0.4401)\end{array}$ & $\begin{array}{l}-1.7064 \\
(0.0115)\end{array}$ & $\begin{array}{l}-0.1068 \\
(0.9028)\end{array}$ & 0.039 \\
\hline
\end{tabular}


Table 2.3: In-sample estimation of factor loadings

Based on equation (1): $r_{i t}-r_{f t}=b_{i}\left(r_{m t}-r_{f t}\right)+s_{i}\left(r_{s m b, t}\right)+h_{i}\left(r_{h m l, t}\right)+\varepsilon_{i t}$, monthly excess returns for each of the equally-weighted 17 industry portfolios are regressed on the historical values of the three factors: MKTEXRT, SMB, HML. This table presents the estimates of the factor loadings and the adjusted R-squares for the 17 industries overall the time horizon from 1953:04 to 2001:10. Enclosed in parentheses are P_values. Definitions for the 17 industry portfolios are available on Kenneth French's website.

\begin{tabular}{ccccc}
\hline Industry & $\hat{b}_{i}$ & $\hat{h}_{i}$ & $\hat{s}_{i}$ & $\begin{array}{c}\text { Adjusted } \\
\mathrm{R}^{2}\end{array}$ \\
\hline \hline Food & 0.803 & 0.408 & 0.618 & 0.824 \\
& $(<0.0001)$ & $(<0.0001)$ & $(<0.0001)$ & $(<0.0001)$ \\
Mines & 0.851 & 0.411 & 0.808 & 0.478 \\
& $(<0.0001)$ & $(<0.0001)$ & $(<0.0001)$ & $(<0.0001)$ \\
Oil & 1.023 & 0.407 & 0.452 & 0.485 \\
& $(<0.0001)$ & $(<0.0001)$ & $(<0.0001)$ & $(<0.0001)$ \\
Clths & 0.956 & 0.588 & 1.043 & 0.793 \\
& $(<0.0001)$ & $(<0.0001)$ & $(<0.0001)$ & $(<0.0001)$ \\
Durbl & 1.013 & 0.399 & 1.06 & 0.851 \\
& $(<0.0001)$ & $(<0.0001)$ & $(<0.0001)$ & $(<0.0001)$ \\
Chems & 1.024 & 0.376 & 0.621 & 0.856 \\
& $(<0.0001)$ & $(<0.0001)$ & $(<0.0001)$ & $(<0.0001)$ \\
Cnsum & 0.922 & -0.196 & 1.039 & 0.792 \\
& $(<0.0001)$ & $(<0.0001)$ & $(<0.0001)$ & $(<0.0001)$ \\
Cnstr & 1.056 & 0.569 & 0.940 & 0.865 \\
& $(<0.0001)$ & $(<0.0001)$ & $(<0.0001)$ & $(<0.0001)$ \\
Steel & 1.118 & 0.596 & 0.753 & 0.768 \\
& $(<0.0001)$ & $(<0.0001)$ & $(<0.0001)$ & $(<0.0001)$ \\
\hline
\end{tabular}

\begin{tabular}{ccccc}
\hline Industry & $\hat{b}_{i}$ & $\hat{h}_{i}$ & $\hat{s}_{i}$ & $\begin{array}{c}\text { Adjusted } \\
\mathrm{R}^{2}\end{array}$ \\
\hline \hline FabPr & 0.996 & 0.488 & 0.848 & 0.833 \\
& $(<0.0001)$ & $(<0.0001)$ & $(<0.0001)$ & $(<0.0001)$ \\
Machn & 1.089 & 0.037 & 1.193 & 0.895 \\
& $(<0.0001)$ & $(<0.0001)$ & $(<0.0001)$ & $(<0.0001)$ \\
Cars & 1.042 & 0.566 & 0.919 & 0.799 \\
& $(<0.0001)$ & $(<0.0001)$ & $(<0.0001)$ & $(<0.0001)$ \\
Trans & 1.062 & 0.546 & 0.832 & 0.846 \\
& $(<0.0001)$ & $(<0.0001)$ & $(<0.0001)$ & $(<0.0001)$ \\
Utils & 0.644 & 0.473 & 0.015 & 0.598 \\
& $(<0.0001)$ & $(<0.0001)$ & $(0.63)$ & $(<0.0001)$ \\
Rtail & 0.943 & 0.334 & 0.874 & 0.792 \\
& $(<0.0001)$ & $(<0.0001)$ & $(<0.0001)$ & $(<0.0001)$ \\
Finan & 0.929 & 0.632 & 0.638 & 0.832 \\
& $(<0.0001)$ & $(<0.0001)$ & $(<0.0001)$ & $(<0.0001)$ \\
Other & 1.017 & 0.01 & 1.09 & 0.896 \\
& $(<0.0001)$ & $(0.75)$ & $(<0.0001)$ & $(<0.0001)$ \\
\hline
\end{tabular}




\section{Table 2.4: Out of sample trading strategy performance of F\&F three-factor model based on common practice}

In common practice, the factor premiums are estimated by averaging historical factor returns and the factor loadings are estimated by regressing historical asset excess returns on historical factor returns. Conducted on the 17 equally weighted industry portfolios, the simple trading strategy is to hold (long) the portfolio with the highest expected excess return and to sell (short) the portfolio with the lowest expected excess return, which is referred to as ' Max1-Min1' ('Max3-Min3' refers to holding and selling three portfolios with highest and lowest excess returns respectively). The denotations are explained as follows: long_ac --realized return from long position, long_ex --- expected return from long position, short_ac --- realized return from short position, short_ex --- expected return from short position, 1_s_ac --- realized return from the zero-investment portfolio (difference between long and short positions), l_s_ex --- expected return from the zero-investment portfolio, long-mkt --- excess return of long position over market excess return, short-mkt --- excess return of short position over market excess return, l_s_mkt ---excess return of zero investment portfolio over market excess return, mktexrt --- market excess return (served as a benchmark ).

\begin{tabular}{ccccc}
\multicolumn{5}{c}{ FF3factor---Max_Min } \\
\hline & mean(\%) & std(\%) & t-statistic & Annualized return \\
\hline \hline long_ac & 0.704 & 6.299 & 2.406 & 0.088 \\
long_ex & 1.070 & 0.189 & 121.478 & 0.136 \\
short_ac & 0.509 & 3.472 & 3.156 & 0.063 \\
short_ex & 0.517 & 0.046 & 244.692 & 0.064 \\
l_s_ac & 0.195 & 5.467 & 0.767 & 0.024 \\
l_s_ex & 0.552 & 0.167 & 71.228 & 0.068 \\
long-mkt & 0.246 & 4.065 & 1.299 & 0.030 \\
short-mkt & 0.051 & 3.403 & 0.319 & 0.006 \\
ls-mkt & -0.264 & 5.202 & -1.091 & -0.031 \\
mktrt & 0.459 & 4.456 & 2.216 & 0.056 \\
\hline
\end{tabular}

FF3factor---Max3_Min3

\begin{tabular}{ccccc}
\hline & mean(\%) & std(\%) & t-statistic & Annualized return \\
\hline \hline long_ac & 0.610 & 5.895 & 2.228 & 0.076 \\
long_ex & 1.023 & 0.155 & 141.630 & 0.130 \\
short_ac & 0.676 & 4.517 & 3.220 & 0.084 \\
short_ex & 0.633 & 0.075 & 181.630 & 0.079 \\
l_s_ac & -0.065 & 3.088 & -0.456 & -0.008 \\
l_s_ex & 0.389 & 0.090 & 92.874 & 0.048 \\
long-mkt & 0.152 & 3.457 & 0.943 & 0.018 \\
short-mkt & 0.217 & 2.584 & 1.807 & 0.026 \\
ls-mkt & -0.524 & 4.508 & -2.503 & -0.061 \\
mktrt & 0.459 & 4.456 & 2.216 & 0.056 \\
\hline
\end{tabular}


Table 2.5: Out of sample trading strategy performance of the F\&F three-factor model based on the estimation procedures described in section IV

As for the estimation procedures adopted in this chapter, three factor premiums are estimated by means of their own lags and some business cycle variables (such as term premium, default risk premium, dividend yield, industrial production growth rate and short interest rate) and factor loadings are estimated by equation (1), where industry portfolios' excess returns are regressed on the historical values of factor premiums.

\section{Max1 Min1}

\begin{tabular}{ccccc}
\hline & mean(\%) & std(\%) & t-statistic & Annualized return \\
\hline \hline long_ac & 1.037 & 5.833 & 3.827 & 0.132 \\
long_ex & 1.401 & 1.754 & 17.183 & 0.182 \\
short_ac & 0.086 & 6.116 & 0.303 & 0.010 \\
short_ex & -0.396 & 1.533 & -5.561 & -0.047 \\
l_s_ac & 0.951 & 5.883 & 3.479 & 0.120 \\
l_s_ex & 1.797 & 1.231 & 31.414 & 0.238 \\
long-mkt & 0.578 & 3.916 & 3.179 & 0.072 \\
short-mkt & -0.373 & 4.536 & -1.769 & -0.044 \\
ls-mkt & 0.492 & 7.253 & 1.461 & 0.061 \\
mktrt & 0.459 & 4.456 & 2.216 & 0.056 \\
\hline
\end{tabular}

Max3_Min3

\begin{tabular}{ccccc}
\hline & mean(\%) & std(\%) & t-statistic & Annualized return \\
\hline \hline long_ac & 1.018 & 5.781 & 3.791 & 0.129 \\
long_ex & 1.161 & 1.830 & 13.645 & 0.149 \\
short_ac & 0.211 & 5.720 & 0.795 & 0.026 \\
shor_ex & -0.083 & 1.666 & -1.078 & -0.010 \\
l_s_ac & 0.807 & 3.793 & 4.580 & 0.101 \\
l_s_ex & 1.244 & 0.822 & 32.572 & 0.160 \\
long-mkt & 0.560 & 3.469 & 3.470 & 0.069 \\
short-mkt & -0.248 & 3.572 & -1.492 & -0.029 \\
ls-mkt & 0.348 & 5.729 & 1.308 & 0.043 \\
mktrt & 0.459 & 4.456 & 2.216 & 0.056 \\
\hline
\end{tabular}


Table 2.6: Out of sample trading strategy performance of CAPM based on the estimation procedures described in section IV

In this case, only one factor premium (market excess return) and its risk loading need to be estimated.

Max1_Min1

\begin{tabular}{ccccc}
\hline \multicolumn{5}{c}{ Max1_Min1 } \\
\hline \hline long_ac & 0.699 & 5.635 & 2.670 & 0.087 \\
long_ex & 0.610 & 1.495 & 8.783 & 0.076 \\
short_ac & 0.410 & 5.753 & 1.535 & 0.050 \\
short_ex & -0.069 & 1.317 & -1.120 & -0.008 \\
l_s_ac & 0.289 & 6.503 & 0.955 & 0.035 \\
l_s_ex & 0.679 & 0.591 & 24.701 & 0.085 \\
long-mkt & 0.240 & 4.129 & 1.252 & 0.029 \\
short-mkt & -0.049 & 4.214 & -0.248 & -0.006 \\
ls-mkt & -0.170 & 7.924 & -0.462 & -0.020 \\
mktrt & 0.459 & 4.456 & 2.216 & 0.056 \\
\hline & & & & \\
& & Max3_Min3 & \\
\hline & mean(\%) & std(\%) & t-statistic & Annualized return \\
\hline \hline long_ac & 0.890 & 5.688 & 3.366 & 0.112 \\
long_ex & 0.544 & 1.523 & 7.683 & 0.067 \\
short_ac & 0.496 & 5.575 & 1.914 & 0.061 \\
short_ex & 0.034 & 1.381 & 0.529 & 0.004 \\
l_s_ac & 0.394 & 4.064 & 2.086 & 0.048 \\
l_s_ex & 0.510 & 0.448 & 24.475 & 0.063 \\
long-mkt & 0.431 & 3.517 & 2.636 & 0.053 \\
short-mkt & 0.037 & 3.427 & 0.231 & 0.004 \\
ls-mkt & -0.065 & 5.977 & -0.234 & -0.008 \\
mktrt & 0.459 & 4.456 & 2.216 & 0.056 \\
\hline
\end{tabular}


Table 2.7: Out-of-sample performance for five different means of in-sample selection over seven different horizons The evaluation criteria is based on the out-of-sample average annualized return of zero-investment strategy (l_s_ac). BC means that factor premiums are estimated from business cycle variables; $\mathrm{CP}$ means that factor premiums are estimated by the common practice.

\begin{tabular}{|c|c|c|c|c|c|c|c|c|c|c|c|}
\hline \multirow{2}{*}{\multicolumn{2}{|c|}{$\underline{\underline{\text { L_S_ac }}}$}} & \multicolumn{2}{|c|}{ F\&F three-factor model (BC) } & \multicolumn{2}{|c|}{ F\&F three-factor model (CP) } & \multicolumn{2}{|c|}{ CAPM (BC) } & \multicolumn{2}{|c|}{ CAPM (CP) } & \multicolumn{2}{|c|}{ Naïve } \\
\hline & & Mean & t-statistic & Mean & t-statistic & Mean & t-statistic & Mean & t-statistic & Mean & t-statistic \\
\hline & Max1-Min1 & 0.120 & 3.479 & 0.024 & 0.767 & 0.035 & 0.955 & 0.047 & 1.263 & 0.037 & 0.962 \\
\hline 1 month & Max3-Min3 & 0.101 & 4.580 & -0.008 & -0.456 & 0.048 & 2.086 & 0.020 & 0.806 & 0.011 & 0.445 \\
\hline & Max1-Min1 & 0.039 & 2.265 & -0.005 & -0.338 & 0.021 & 1.082 & 0.005 & 0.281 & 0.026 & 0.580 \\
\hline 3 month & Max3-Min3 & 0.017 & 1.548 & -0.007 & -0.726 & 0.020 & 1.623 & -0.002 & -0.189 & 0.012 & 0.437 \\
\hline & Max1-Min1 & -0.006 & -0.363 & -0.005 & -0.427 & 0.027 & 1.696 & 0.002 & 0.149 & 0.030 & 0.532 \\
\hline 6 month & Max3-Min3 & -0.003 & -0.292 & -0.015 & -1.775 & 0.018 & 1.802 & -0.007 & -0.679 & 0.007 & 0.189 \\
\hline & Max1-Min1 & 0.059 & 5.655 & -0.006 & -0.584 & 0.013 & 1.238 & -0.010 & -1.028 & -0.017 & -1.205 \\
\hline 1 year & Max3-Min3 & 0.026 & 3.380 & -0.016 & -2.192 & 0.012 & 1.525 & -0.028 & -3.749 & -0.027 & -3.415 \\
\hline & Max1-Min1 & 0.031 & 3.883 & -0.055 & -5.007 & 0.011 & 1.800 & -0.020 & -3.182 & -0.013 & -1.069 \\
\hline 2 years & Max3-Min3 & 0.021 & 3.862 & -0.025 & -4.264 & -0.014 & -3.174 & -0.007 & -1.670 & -0.015 & -2.362 \\
\hline & Max1-Min1 & -0.024 & -4.077 & -0.056 & -5.944 & 0.008 & 1.633 & -0.010 & -1.976 & -0.018 & -1.735 \\
\hline 3 years & Max3-Min3 & -0.020 & -4.849 & -0.032 & -5.560 & -0.003 & -0.791 & 0.002 & 0.537 & -0.013 & -2.419 \\
\hline & Max1-Min1 & 0.003 & 0.595 & -0.052 & -5.588 & 0.001 & 0.223 & 0.012 & 2.472 & -0.024 & -2.572 \\
\hline 4 years & Max3-Min3 & -0.008 & -2.287 & -0.021 & -3.815 & 0.010 & 3.330 & 0.016 & 5.250 & -0.010 & -2.222 \\
\hline
\end{tabular}


Figure 2.1: Out-of-sample performance (Max1-Min1) for five different means of insample selection over seven different horizons

A represents F\&F three-factor model with factor premiums estimated by business cycle variables; B represents F\&F three-factor model with factor premiums estimated by common practice; $C$ represents CAPM with market excess return estimated by business cycle variables; D represents CAPM with market excess returns estimated by common practice; E represents a naïve estimation of 17 industries' returns by averaging their historical returns.

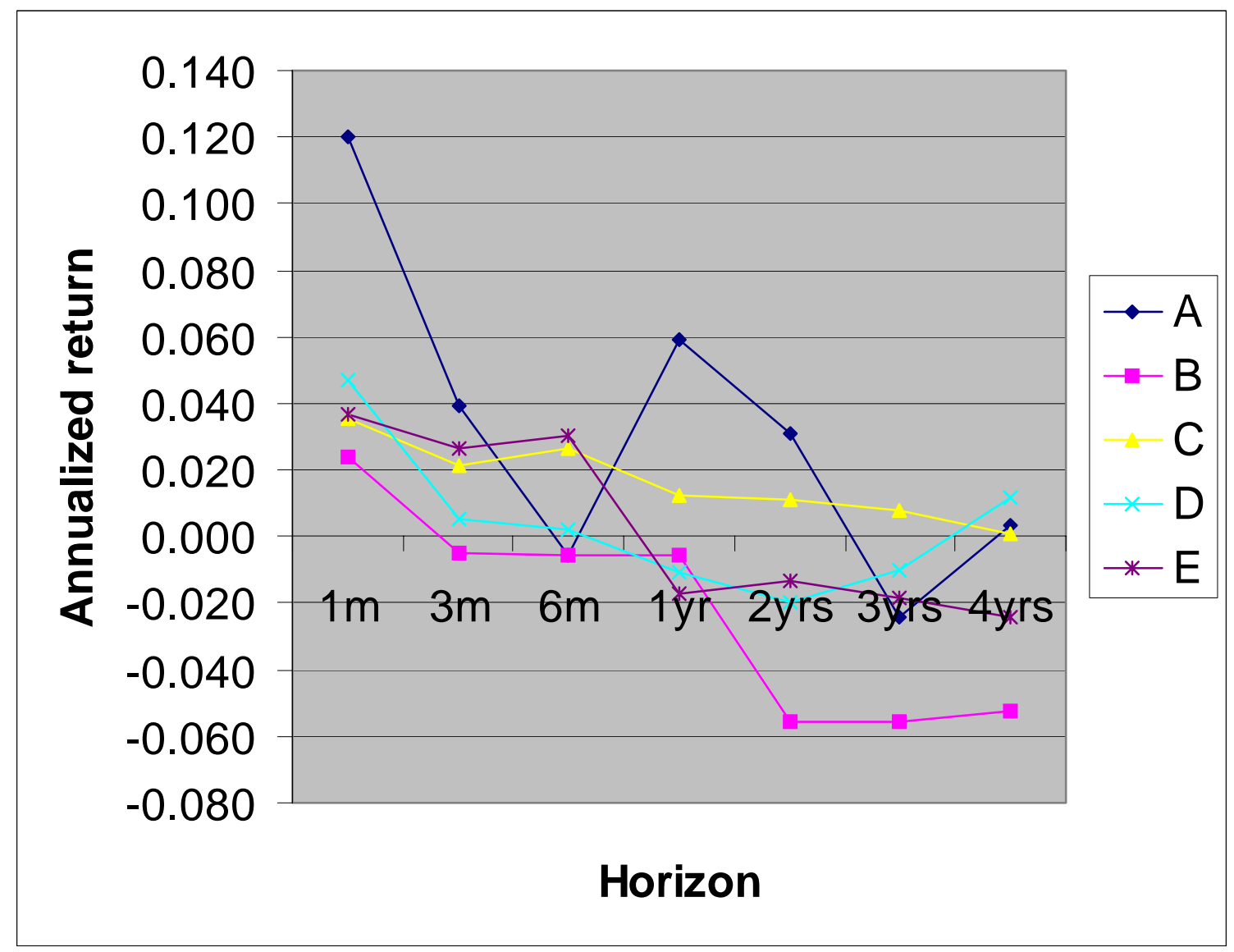


Table 2.8: Out-of-sample performance for more comparable cases

The evaluation criteria is based on the out-of-sample average return of zero-investment strategy (l_s_ac)

$\mathrm{BC}$ means that factor premiums are estimated from business cycle variables.

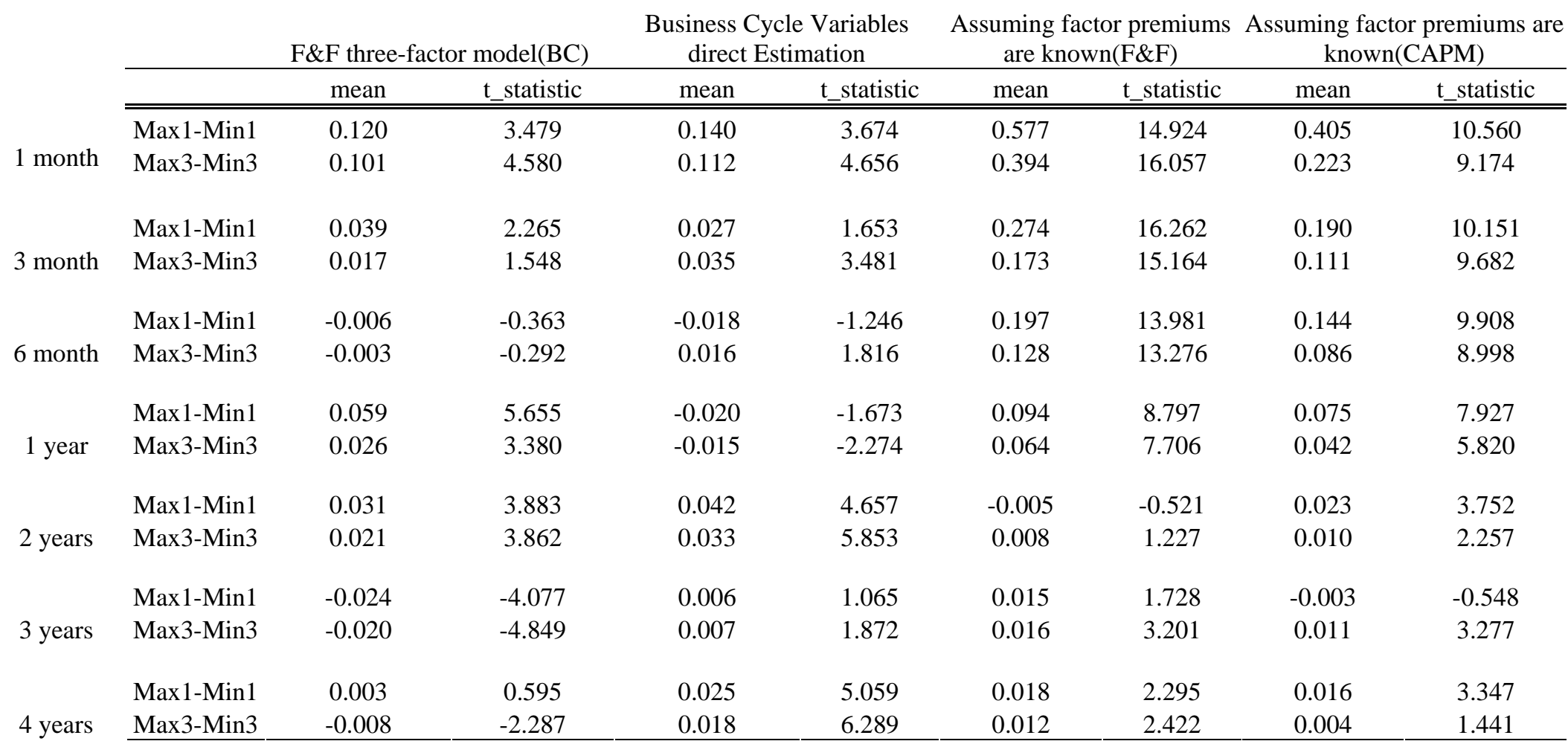


Figure 2.2: Out-of-sample performance (Max1-Min1) for four different comparable cases F\&F represents F\&F three-factor model with factor premiums estimated by business cycle variables; $\mathrm{BC}$ represents the case where portfolios' returns are estimated directly by the business cycle variables; 3RP represents F\&F three-factor model with factor premiums assumed as known beforehand; MKT represents CAPM with market excess returns assumed as known already.

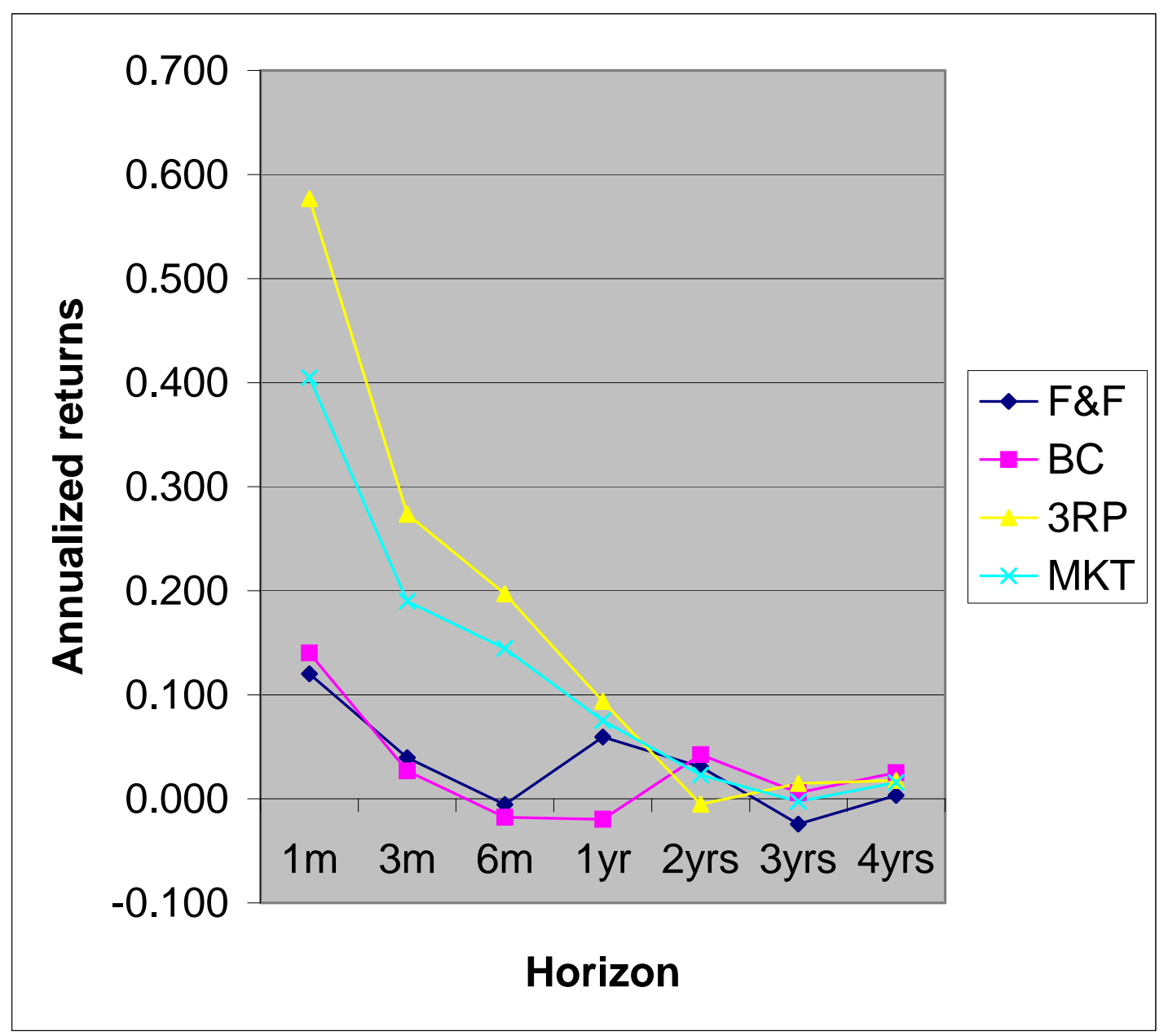


Table 2.9: Test for the difference between actual excess return and expected excess return

The test null hypothesis is the mean difference between actual excess return and expected excess return is zero. The mean difference is annualized return.

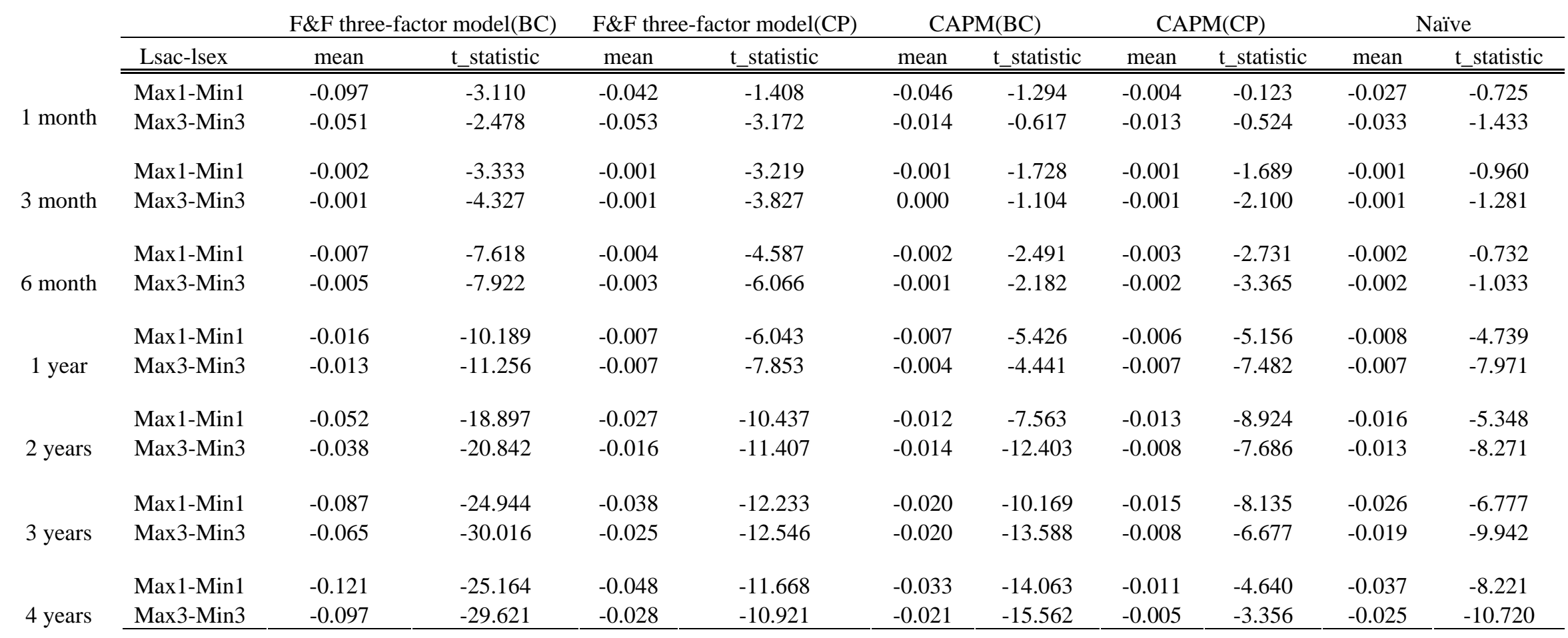


Table 2.10: Conditional Mean Dominance for the out-of-sample performance for four different methods of in-sample selection

One-month holding period is considered. The four methods of in-sample selection are Fama \& French three-factor model with factor premiums estimated by business cycle variables (F\&F_BC), CAPM with factor premiums estimated by business cycle variables (CAPM_BC), Fama \& French three-factor model with factor premiums estimated by averaging the historical factor premiums (F\&F_CP), and CAPM with factor premiums estimated by averaging the historical factor premiums (CAPM_CP). CMD ordinates are calculated for the four methods. The corresponding CMD ordinates are statistically different from zero at the 5 percent level when their Z-scores are compared with the SMM critical value of 2.81. The CMD ordinate at 1 is equivalent to the unconditional mean return.

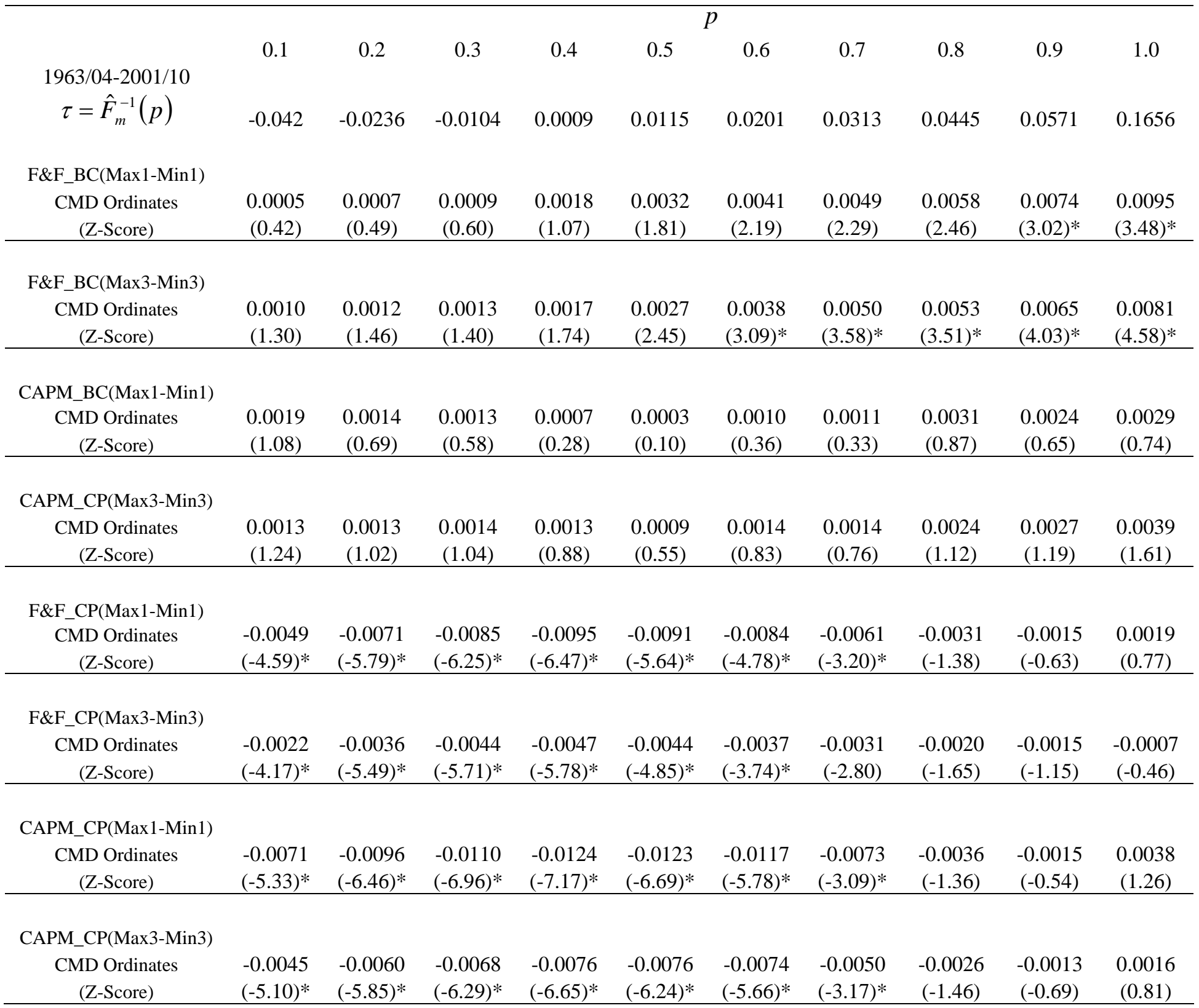




\section{CHAPTER 3}

Common and country-specific components in national stock prices 


\section{Chapter 3}

\section{Common and country-specific components in national stock prices}

\subsection{Introduction}

Ample attention has been paid to the predictability of equity returns and some trading rules have been developed to exploit the predictable portion in equity returns. DeBondt and Thaler (1985, 1987 and 1990) claim that by holding 'losers' (i.e. securities that have underperformed the market index for 3 to 5 years) and shorting 'winners' (i.e. securities that have outperformed the market index for 3 to 5 years), one can profit on average. By investigating the New York Stock Exchange in the period 1962-1985, Lo and MacKinlay (1988) reject the null hypothesis that stock prices follow a random walk process and provide significant evidence that there is positive serial correlation in security indices. Jegadeesh (1990) puts forward a VAR model in order to exploit the mean reversion in securities and finds that large profits exist for trading period which is over 12 month. Lakonishok, Shleifer and Vishny (1994) take advantage of the mean reversion in earnings to price ratio, dividends to price ratio and book to market value ratio and devise a variety of trading strategies which uncover large profits. Employing cross-sectional variation in national equity indices, Balvers, Wu and Gilliland (2000) formulate parametric contrarian trading strategies, which exploit mean reversion across national indices and outperform the standard contrarian strategy, a buy-and-hold strategy, and a random-walk-based strategy. 
Specifically, following Poterba and Summer (1988), Balvers et al. (2000) assume that all 18 countries in their sample share a single permanent component based on the observation that real per capita GDP across OECD countries converges to the same steady state, and so all country-specific shocks are expected to be stationary. What is noteworthy is that in their model, they set the cointegrating vector between the price of each country and the world price as [1,1]. A similar argument can be found in the work of Kasa (1992), who examines the equity indices for the United States, Canada, Germany, Japan, and the United Kingdom by applying Johansen tests for common trends, and suggests that stock prices in all these countries share one single common stochastic trend and also finds that the factor loadings on the common trend are different over those countries, which means the cointegration vector between each country and the common trend is different from [1,1]. However, Richards (1995) examines the predictability of relative returns, which are defined as the difference between an individual country's return and the return on the capitalization-weighted rest-of-world index. He argues that if there is a single common trend among all the involved countries' indices, the relative price should follow a stationary process. So by means of the regression technique of Fama and French (1988), the slope coefficient estimates should be close to zero in the short run and approach -0.5 in the long run. However, according to his results, the coefficient estimates exhibit a U-shaped pattern, i.e. coefficient estimates being close to zero in the short run, and then gradually moving toward -0.5 , and finally returning to zero in the long run. He interprets this U-shaped pattern in autocorrelation coefficients of relative returns as indicating that the stock price indices of different countries comprise of 
a common world price index and two country-specific components, one permanent and the other transitory. However, even if all the countries involved share one common trend, the difference between an individual country’s log return index and the log capitalization weighted rest-of-world index does not necessarily remove the common trend completely, therefore in general, the relative returns as constructed by Richards could also take on a U-shaped pattern in the autocorrelation coefficients even if there is no country-specific permanent component. As a result, the U-shaped pattern itself could not serve as convincing evidence for the existence of a country-specific trend component unless we control for the actual cointegrating relationship between each country and the common permanent component.

In this chapter, I first investigate the mean reversion in the 18 OECD national stock price indices as Balvers et al. (2000) does, but the difference is that I allow the cointegrating vector to change over all countries. Not only the factor loadings on the world price are significantly different from 1 for all 18 countries, but also the zeroinvestment trading strategy generates higher excess returns when the cointegration vector is allowed to change than when it is arbitrarily set at [1,1]. Secondly, I set up a general state space model to investigate whether there exist country-specific components permanent or transitory among the G7 countries. Using a Kalman filter recursive procedure and maximum likelihood estimation, I find that not only do the G7 countries have different sensitivities to the world permanent and transitory components, but they also have their own country-specific permanent and transitory components. This result somehow supports the findings of Richards (1995) that these countries are not 
cointegrated around one stochastic common trend and therefore implies that there is a potential long-run international diversification benefit.

The remainder of the chapter proceeds as follows. Section 3.2 briefly reviews previous studies on national stock prices. Section 3.3 investigates the mean reversion in national stock prices controlling for cointegrating vectors. A general state space model is designed in section 3.4 to examine the common and country-specific components in national stock prices. Section 3.5 concludes the chapter and discusses the implications.

\subsection{Review of previous studies}

Balvers et al. (2000) adapt the model of Fama and French (1988) and Summers (1986) and applies it in a global context. They examine 18 OECD countries and argue that since real per capita GDP in these countries converges to the same steady state, values of representative firms in these countries should converge as well. So, they assume that all permanent shocks are global and any country-specific shocks are transitory. In empirical tests, they use the world price index as the permanent component for all the countries' prices. Specifically, in their model, country equity prices are expressed as $P_{t}^{j}=$ $y_{t}+x_{t}^{i}$, where $y_{t}$ represents the permanent price component and in their case, $y_{t}$ is represented by the world price index $P_{t}^{r}$ which is assumed to follow a random walk; $x_{t}^{i}$ represents the temporary component for a particular country and is assumed to follow a AR(1) process. As we can see, they explicitly set the cointegration vector between the 
price of each country and the world price as $[1,1]$. And that is why in their empirical model:

$R_{t+1}^{i}-R_{t+1}^{r}=\alpha^{i}-\lambda\left(P_{t}^{i}-P_{t}^{r}\right)+\sum_{j=1}^{k} \phi_{j}^{i}\left(R_{t+1-j}^{i}-R_{t+1-j}^{r}\right)+\omega_{t+1}^{i}$,

$P_{t}^{i}-P_{t}^{r}$ can be backed out by accumulating the return differential $\sum_{s=0}^{t}\left(R_{s}^{i}-R_{s}^{r}\right)$.

However, if the cointegration vector is not $[1,1]$ or if there exists a country-specific permanent component, then $P_{t+1}^{i}-P_{t+1}^{r}$ is no longer stationary so that the estimate of $\lambda$ would be expected to be insignificantly different from zero.

A similar problem can be found in Richards (1995), who applies the regression technique of Fama and French (1988) to the 16 OECD national relative returns. The relative return index is defined as $R R I_{i, t}=\log X_{i, t}-\log R O W_{i, t}$, i.e. the log difference between the return index $\left(X_{i, t}\right)$ for a particular country and the capitalization-weighted return index $\left(R O W_{i, t}\right)$ for the rest-of-world. He assumes that the relative return index includes a permanent component $q_{i, t}$ and a stationary component $z_{i, t}: R R I_{i, t}=q_{i, t}+z_{i, t}$; $q_{i, t}=q_{i, t-1}+\mu_{i}+\eta_{i, t}$, where $\mu_{i}$ is a drift term and $\eta_{i, t}$ is a white noise innovation. Then, the k-period relative return $r r_{i}(t, t+k)$ is defined as $r r_{i}(t, t+k)=R R I_{i, t+1}-R R I_{i, t}$. By way of the regression technique of Fama and French (1988), the k-period return is regressed on the lagged k-period return:

$$
r r_{i}(t, t+k)=\alpha_{i}(k)+\beta_{i}(k) * r r_{i}(t-k, t)+\varepsilon_{i}(t, t+k) \text {. So, if there were no stationary }
$$

component in the relative return index, the expected value of $\beta_{t}(k)$ would be zero for all 
$\mathrm{k}$; if there were no permanent component, the expected value of $\beta_{t}(k)$ would be close to zero for low $\mathrm{k}$ and approach -0.5 for high $\mathrm{k}$; and if both parts existed, the expected value of $\beta_{t}(k)$ would take on a U-shaped pattern - close to zero for low $\mathrm{k}$, reaching -0.5 for higher $\mathrm{k}$ when the transitory component is relatively more important, then climbing up to zero again when the permanent part dominates. In light of the fact that his empirical results exhibit a U-shaped pattern in the estimates of $\beta_{t}(k)$, he suggests that the national return indices are not cointegrated around a single common trend because if they were, the relative return index would only contain a stationary component. However, the same logic would apply in this case that since no theory indicates that the difference between each country's log return index and the log capitalization-weighted rest-of-world series would completely cancel out their permanent component, the relative return index could still be non-stationary even if all the countries involved share one common permanent component. Therefore, the U-shaped pattern itself is not sufficient evidence against the cointegration among the national return indices.

\subsection{Mean reversion in control of cointegration vector}

In this section, I examine the mean reversion in the national stock price indices in consideration of the actual cointegratiing vectors. Following Balvers et al. (2000), I assume that the 18 OECD countries share a common trend---the world price index and all the country-specific components are stationary. The only difference is that I do not impose the cointegrating relationship. So, the log price index of each country can be

expressed as $P_{t}^{i}=\varphi^{i} * P_{t}^{w}+x_{t}^{j}$. Since $\varphi^{i}$ is unknown and $x_{t}^{j}$ is unobservable, it is natural to 
employ the Kalman filter procedure to estimate the unknown parameters. But before a state-space model is set up, it is interesting to check first whether or not the difference between a country's price index and the world price index $\left(P_{t}^{i}-P_{t}^{w}\right)$ follows a stationary process. The test is the traditional augmented Dickey-Fuller unit root test. As for the data, monthly stock market price indices are obtained from Morgan Stanley Capital International (MSCI) for 18 OECD countries ${ }^{21}$ and the world ${ }^{22}$. The sample period is December 1969 to May 2003. The price indices for each country include reinvested gross dividends and are denominated in U.S. dollar. Table 3.1 reports the test results. It is demonstrated that the null hypothesis of a unit root $\left(\beta^{i}=0\right)$ cannot be rejected for 12 out of the 18 counties at conventional significance levels. Therefore, for most countries, the relative price index $P_{t}^{i}-P_{t}^{w}$ can not be assumed to follow a stationary process. The reason could simply be that the cointegrating vector between a country's price index and the world price index is not $[1,1]$. In order to control for the actual cointegrating relationship, I use the following state-space model to deal with the problem:

Measurement equation: $P_{t}^{i}-P_{t}^{w}=\alpha^{i}+\theta^{i} P_{t}^{w}+x_{t}^{i}$;

Transition equation: $x_{t}^{i}=\delta^{i} x_{t-1}^{i}+v_{t}^{i}$

Where $P_{t}^{i}$ is the $\log$ price index at time $\mathrm{t}$ for country $i ; P_{t}^{w}$ is the world $\log$ price index at time $t ; x_{t}^{i}$ represents the unobservable temporary price component for country

\footnotetext{
${ }^{21}$ These countries are: Australia, Austria, Belgium, Canada, Denmark, France, Germany, Hong Kong, Italy, Japan, Netherlands, Norway, Singapore, Spain, Sweden, Switzerland, United Kingdom, and the United States.

${ }^{22}$ The MSCI World Index consists of the following 23 developed market country indices: Australia, Austria, Belgium, Canada, Denmark, Finland, France, Germany, Greece, Hong Kong, Ireland, Italy, Japan, Netherlands, New Zealand, Norway, Portugal, Singapore, Spain, Sweden, Switzerland, the United Kingdom and the United States.
} 
$i$ at time t and is assumed to follow an AR (1) process; $\alpha^{i}$ is the intercept in the measurement equation for country $i ; \theta^{i}$ provides information about the actual cointegration relationship between country $i$ 's log price index and the world log price index; $\delta^{i}$ is the $\operatorname{AR}(1)$ coefficient, and for stationarity, it is close to but less than $1 ; v_{t}^{i}$ is a mean-zero normal term; there is no error term in the measurement equation.

Once a state space model is set up, the Kalman filter recursive procedure and maximum likelihood estimation method can be used to estimate the parameters. ${ }^{23}$ From Table 3.2, it is observed that, for most countries, $\hat{\theta}^{i}$ is significantly different from zero, which means that the cointegrating vectors between these countries' price indices and the world price index are not [1,1]. This result implies that imposing a cointegrating vector $[1,1]$ might have caused the problems discussed in the previous section. Meanwhile, as for the speed measurement of mean reversion, $\hat{\delta}^{i}$ conforms to the assumption that its value is close to but less than 1. Except for Japan, the Netherlands, Switzerland, and the United States, the null hypothesis that $\delta^{i} \geq 1$ can be rejected for the other 14 countries at least at the 10 percent significance level. For the pure mean reversion scenario, the halflife is simply calculated as $\ln (0.5) / \ln \left(\hat{\delta}^{i}\right)$. Based on the $\hat{\delta}^{i}$ for these countries, the halflife ranges from 10 months to 99 months, but for most countries, the half-life is about 3-5 years, which is consistent with previous studies. ${ }^{24}$ Therefore, to some extent, the simple state-space model detects mean reversion for the national stock indices. A reasonable

\footnotetext{
${ }^{23}$ Details about the specific Kalman filter procedure are described in the Appendix.

${ }^{24}$ See Balvers et al. (2000),
} 
follow-up is to find out whether the predictability of national stock indices due to mean reversion has any economic significance.

This chapter closely follows the parametric trading strategy approach of Balvers et al. (2000). To compare with their results, I first examine the sample period from December 1969 to December $1996^{25}$. The actual strategy is formulated as follows: starting at $1 / 2$ of the total sample, the state-space model is estimated for the 18 countries; then the parameter estimates are used to calculate the expected returns for the upcoming month; next, to hold the portfolio(s) with the highest expected returns and to short sell the portfolio(s) with the lowest expected returns (so far, all the prior data points are used to sort out the portfolios); with the holding period set as 12,24,36,48,and 60 months, the actual returns on this trading strategies can be calculated. The strategy of only holding the country portfolio with the highest expected return is denoted as the 'Max1'; the strategy of only selling the country portfolio with the lowest expected return is denoted as the 'Min1'; the zero-investment strategy of buying Max1 and shorting is referred to as 'Max1-Min1'; and in the same way 'Max3' and 'Min3' refer to the strategies of holding the three country indexes with, respectively, the highest and lowest expected returns; so, 'Max3-Min3' means the zero-investment strategy of holding Max3 and selling Min3. Then, the same strategies are repeated until the end of the sample period. Table 3 presents the average returns from these strategies for two different state-space models: the first model is the one I used above to obtain the actual cointegrating relationship between countries' price indices and the world price index; the second one is similar to the model

\footnotetext{
${ }^{25}$ The difference is that I use monthly data in the test instead of annual data.
} 
in Balvers et al. (2000), which presumes that the difference between a country's price index and the world price index is purely stationary. Also in Table 3.4, for robustness, I report the results for the full sample period: December 1969 to May 2003. As we can see in Table 3.3, the average annualized return from strategy Max1-Min1 is about 9 percent for Model 1 and about 3.5 percent for Model 2. The average annualized return from strategy Max3-Min3 from Model 1 is also higher than that for Model 2. And what is consistent with previous studies is that as the holding period (K) increases, the average return from the zero-investment strategies also increases just as the mean reversion in prices implies. However, from Table 3.4 where the full sample period is examined, neither of the two models is superior to the other. Their annualized returns are about the same, although the zero-investment profit exhibits a tendency to increase as the holding period increases. Could the reason be that the structures of the national stock price indices changed after 1996 or that the assumptions about the models and world price index brought about the results? The answer to this question is not the focus of this chapter. Based on the results from Table 3.3 and Table 3.4, a proper conclusion could be reached that controlling the actual cointegrating relationship between each individual country's price index and the world price index will at least perform as well as ignoring it. Nevertheless, it is worthwhile to relax the assumptions to get a better idea of the time series features of the national stock price indices because, theoretically speaking, the common trend is not observable and the country-specific trend, if it exists, is not observable either. 


\subsection{A general dynamic factor model in consideration of common and country- specific components in national stock prices}

In this section, a general dynamic factor model is set up to decompose the national stock price indices into a trend component and a cyclical component ${ }^{26}$. A state space model is specified as follows for the G7 countries $^{27}$ :

Measurement equation --- $p_{t}^{w}=p_{t}^{w t}+p_{t}^{w s}$

$$
p_{t}^{i}=p_{t}^{i t}+p_{t}^{i s}, i=1,2, \ldots 7
$$

Transition equations --- $p_{t}^{w t}=\mu+p_{t-1}^{w t}+\varepsilon_{t}, \varepsilon_{t} \sim$ i.i.d.N $\left(0, \sigma_{\varepsilon}^{2}\right)$

$$
\begin{aligned}
& p_{t}^{w s}=\varphi p_{t-1}^{w s}+\eta_{t}, \eta_{t} \sim \text { i.i.d. } N\left(0, \sigma_{\eta}^{2}\right) \\
& p_{t}^{i t}=\mu^{i}+p_{t-1}^{i t}+v_{t}^{i}, v_{t}^{i} \sim \text { i.i.d. } N\left(0, \sigma_{v i}^{2}\right) \\
& p_{t}^{i s}=\varphi^{i} p_{t-1}^{i s}+w_{t}^{i}, w_{t}^{i} \sim \text { i.i.d. } N\left(0, \sigma_{w i}^{2}\right)
\end{aligned}
$$

In this model, $p_{t}^{i}$ represents the stock price index for country $i$ and it is decomposed into a stochastic trend $p_{t}^{i t}$ which follows a random walk with a drift and a transitory component $p_{t}^{i s}$ which follows an $\mathrm{AR}(1)$ process. The permanent and transitory innovations for the world index and for the index of each country $\left(\varepsilon_{t}\right.$ and $\eta_{t}, v_{t}^{i}$ and $\left.w_{t}^{i}\right)$ are assumed to be uncorrelated with one another at all lags. To analyze the difference of each country in their magnitude of sharing the world components (common components)

\footnotetext{
${ }^{26}$ Since the real prices are obtained by using seasonally adjusted CPI, I do not need to include the seasonal component in this model.

${ }^{27}$ G7 countries include the United States, the United Kingdom, France, Germany, Italy, Canada and Japan.
} 
and the existence and importance of country-specific components, not only do I allow correlations between all the permanent innovations and correlations between all the transitory innovations, but I also assume linearity in these correlations. To be specific ${ }^{28}$, I assume that $v_{t}^{i}=\lambda^{i} \varepsilon_{t}+u_{t}^{i}$ and $w_{t}^{i}=\theta^{i} \eta_{t}+s_{t}^{i}$, where $\lambda^{i}$ is the share of country $i$ 's total permanent shock in the world permanent shock, and $u_{t}^{i}$ is the country $i$ 's specific permanent shock; $\theta^{i}$ is the share of country $i$ 's total transitory shock in the world transitory shock and $s_{t}^{i}$ is country $i$ 's specific transitory component. As shown below, $\lambda^{i}$ and $\theta^{i}$ can be easily derived:

(1) Take the variance on both sides: $\sigma_{v^{i}}^{2}=\lambda_{i}^{2} \sigma_{\varepsilon}^{2}+\sigma_{u^{i}}^{2}$, and $\sigma_{w^{i}}^{2}=\theta_{i}^{2} \sigma_{\eta}^{2}+\sigma_{s^{i}}^{2}$ Note that the country-specific component is orthogonal to the world component.

(2) Calculate the covariance between the world shock and the country total shock of the same sort: $\operatorname{Cov}\left(v_{t}^{i}, \varepsilon_{t}\right)=\operatorname{Cov}\left(\lambda^{i} \varepsilon_{t}+u_{t}^{i}, \varepsilon_{t}\right)=\lambda^{i} \sigma_{\varepsilon}^{2}$

$$
\operatorname{Cov}\left(w_{t}^{i}, \eta_{t}\right)=\operatorname{Cov}\left(\theta^{i} \eta_{t}+s_{t}^{i}, \eta_{t}\right)=\theta^{i} \sigma_{\eta}^{2}
$$

Since the covariances and the variances can be estimated from the state-space model, $\lambda^{i}$ and $\theta^{i}$ can be obtained by (2). Plugging $\lambda^{i}$ and $\theta^{i}$ into (1), I get the estimates for the country-specific components: $\sigma_{u^{i}}^{2}$ and $\sigma_{s^{i}}^{2}$. The setup of the general state-space model and the assumption of linearity facilitate the anatomy of the national stock market indices in such a quantitative level that not only can we compare for each country the magnitudes between the permanent shock and the transitory shock, but we can also distinguish the

\footnotetext{
${ }^{28}$ Though the components of the same sort (permanent or transitory) between countries are surely correlated, I only focus on the correlation between the world and each country since it is the key interest of this chapter.
} 
common shocks shared by each country from the country-specific shocks. The main interest of this chapter is to find out whether there is a country-specific component and if so, how big it is. The significance of this model lies in the implication for international portfolio investment. That is, if there is no country-specific permanent component, then all the countries of interest share the same stochastic trend and there are no long-run international diversification benefits; however, if there is, the risk-averse international investors should benefit from putting their eggs in different baskets.

In this state-space model, there are 8 measurement equations ${ }^{29}$ and 16 transition equations. For each country, there are two state variables. In total we have 16 state variables and 88 parameters to estimate. The price index data - quarterly frequency from 1969.4 to 2003.2 for the G7 countries and the world price index are obtained from the MSCI website, and they are all denominated in US dollars and discounted by the seasonally-adjusted $\mathrm{CPI}^{30}$ to convert to the real terms.

The Kalman filter procedure and the Maximum likelihood method (Harvey, 1989) is used to estimate the state space parameters. The estimated variance parameters indicate the relative importance and relative contribution of each component in the state vector in explaining the total variation in the time series and also provide information on the size of the non-stationary (permanent) and the stationary (transitory) component in the series.

\footnotetext{
${ }^{29}$ One is for the world price index and the other 7 equations are for the G7 countries.

${ }^{30}$ The seasonally-adjusted CPI is obtained from the Federal Reserve Bank at St.Louis.
} 
Table 3.5: Drifts and AR(1) coefficients estimates for the state space model

\begin{tabular}{|c|c|c|c|c|c|}
\hline country & $\mu$ & $\varphi$ & $\sigma_{v^{i}}^{2}$ & $\sigma_{w^{i}}^{2}$ & $\sigma_{w^{i}}^{2} /\left(\sigma_{v^{i}}^{2}+\sigma_{w^{i}}^{2}\right)$ \\
\hline $\begin{array}{l}\text { World } \\
\text { Index }\end{array}$ & $1.2272(0.5086)$ & $0.4962(0.1651)$ & 40.07 & 4.51 & 0.10 \\
\hline Canada & $0.8153(0.5817)$ & $0.9107(0.0587)$ & 38.94 & 29.39 & 0.43 \\
\hline France & $1.3115(0.5174)$ & $0.8944(0.0388)$ & 49.63 & 52.43 & 0.51 \\
\hline Germany & $1.1397(0.5584)$ & $0.6957(0.0794)$ & 47.62 & 35.01 & 0.42 \\
\hline Italy & $0.3175(0.6155)$ & $0.9913(0.0134)$ & 101.10 & 18.23 & 0.15 \\
\hline Japan & $1.3012(0.7559)$ & $0.9779(0.0316)$ & 85.62 & 25.24 & 0.23 \\
\hline $\begin{array}{l}\text { United } \\
\text { Kingdom }\end{array}$ & 1.5462 (0.6943) & 0.8375 (0.059) & 62.13 & 37.01 & 0.37 \\
\hline $\begin{array}{l}\text { United } \\
\text { States }\end{array}$ & $1.3536(0.5817)$ & $0.4914(0.1447)$ & 43.42 & 5.80 & 0.12 \\
\hline
\end{tabular}

Note: the standard errors are in the parentheses.

Table 3.5 shows the estimates for the drift $\mu$ and the AR(1) coefficient $\varphi$ for the world and each country's stock market index. Judging from the drift $\mu$, except Canada and Italy, the countries exhibit significant growth in their stock market during this period 1969.4 - 2003.2. The growth rates of France, Germany, Japan, United Kingdom and United States are close to that of the world index. The AR(1) coefficient $\varphi$ measures the speed $(1-\varphi)$ of mean reversion ( predictability ) of the transitory component. As shown, Canada, Italy, and Japan's stock markets do not seem to have a transitory component with $\varphi$ estimates statistically close to 1 . So, these stock markets are expected to have very little predictability. On the contrary, the stock markets of France, Germany, the United Kingdom and the United States do seem to have a transitory component. To see how predictable returns in these countries are, we also need to compare the importance of the permanent shock with that of the transitory shock for each country. Table 3.5 also includes the variance decomposition results. The ratio $\sigma_{w}^{2} /\left(\sigma_{v}^{2}+\sigma_{w}^{2}\right)$ shows the percentage of the transitory shock in the total variation of conditional market return at 
time $t$. Since Canada, Italy and Japan’s stock market do not seem to have a cyclical component, the significance of this ratio should be discounted. For the other countries, France, Germany and United Kingdom's stock markets seem to have a significant transitory component with ratios of 51\%, $42 \%$ and $37 \%$ respectively. It implies that these three markets are highly predictable. With a ratio of $12 \%$, the stock market of United States has much less predictability. And it is interesting to notice, though expected, that with the strikingly similar estimates of $\mu, \varphi$ and $\sigma_{w}^{2} /\left(\sigma_{v}^{2}+\sigma_{w}^{2}\right)$, the stock index of United States could be regarded as representing the world index.

Table 3.6: Estimation of the share of common trend and country-specific trend

\begin{tabular}{lccccc}
\hline country & $\sigma_{w^{i}}^{2}$ & $\operatorname{Cov}\left(\varepsilon, v_{i}\right)$ & $\lambda_{i}$ & $\sigma_{u^{i}}^{2}$ & $\sigma_{u^{i}}^{2} / \sigma_{w^{i}}^{2}$ \\
\hline \hline World Index & $40.065(5.5074)$ & na & na & na & \\
Canada & $38.9391(11.8831)$ & $34.6074(7.1504)$ & 0.8638 & 9.046 & 0.23 \\
France & $49.6263(11.32)$ & $42.6534(7.0797)$ & 1.0646 & 4.2173 & 0.08 \\
Germany & $47.6237(10.1796)$ & $32.0974(6.3717)$ & 0.8011 & 21.9094 & 0.46 \\
Italy & $101.1013(19.6269)$ & $40.8147(7.4321)$ & 1.0187 & 59.5227 & 0.59 \\
Japan & $85.6152(13.9599)$ & $43.7745(7.4366)$ & 1.0926 & 37.7878 & 0.44 \\
United Kingdom & $62.1297(13.2616)$ & $46.2053(7.3218)$ & 1.1533 & 8.843 & 0.14 \\
United States & $43.4164(6.2475)$ & $37.1727(5.5539)$ & 0.9278 & 8.9272 & 0.21 \\
\hline Note: the standard errors are in parentheses. & & & & \\
\hline
\end{tabular}

Table 3.7: Estimation of the share of common cycle and country-specific cycle

\begin{tabular}{lccccc}
\hline country & $\sigma_{w^{i}}^{2}$ & $\operatorname{Cov}\left(\eta, w_{i}\right)$ & $\theta_{i}$ & $\sigma_{s^{i}}^{2}$ & $\sigma_{s^{i}}^{2} / \sigma_{w^{i}}^{2}$ \\
\hline \hline world index & $4.5083(2.6599)$ & na & na & na & na \\
Canada & $29.3874(9.9388)$ & $7.0813(4.3756)$ & 1.5707 & 18.265 & 0.62 \\
France & $52.4306(9.733)$ & $5.9376(3.7191)$ & 1.317 & 44.6106 & 0.85 \\
Germany & $35.0086(8.789)$ & $6.7109(3.9205))$ & 1.4886 & 25.0191 & 0.71 \\
Italy & $18.2304(13.8551)$ & $2.2967(3.0419)$ & 0.5094 & 17.0605 & 0.94 \\
Japan & $25.2434(7.6316)$ & $6.997(3.4934))$ & 1.552 & 14.3842 & 0.57 \\
United Kingdom & $37.0137(10.3199)$ & $2.6596(4.4159)$ & 0.5899 & 35.4447 & 0.96 \\
United States & $5.8029(3.2887)$ & $4.6898(2.7748)$ & 1.0402 & 0.9244 & 0.16 \\
\hline Note: the standard errors are in the parentheses. & & & & \\
\hline
\end{tabular}


Table 3.6 reports the estimates of the shares of world (common) trend, and the country-specific trend. The variation in the value of $\lambda_{i}$ among the 7 countries indicates that the world permanent shock affects these countries differently. Some countries are more sensitive to the world permanent shock, such as Japan and United Kingdom; some countries are less sensitive, like Canada and Germany; and the other countries have a sensitivity of about one unit to the world permanent shock. Moreover, if we look at the ratio of the country-specific permanent shock over the total permanent shock --- $\sigma_{u^{i}}^{2} / \sigma_{v}^{2}$, Germany, Italy and Japan’s stock markets face a significant country-specific permanent shock with the ratio of $46 \%, 59 \%$ and $44 \%$ respectively. The other countries' markets have much smaller specific permanent shocks. And for France, the ratio is the smallest 8\%. This result is in accordance with Richards (1995)'s conclusion that national stock markets are not cointegrated around a common stochastic trend and there do seem to exist country-specific stochastic trends. Consequently, in the long-run, international riskaverse investors would probably be better off through diversification.

Furthermore, Table 3.7 presents the estimates of the shares of the world cycle and the country-specific cyclical component. The values ${ }^{31}$ of $\theta_{i}$ show that the world transitory shock has evidently different effects on each country. However, compared with the overall cyclical shock of each country, the world shock is so much smaller that it does not make a big difference for each country, except for United States. In fact, the ratio of the country-specific transitory shock over the total transitory shock shows that most of the

\footnotetext{
${ }^{31}$ For the same reason stated above, the value of $\theta_{i}$ doesn't apply to the stock markets of Canada, Italy and Japan.
} 
cyclical shock is country-specific, $85 \%$ for France, $71 \%$ for Germany and $96 \%$ for the United Kingdom. This result implies that the predictability of these stock markets mostly comes from their country-specific transitory shocks.

\subsection{Conclusion}

Two questions are explored in this chapter: Does every country’s stock market price have a one-on-one relationship with the world price? Do country-specific components exist?

By setting up a state space model which does not restrict the cointegrating vector between each country and the world price to be $[1,1]$, I find that the factor loadings on the world price are significantly different from 1 for almost all the 18 OECD countries. In addition, a simple zero-investment trading strategy generates higher out of sample excess returns when the cointegrating vector is allowed to change than when it is arbitrarily set at $[1,1]$. As a result, the answer to the first question is no: each country has a different degree of sensitivity to the world price. For the second question, I propose a general state space model to decompose the national stock prices for the G7 countries into permanent and transitory components. With the assumption that a country's permanent shock and transitory shock are linearly correlated with the world’s permanent shock and transitory shock, the inference from the variance-covariance matrix of disturbances indicates that the G7 countries seem to have their own country-specific permanent and transitory components. Based on the variance decomposition analysis, Germany, Italy and Japan’s country-specific permanent shocks account for about half of their total permanent shock. 
And most of France, Germany and United Kingdom's transitory shock is found to be country-specific. This result confirms the findings of Richards (1995) that the national stock market prices are not cointegrated around one stochastic common trend and therefore implies that there is a potential long-run international diversification benefit. 
Table 3.1: Augmented Dickey-Fuller unit root test for the difference between a country's price index and the world index $\left(P_{t}^{i}-P_{t}^{w}\right)$

The econometric test model is specified as:

$$
\Delta\left(P_{t+1}^{i}-P_{t+1}^{w}\right)=\alpha^{i}+\beta^{i}\left(P_{t}^{i}-P_{t}^{w}\right)+\sum_{j=1}^{k} \phi_{j}^{i}\left[\Delta\left(P_{t+1-j}^{i}-P_{t+1-j}^{w}\right)\right]+\omega_{t+1}^{i},
$$

the null hypothesis is $\mathrm{H}_{0}: \beta^{i}=0$ and the alternative hypothesis is $\mathrm{H}_{1}: \beta^{i}<0$. The lag truncation $\mathrm{k}$ is chosen based on the Akaike Information criterion (AIC). The sample period is from December 1969 to May 2003. The table reports the ADF t-statistic and the critical values which are obtained from Fuller (1976).

\begin{tabular}{lc}
\hline Country & $P_{t}^{i}-P_{t}^{w}$ \\
\hline \hline Australia & $-2.923^{* *}$ \\
Austria & -1.997 \\
Belgium & -1.659 \\
Canada & -1.473 \\
Denmark & $-2.661^{*}$ \\
France & -2.555 \\
Germany & $-2.964^{* *}$ \\
Hong Kong & $-2.995^{* *}$ \\
Italy & $-3.426^{* *}$ \\
Japan & -1.167 \\
Netherlands & -0.95 \\
Norway & $-2.942^{* *}$ \\
Singapore & -1.832 \\
Spain & -1.443 \\
Sweden & -1.389 \\
Switzerland & -1.416 \\
United Kingdom & -2.358 \\
United States & -0.699 \\
& \\
Critical values & \\
10 percent & \\
5 percent & -2.571 \\
1 percent & -2.869 \\
\hline
\end{tabular}

* and ** denote statistical significance at 10 and 5 percent levels, respectively. 
Table 3.2: Mean reversion in control of the cointegration relationship between national stock price indices and the world price index A Kalman filter recursive procedure and Maximum likelihood estimation method are applied to the following state space model: Measurement equation: Measurement equation: $P_{t}^{i}-P_{t}^{w}=\alpha^{i}+\theta^{i} * P_{t}^{w}+x_{t}^{i}$; Transition equation: $x_{t}^{i}=\delta^{i} * x_{t-1}^{i}+v_{t}^{i}$. The sample period is from December 1969 to May 2003.

\begin{tabular}{|c|c|c|}
\hline Country & $\theta^{i}$ & $\delta^{i}$ \\
\hline \multirow{3}{*}{ Australia } & $\mathrm{H}_{0}: \theta^{i}=0$ & $\mathrm{H}_{0}: \delta^{i}=0 \quad \mathrm{H}_{0}: \delta^{i} \geq 1$ \\
\hline & $-0.129 * *$ & $0.936^{* *}$ \\
\hline & $(-3.040)$ & (51.010) \\
\hline \multirow[t]{2}{*}{ Austria } & $-0.508 * *$ & $0.986^{* *}$ \\
\hline & $(-8.645)$ & $(154.240)$ \\
\hline \multirow[t]{2}{*}{ Belgium } & $-0.152 * *$ & $0.993^{*}$ \\
\hline & $(-3.583)$ & (199.430) \\
\hline \multirow[t]{2}{*}{ Canada } & -0.032 & $0.991^{*}$ \\
\hline & $(-0.932)$ & $(160.830)$ \\
\hline \multirow[t]{2}{*}{ Denmark } & $-0.291 * *$ & $0.990^{*}$ \\
\hline & $(-5.637)$ & $(141.830)$ \\
\hline \multirow[t]{2}{*}{ France } & $0.089 *$ & $0.958^{* *}$ \\
\hline & $(1.841)$ & (65.530) \\
\hline \multirow[t]{2}{*}{ Germany } & -0.053 & $0.961^{* *}$ \\
\hline & $(-1.261)$ & (73.810) \\
\hline \multirow[t]{2}{*}{ Hong Kong } & $0.227^{* *}$ & $0.960^{* *}$ \\
\hline & $(2.747)$ & (80.450) \\
\hline \multirow[t]{2}{*}{ Italy } & $-0.144 * *$ & $0.972^{* *}$ \\
\hline & $(-2.020)$ & (106.570) \\
\hline
\end{tabular}

\begin{tabular}{|c|c|c|}
\hline Country & $\theta^{i}$ & $\delta^{i}$ \\
\hline \multirow{3}{*}{ Japan } & $\mathrm{H}_{0}: \theta^{i}=0$ & $\mathrm{H}_{0}: \delta^{i}=0 \quad \mathrm{H}_{0}: \delta^{i} \geq 1$ \\
\hline & 0.005 & 0.994 \\
\hline & $(0.105)$ & $(184.670)$ \\
\hline \multirow[t]{2}{*}{ Netherlands } & -0.032 & 0.996 \\
\hline & $(-0.965)$ & $(250.250) \quad(-1.058)$ \\
\hline \multirow[t]{2}{*}{ Norway } & -0.067 & $0.971^{* *}$ \\
\hline & $(-1.129)$ & $(79.750) \quad(-2.413)$ \\
\hline \multirow[t]{2}{*}{ Singapore } & $0.114^{* *}$ & $0.990^{*}$ \\
\hline & $(2.026)$ & $(144.910)$ \\
\hline \multirow[t]{2}{*}{ Spain } & $-0.120 * *$ & $0.993^{*}$ \\
\hline & $(-2.058)$ & (184.775) \\
\hline \multirow[t]{2}{*}{ Sweden } & 0.040 & $0.991^{*}$ \\
\hline & $(0.694)$ & $(154.980)$ \\
\hline \multirow[t]{2}{*}{ Switzerland } & $-0.106^{* *}$ & 0.992 \\
\hline & $(-2.457)$ & $(145.890)$ \\
\hline \multirow[t]{2}{*}{ United Kingdom } & $0.118^{* *}$ & $0.951^{* *}$ \\
\hline & $(2.720)$ & $(96.650) \quad(-5.041)$ \\
\hline \multirow[t]{2}{*}{ United States } & $-0.075 * *$ & 0.997 \\
\hline & $(-3.367)$ & $(161.910) \quad(-0.492)$ \\
\hline
\end{tabular}

* and ** denote statistical significance at 10 and 5 percent levels, respectively. 
Table 3.3: Out-of-sample performance of a parametric contrarian trading strategy Parameters are estimated for two different state space models

Model 1: Measurement equation: $P_{t}^{i}-P_{t}^{w}=\alpha^{i}+\theta^{i} * P_{t}^{w}+x_{t}^{i}$; Transition equation: $x_{t}^{i}=\delta^{i} * x_{t-1}^{i}+v_{t}^{i}$

Model 2: Measurement equation: $P_{t}^{i}-P_{t}^{w}=\alpha^{i}+x_{t}^{i}$; Transition equation: $x_{t}^{i}=\delta^{i} * x_{t-1}^{i}+v_{t}^{i}$

The sample period is from December 1969 to December 1996. The first in-sample estimation includes half of the total data points: December 1969 to September 1985. K denotes the holding period ( in months). Only 'Max1-Min1' and 'Max3-Min3' are marked with significance level. And the average annualized world index return over the full sample period is 0.149 .

Model1

Model2

\begin{tabular}{|c|c|c|c|}
\hline & & & \\
\hline \multirow[t]{4}{*}{ Holding period } & Strategy & Annualized mean return & Annualized mean return \\
\hline & Max1 & 0.199 & 0.213 \\
\hline & Min1 & 0.151 & 0.176 \\
\hline & Max1-Min1 & $0.048 *$ & 0.027 \\
\hline \multirow[t]{6}{*}{$K=12$} & Max3 & 0.193 & 0.191 \\
\hline & Min3 & 0.142 & 0.153 \\
\hline & Max3-Min3 & $0.050 * *$ & $0.039 * *$ \\
\hline & Max1 & 0.222 & 0.201 \\
\hline & Min1 & 0.127 & 0.167 \\
\hline & Max1-Min1 & $0.093^{* *}$ & $0.034 *$ \\
\hline \multirow[t]{6}{*}{$K=24$} & Max3 & 0.196 & 0.197 \\
\hline & Min3 & 0.136 & 0.153 \\
\hline & Max3-Min3 & $0.059 * *$ & $0.045^{* *}$ \\
\hline & Max1 & 0.232 & 0.199 \\
\hline & Min1 & 0.121 & 0.167 \\
\hline & Max1-Min1 & $0.106^{* *}$ & $0.036 * *$ \\
\hline \multirow[t]{6}{*}{$K=36$} & Max3 & 0.197 & 0.202 \\
\hline & Min3 & 0.142 & 0.160 \\
\hline & Max3-Min3 & $0.054 * *$ & $0.044 * *$ \\
\hline & Max1 & 0.236 & 0.193 \\
\hline & Min1 & 0.116 & 0.157 \\
\hline & Max1-Min1 & $0.111^{* *}$ & $0.036 * *$ \\
\hline \multirow[t]{6}{*}{$\mathrm{K}=48$} & Max3 & 0.193 & 0.198 \\
\hline & Min3 & 0.157 & 0.158 \\
\hline & Max3-Min3 & $0.036 * *$ & $0.040 * *$ \\
\hline & Max1 & 0.234 & 0.190 \\
\hline & Min1 & 0.098 & 0.151 \\
\hline & Max1-Min1 & $0.116^{* *}$ & $0.040 * *$ \\
\hline \multirow[t]{3}{*}{$\mathrm{K}=60$} & Max3 & 0.202 & 0.192 \\
\hline & Min3 & 0.140 & 0.157 \\
\hline & Max3-Min3 & $0.060 * *$ & $0.037 * *$ \\
\hline
\end{tabular}


Table 3.4: Out-of-sample performance of a parametric contrarian trading strategy Parameters are estimated for two different state space models

Model 1: Measurement equation: $P_{t}^{i}-P_{t}^{w}=\alpha^{i}+\theta^{i} * P_{t}^{w}+x_{t}^{i}$; Transition equation: $x_{t}^{i}=\delta^{i} * x_{t-1}^{i}+v_{t}^{i}$

Model 2: Measurement equation: $P_{t}^{i}-P_{t}^{w}=\alpha^{i}+x_{t}^{i}$; Transition equation: $x_{t}^{i}=\delta^{i} * x_{t-1}^{i}+v_{t}^{i}$

The full sample period is from December 1969 to May 2003. The first in-sample estimation includes half of the total data points: December 1969 to September 1985. K denotes the holding period ( in months). Only 'Max1-Min1' and 'Max3-Min3' are marked with significance level. And the average annualized world index return over the full sample period is 0.07.

Model1

Model2

\begin{tabular}{|c|c|c|c|}
\hline & \\
\hline \multirow[t]{2}{*}{ Holding period } & Strategy & Annualized mean return & Annualized mean return \\
\hline & Max1 & 0.074 & 0.106 \\
\hline \multirow{5}{*}{$\mathrm{K}=12$} & Min1 & 0.036 & 0.041 \\
\hline & Max1-Min1 & $0.038 *$ & $0.065 * *$ \\
\hline & Max3 & 0.087 & 0.091 \\
\hline & Min3 & 0.061 & 0.057 \\
\hline & Max3-Min3 & 0.026 & $0.034 * *$ \\
\hline \multirow{7}{*}{$K=24$} & Max1 & 0.092 & 0.120 \\
\hline & Min1 & 0.033 & 0.044 \\
\hline & Max1-Min1 & $0.063 * *$ & $0.074^{* *}$ \\
\hline & Max3 & 0.090 & 0.102 \\
\hline & Min3 & 0.053 & 0.063 \\
\hline & Max3-Min3 & $0.035 * *$ & $0.039 * *$ \\
\hline & Max1 & 0.102 & 0.113 \\
\hline \multirow{5}{*}{$K=36$} & Min1 & 0.019 & 0.044 \\
\hline & Max1-Min1 & $0.075^{* *}$ & $0.066 * *$ \\
\hline & Max3 & 0.089 & 0.094 \\
\hline & Min3 & 0.055 & 0.065 \\
\hline & Max3-Min3 & $0.034 * *$ & $0.028 * *$ \\
\hline \multirow{7}{*}{$K=48$} & Max1 & 0.100 & 0.102 \\
\hline & Min1 & 0.016 & 0.040 \\
\hline & Max1-Min1 & $0.073^{* *}$ & $0.057 * *$ \\
\hline & Max3 & 0.085 & 0.085 \\
\hline & Min3 & 0.056 & 0.064 \\
\hline & Max3-Min3 & $0.028 * *$ & $0.021 * *$ \\
\hline & Max1 & 0.087 & 0.088 \\
\hline \multirow{5}{*}{$K=60$} & Min1 & 0.014 & 0.038 \\
\hline & Max1-Min1 & $0.060 * *$ & $0.044 * *$ \\
\hline & Max3 & 0.074 & 0.076 \\
\hline & Min3 & 0.056 & 0.065 \\
\hline & Max3-Min3 & $0.018 * *$ & $0.010 * *$ \\
\hline
\end{tabular}

* and ** denote statistical significance at 10 and 5 percent levels, respectively. 


\section{CHAPTER 4}

Pricing permanent and transitory betas 


\section{Chapter 4}

\section{Pricing permanent and transitory betas}

\subsection{Introduction}

Siegel (1999) argues that stocks are relatively safer for long-term investors, but this cannot be true if asset returns are IID, because then the means and variances of all asset returns increase in proportion with the investment horizon. Poterba and Summers (1988) and Campbell (1991) present direct and indirect evidence, respectively, for the existence of negative univariate autocorrelations of stock returns, mean reversion. Campbell (2000) states that, if stock returns are mean reverting, this implies that investment opportunities are time-varying. As demonstrated in Poterba and Summers (1988) and Fama and French (1988), the stock price level can be generally described as the sum of two components - a trend component and a cyclical component. The fact that the predictability of stock returns comes from the cyclical component relates the transitory shocks to the timevarying investment opportunities. Moreover, Merton (1969, 1971, and 1973) shows that if investment opportunities are varying over time, then long-term investors generally care about shocks to investment opportunities, as well as shocks to wealth itself, because investment opportunities affect the conditional distribution of future returns. Then, it seems natural to ask, comparing these two different shocks, which shock is more volatile; and, more intriguingly, how the investors would price these two different shocks. Campbell and Vuolteenaho (2003, NBER) derive a two-factor intertemporal asset-pricing model where one factor reflects news about the market's future cash flows and the other reflects news about the market's discount rates; the discount rate news is much more volatile than the cash-flow news. Based on Campbell (1993)'s discrete-time 
intertemporal asset pricing model, they also derive that the cash-flow beta has a higher price of risk than the discount-rate beta, and the ratio of the two risk prices equals the risk aversion coefficient of a representative investor. They show that their two-factor model can explain the value and size effects and is substantially better than the static CAPM in explaining the cross-section of asset returns. Furthermore, compared with unrestricted factor models such as the Fama and French (1993) model, Campbell and Vuolteenaho (2003)'s two-factor intertemporal asset pricing model provides a theoretical explanation for the higher average returns on value stocks and small stocks as necessary compensation for risk.

In their chapter, they also state that the two components (cash flow news and discount rate news) in market returns can be interpreted as permanent and transitory shocks to wealth. The shock to cash-flow is regarded as permanent since the returns generated by cash-flow news are never reversed subsequently, and the shock to the discount rate is considered transitory since returns generated by discount rate news are offset by lower returns in the future. Accordingly, it is reasonable to argue that long-term investors are more averse to permanent shocks than to transitory shocks, which is suggested theoretically and empirically in their paper when they find that the price of cash-flow risk is higher than the price of discount rate risk. In a similar spirit of Campbell and Vuolteenaho (2003) but from a different perspective, in this chapter, we directly decompose the market returns into permanent and transitory components and investigate how these two components are priced. Instead of using a VAR model to decompose market return, we apply some commonly used decomposition methods: the HodrickPrescott approach and an unobserved component approach (or the state-space model). 
There is a large literature that has proposed various methods of decomposing a univariate series into permanent and transitory components. Beveridge and Nelson (1981) apply ARIMA methods to decompose a non-stationary time-series into a permanent and a temporary component. Making the trend component of real GDP or GNP a random walk with drift rather than a deterministic function of time, Nelson and Plosser (1982) match a model consisting of permanent and temporary components to an autocorrelation function to infer the relative size of each component. Watson (1986) and Clark (1987) use unobserved-components models to decompose GNP series into two components. Harvey (1989, 2000) suggests a local linear trend model which allows the drift term to change over time to accommodate the persistent fluctuations in the mean growth rates. Hodrick and Prescott (1997) (H-P) propose an approach to compute the permanent component of a non-stationary series by minimizing the variance of the series around its permanent component, subject to a penalty that constrains the second difference of the permanent component. Rotemberg (1999) suggests a heuristic method of time series decomposition to ensure that the estimated trend minimizes the autocorrelation of the cyclical component and the cross-correlation of the trend and cycle components over a certain period of time. Baxter and King (1999) propose a band-pass filter that isolates the components of the time series with fluctuations between 6 and 32 quarters and removes the components of higher and lower frequencies as "noncyclical”. Developed by Boschan and Ebanks (1978) and restudied by Zarnowitz and Ozyildirim (2001), the Phase Average Trend (PAT) approach was explicitly intended to measure growth cycles and the results from this approach seem similar to the results obtained with the H-P and band-pass filtering methods. 
Most of the economic literature on decomposition has been targeted to macroeconomic variables, such as real GDP or real GNP, consumption, investment, the unemployment rate, the current account, etc. Summers (1986) and Poterba and Summers (1988) propose to model the stock market price as a combination of a permanent component (fundamental component) and a stationary component. Based on this socalled "fad" model, some empirical methodologies were developed to analyze mean reversion in stock prices, such as the variance ratio test by Cochrane (1988) and the autoregression test by Fama and French (1988). This chapter employs the "fad" model proposed by Kim and Kim (1996) which considers switching regimes in the disturbances. This "fad" model - unobserved components model with Markov-switching variances (UC-MS) --- can be represented as a state-space model and estimated by the Kalman Filter procedure. For comparison, the H-P filter is applied since it has been the most popular decomposition method and, based on the fit to the actual data, it performs at least as well as any other method mentioned above. The decomposition results show that for the H-P approach most of the variation in market return is attributable to the cyclical component, whereas for the UC-MS approach, the low-volatility state of the cyclical component dominates, which confirms the characteristic of the cyclical component as 'short-lived'; moreover, for the high-volatility state, the variance of the cyclical shock is only about twice as much as that of the permanent component.

In the context of Merton's (1973) intertemporal asset pricing model, we formally derive a two-beta model which has two risk factors: one is perfectly correlated with the permanent shock and the other is perfectly correlated with the transitory shock. We calculate the permanent beta and the transitory beta for the Fama and French 25 size and 
book-to-market portfolios. Differences in the values of both betas show a pattern among the portfolios: small-firm stocks generally have larger permanent betas than large-firm stocks; value stocks, in most cases, also have larger permanent betas than growth stocks. Motivated by this regularity in the betas, we evaluate our two-beta model in a traditional two-pass regression framework. However, the results do not provide enough evidence to claim that our two-beta asset pricing model performs significantly better than the CAPM. Nevertheless, derived from an embedded stochastic discount factor, a conditional six-beta model and its alternative four-beta model perform as well as the Fama and French threefactor model does.

The next section uses the H-P approach and the UC-MS approach to decompose the market returns into permanent and transitory components. Section 4.3 proposes the twobeta intertemporal asset pricing model, which is assessed and compared with the CAPM and the Fama and French three-factor model in section 4.4. Section 4.5 presents the derivation and the evaluation of a six-beta pricing model. Section 4.6 concludes and makes some suggestions for future research.

\subsection{Decomposition of market returns}

This section is contributed to an analysis of the decomposition of the real stock market price. Two decomposition methods are under discussion. The unobserved component (UC) approach, also called state space model, explicitly anatomizes the market price series as a combination of a permanent and a transitory components and specifies the dynamics of both components for the permanent one to follow a random walk with drift and the transitory one to follow a stationary autoregressive process. In contrast, the Hodrick and Prescott decomposition does not utilize standard time series 
analysis, but is based on prior knowledge, implied by neoclassical growth theory ${ }^{32}$ that the growth component of aggregate economic time series varies smoothly over time.

\subsubsection{Hodrick-Prescott decomposition (H-P)}

Based on the prior knowledge that the growth (trend) component varies smoothly over time, the H-P approach, as does the UC approach, attributes much of the variation to a cyclical component. As shown in their model ${ }^{33}$, an observed time series $y_{t}$ is the sum of a growth component $g_{t}$ and a cyclical component $c_{t}: y_{t}=g_{t}+c_{t}$, for $t=1, \ldots, T$.

$$
\underset{\left\{g_{t}\right\}_{t=1}^{T}}{\operatorname{Min}}\left\{\sum_{t=1}^{T} c_{t}^{2}+\lambda \sum_{t=3}^{T}\left[\left(g_{t}-g_{t-1}\right)-\left(g_{t-1}-g_{t-2}\right)\right]^{2}\right\}
$$

where $\lambda$ is the smoothing parameter which penalizes variability in the growth component series. The larger the value of $\lambda$, the smoother is the growth component. Mostly in practice, the value of $\lambda$ is suggested to be 100 for annual data, 1600 for quarterly data, and 14400 for monthly data. The subject for decomposition in this section is the value-weighted real market price for the U.S. stock market. The value-weighted real price index is backed out from the value-weighted real market return. The nominal market return over NYSE, AMEX, and NASDAQ stocks from July 1926 to December 2003 is obtained from the CRSP database, and the seasonally adjusted Consumer Price Index is obtained from the Bureau of Labor Statistics. Besides monthly price, the quarterly and annual prices are also created from quarterly returns and annual returns, respectively. Table 4.1 shows the descriptive statistics for the real stock market returns for monthly, quarterly and annual cases. The positive autocorrelation $\rho_{1}$ for the monthly return and the negative autocorrelation $\rho_{4}$ to $\rho_{16}$ for the quarterly return suggest the

\footnotetext{
${ }^{32}$ See Lucas (1980) and Mitchell (1913) for interpretation.

${ }^{33}$ Hodrick and Prescott (1997)
} 
possibility of momentum and mean reversion. Figures 1 through 6 show the trend and the cycle of the value-weighted real stock market price decomposed by the H-P method. Figure 4.1 and figure 4.2 are for the monthly price, figure 4.3 and figure 4.4 are for the quarterly price, and figure 4.5 and figure 4.6 are for the annual price. From figures 4.2, 4.4 and 4.6, the cyclical component seems to reveal the great bull markets during the 1900s: 1949 to 1966 and 1982 to 2000 and also the important bear markets, the Great Depression of 1929-1933, the oil crisis of 1973-74 and the market crash in October 1987. Since the price is in logarithms, the change in price, $y_{t}-y_{t-1}$, corresponds to the real stock market return; and since $y_{t}=g_{t}+c_{t}, y_{t}-y_{t-1}=\left(g_{t}-g_{t-1}\right)+\left(c_{t}-c_{t-1}\right)$. So, $g_{t}-g_{t-1}$ is the permanent component of the total real market return and $c_{t}-c_{t-1}$ is the transitory real market return. Table 4.2 summarizes the behavior of the derived permanent and transitory components of the real market return from the H-P decomposition. All of the monthly, quarterly, annual data show that the variance of the transitory component is much larger than that of the permanent component $\left(\sigma_{\text {cycle }}^{2} / \sigma_{\text {trend }}^{2}=43,52\right.$ and 20 for monthly, quarterly and annual data respectively). This result is consistent with the finding of Campbell (1991) and Campbell and Vuolteenaho (2003) that discount-rate news is the dominant component of the market return when discount-rate news is associated with the transitory component of the market return. It is also shown in Table 4.2 that the trend and the cycle are almost uncorrelated with one another. If the trend and the cycle contain different information about market return, and if they represent different kind of risks to investors, how would the investors price these two different shocks to market price? The exploration of an answer to this question will be presented in the following sections. 


\subsubsection{The unobserved component (UC) approach}

In this approach, $\log$ real market price $p_{t}$ can be modeled in the following form:

$$
p_{t}=q_{t}+z_{t}
$$

$q_{t}=q_{t-1}+\alpha+\eta_{t}, \eta_{t} \sim$ i.i.d..$N\left(0, \sigma_{\eta}^{2}\right)$

$z_{t}=\phi(L) z_{t}+\varepsilon_{t}, \varepsilon \sim$ i.i.d.N $\left(0, \sigma_{\varepsilon}^{2}\right)$

$\phi(L)$ is the lag operator. $\operatorname{Cov}\left(\eta_{t}, \varepsilon_{t \pm k}\right)=\sigma_{\eta \varepsilon}$ for $\mathrm{k}=0$; 0 otherwise.

$q_{t}$ is the stochastic trend (permanent component) with a drift (i.e. growth rate) $\alpha$, which is assumed to evolve slowly over time; $z_{t}$ is the cycle (persistent but transitory component) which is assumed to have an autoregressive process. Then, the difference of $p_{t}$ is the corresponding return;

$r_{t}=p_{t}-p_{t-1}=\alpha+\left(z_{t}-z_{t-1}\right)+\eta_{t}$

$\eta_{t}$ is the innovation (shock) to the trend and $\varepsilon_{t}$ is the innovation to the cycle. $\eta_{t}$ and $\varepsilon_{t}$ are normally and independently distributed with zero means and variances $\sigma_{\eta}^{2}$ and $\sigma_{\varepsilon}^{2}$, respectively. In decomposing real GDP, Harvey (1985) and Clark (1987), and Harvey and Jaeger (1993) suggest an AR(2) process of $z_{t}$ which allows the cycle process to be periodic in the sense of having a peak in its spectral density function and implies that positive autocorrelation of returns at lag one is accompanied by negative autocorrelation at longer lags. As it is studied with a vast amount of evidence --- the behavior of stock returns exhibits positive short-run autocorrelation, which is called momentum and negative long-run autocorrelation, which is identified as mean reversion --- an $\operatorname{AR}(2)$ process for the cycle would be appropriate for the whole framework. Also, this model 
implies that innovations in the unobserved trend and cycle are uncorrelated: $\sigma_{\eta \varepsilon}=0$, which also implies a very smooth trend and a highly persistent cycle component. This set-up remains the standard treatment of trend-cycle decomposition in the state space framework as in Proietti (2002), although Koopman (1997) considers the possibility of non-zero correlation. For an $\operatorname{AR}(2)$ specification of the transitory component $z_{t}$, the representation of stock market returns from the model in (4.1) - (4.4) can be rewritten in the following state-space form:

$$
\begin{aligned}
& r_{t}=\alpha+\left[\begin{array}{cc}
1 & -1
\end{array}\right]\left[\begin{array}{c}
z_{t} \\
z_{t-1}
\end{array}\right]+\eta_{t} \text {, measurement equation } y_{t}=\mu+H \beta_{t}+e_{t} \\
& {\left[\begin{array}{c}
z_{t} \\
z_{t-1}
\end{array}\right]=\left[\begin{array}{cc}
\phi_{1} & \phi_{2} \\
1 & 0
\end{array}\right]\left[\begin{array}{c}
z_{t-1} \\
z_{t-2}
\end{array}\right]+\left[\begin{array}{c}
\varepsilon_{t} \\
0
\end{array}\right] \text {, transition equation } \beta_{t}=F \beta_{t-1}+v_{t}}
\end{aligned}
$$

Once a state space model is set up, the Kalman filter can be employed to estimate the unobserved components. There are five parameters in this case: $\sigma_{\eta}, \sigma_{\varepsilon}, \alpha, \phi_{1}$ and $\phi_{2}$. Table 4.3 reports the estimation results. The first two columns are the estimates for the permanent and transitory shocks. As is shown, the transitory shock $\sigma_{\varepsilon}$ is precisely estimated and statistically accounts for all the variation in real market returns, since the estimate of $\sigma_{\eta}$ is statistically not different from zero. However, this result is not consistent with previous findings, for instance, the one by Fama and French (1988). If there were no permanent shock, as derived by Fama and French (1988), the coefficient estimate of the first order autoregression of stock returns would approach -0.5 in the long run. However, what they found is that the coefficient estimate bears a U-shaped pattern which indicates that stock returns contain permanent shock as well as transitory shock. A similar demonstration of the existence of a permanent shock can be found in the variance- 
ratio test ${ }^{34}$. The reason that our estimation attributes all the variation to the transitory component might lie in the assumption that the distributions of the permanent and transitory components are identical over time. In other words, lack of consideration of model instability might have caused such a result. To incorporate possible regimeswitching disturbances, we adopt Kim and Kim’s (1996) proposal of modeling Markovswitching variances:

$$
\begin{aligned}
& \sigma_{\eta, t}^{2}=\left(1-S_{\eta, t}\right) \sigma_{\eta 0}^{2}+S_{\eta, t} \sigma_{\eta 1}^{2}, \sigma_{\eta 1}^{2}>\sigma_{\eta 0}^{2} \\
& \sigma_{\varepsilon, t}^{2}=\left(1-S_{\varepsilon, t}\right) \sigma_{\varepsilon 0}^{2}+S_{\varepsilon, t} \sigma_{\varepsilon 1}^{2}, \sigma_{\varepsilon 1}^{2}>\sigma_{\varepsilon 0}^{2}
\end{aligned}
$$

and $S_{\eta, t}$ and $S_{\varepsilon, t}$ take discrete values: 0 or 1 , and are unobserved first-order Markovswitching variables that evolve independently of each other according to the following transition probabilities:

$$
\begin{aligned}
& \operatorname{Pr}\left\{S_{\eta, t}=0 \mid S_{\eta, t-1}=0\right\}=p_{\eta 0}, \operatorname{Pr}\left\{S_{\eta, t}=0 \mid S_{\eta, t-1}=0\right\}=p_{\eta 1} \\
& \operatorname{Pr}\left\{S_{\varepsilon, t}=0 \mid S_{\varepsilon, t-1}=0\right\}=p_{\varepsilon 0}, \operatorname{Pr}\left\{S_{\varepsilon, t}=0 \mid S_{\varepsilon, t-1}=0\right\}=p_{\varepsilon 1}
\end{aligned}
$$

Table 4.4 reports the maximum likelihood estimates of the state space model with Markov-switching disturbances given in (4.5) - (4.8). For all data frequencies, the standard error of the transitory shock $\sigma_{\varepsilon}$ is not significantly different from zero for the low-volatility state ( $S_{s t}=0$ ), but it is significant for the high-volatility state $\left(S_{\varepsilon t}=1\right)$. On the other hand, since the estimates of the transition probability for the low-volatility state $\left(\hat{p}_{\varepsilon 0}\right)$ are larger than those for the high-volatility state $\left(\hat{p}_{\varepsilon 1}\right)$, it implies that the highvolatility state for the transitory shock will not happen as often or as long as the lowvolatility state. In light of this result, it might be tempting to speculate that the high-

\footnotetext{
${ }^{34}$ See Poterba and Summers (1988), Lo and MacKinlay (1988) and Kim, Nelson, and Startz (1991).
} 
volatility state happens only in some rare and severe events, such as the Great Depression, or the OPEC oil shock. Figures 4.7 through 4.12 illustrate the permanent and the transitory components of the real stock market price decomposed by the unobserved components model. Compared with the H-P trend, the UC-MS trend is more volatile; on the other hand, the UC-MS cycle is less volatile than the H-P cycle. The transitory shock for the high-volatility state $\hat{\sigma}_{\varepsilon 1}$ is twice to thrice as much as the permanent shock $\hat{\sigma}_{\eta 1}$. In fact, as analyzed above, the ratio of the H-P transitory variance and the H-P permanent variance $\left(\sigma_{\text {cycle }}^{2} / \sigma_{\text {trend }}^{2}\right)$ is 43, 52 and 20 for monthly, quarterly and annual data respectively, but the corresponding UC-MS ratio is 2.8, 7.8 and 3.1(for the high-volatility state). Furthermore, it is clear to see that the high-volatility state of the transitory shock only shows up in the 'big' events: the Great Depression, the oil crisis, and the 1987 market crash. Also, those high-volatility shocks are not as persistent as the H-P transitory shocks. Moreover, as indicated in Table 4.5, the permanent and the transitory shocks from the UC-MS approach are barely correlated.

So far, from the two different decomposition approaches, we find that the real stock market return contains two distinct shocks: a permanent one and a transitory one. Now, it is intriguing to check how investors view these two shocks and how significant the roles played by them are in explaining asset returns. But, before empirically testing the asset pricing ability of these two shocks, we are interested in formally building a two-factor asset pricing model in a theoretical framework. 


\subsection{Model shocks to market return in a dynamic asset-pricing model.}

In this section, a two-factor model is derived based on Merton's (1973) intertemporal asset pricing model.

For a representative investor, the value function can be written as:

$$
\begin{aligned}
& V\left(w_{t}, z_{t}, z_{t-1}\right)=\underset{c_{t},\left\{s_{t}^{i}\right\}_{i=1}^{n}}{\operatorname{Max}} E_{t}\left[u\left(c_{t}\right)+\beta V\left(w_{t+1}, z_{t+1}, z_{t}\right)\right] \\
& \text { s.t.: } \\
& w_{t+1}=\left(1+r_{t+1}\right)\left(w_{t}-c_{t}\right) \\
& r_{t+1}=r_{t+1}^{f}+\sum_{i=1}^{n} s_{t}^{i}\left(r_{t+1}^{i}-r_{t+1}^{f}\right) \\
& p_{t+1}=q_{t+1}+z_{t+1} \\
& q_{t+1}=q_{t}+\alpha+\eta_{t+1} \\
& z_{t+1}=\phi_{1} z_{t}+\phi_{2} z_{t-1}+\varepsilon_{t+1}
\end{aligned}
$$

Given that price is in log term, taking the first difference on $p_{t+1}$, we have an expression ${ }^{35}$ for market return from (4.13), (4.14), (4.15):

$r_{t+1}=\alpha+\eta_{t+1}+\left(\phi_{1}-1\right) z_{t}+\phi_{2} z_{t-1}+\varepsilon_{t+1}$

The first order conditions are:

$u_{c}\left(c_{t}\right)=\beta E_{t}\left[\left(1+r_{t+1}\right) V_{w}\left(w_{t+1}, z_{t+1}, z_{t}\right)\right]$

$E_{t}\left\{\left(r_{t+1}^{i}-r_{t+1}^{f}\right) N_{w}\left(w_{t+1}, z_{t+1}, z_{t}\right)\right\}=0$, for all $i$

From (4.15), (4.16) and (4.18), we have:

$$
E_{t}\left(r_{t+1}^{i}-r_{t+1}^{f}\right) E_{t}\left[V_{w}\left(w_{t+1}, z_{t+!}, z_{t}\right)\right]=-\operatorname{Cov}_{t}\left\{r_{t+1}^{i}, V_{w}\left(w_{t+1}, z_{t+!}, z_{t}\right)\right\}
$$

\footnotetext{
${ }^{35}$ In this setup, there is no presupposed structure on individual returns other than the assumption of normality. Therefore it is not against Roth (1976)'s portfolio separation theorem.
} 
Assuming normality and applying Stein’s generalized lemma ${ }^{36}$, we have:

$$
\begin{aligned}
& -\operatorname{Cov}_{t}\left\{r_{t+1}^{i}, V_{w}\left(w_{t+1}, z_{t+1}, z_{t}\right)\right\} \\
& =-E_{t} V_{w w}(\cdot) \operatorname{Cov}_{t}\left(r_{t+1}^{i}, w_{t+1}\right)-E_{t} V_{w z}(\cdot) \operatorname{Cov}_{t}\left(r_{t+1}^{i}, z_{t+1}\right)-E_{t} V_{w}(\cdot) \operatorname{Cov}_{t}\left(r_{t+1}^{i}, z_{t}\right) \\
& =-E_{t} V_{w w}(\cdot) \operatorname{Cov}_{t}\left(r_{t+1}^{i}, w_{t+1}\right)-E_{t} V_{w z}(\cdot) \operatorname{Cov}_{t}\left(r_{t+1}^{i}, z_{t+1}\right), \text { where }(\cdot)=\left(w_{t+1}, z_{t+1}, z_{t}\right)
\end{aligned}
$$

since $z_{t}$ is considered a constant under the conditional setup, $\operatorname{Cov}_{t}\left(r_{t+1}^{i}, z_{t}\right)=0$.

From (4.11) and (4.16), a conditional version of the model can be derived as:

$$
\begin{gathered}
-E_{t} V_{w w}(\cdot) \operatorname{Cov}_{t}\left(r_{t+1}^{i}, w_{t+1}\right)-E_{t} V_{w z}(\cdot) \operatorname{Cov}_{t}\left(r_{t+1}^{i}, z_{t+1}\right)= \\
-\left(w_{t}-c_{t}\right) E_{t} V_{w w}(\cdot) \operatorname{Cov}_{t}\left(r_{t+1}^{i}, r_{t+1}\right)-E_{t} V_{w z}(\cdot) \operatorname{Cov}_{t}\left(r_{t+1}^{i}, z_{t+1}\right) \\
=-\left(w_{t}-c_{t}\right) E_{t} V_{w w}(\cdot) \operatorname{Cov}_{t}\left(r_{t+1}^{i}, \eta_{t+1}\right)-\left(w_{t}-c_{t}\right) E_{t} V_{w w}(\cdot) \operatorname{Cov}_{t}\left(r_{t+1}^{i}, \varepsilon_{t+1}\right) \\
-E_{t} V_{w z}(\cdot) \operatorname{Cov}_{t}\left(r_{t+1}^{i}, \varepsilon_{t+1}\right) \\
\mu_{t+1}^{i}-r_{t+1}^{f}=A_{t} \operatorname{Cov}_{t}\left(r_{t+1}^{i}, \eta_{t+1}\right)+B_{t} \operatorname{Cov}_{t}\left(r_{t+1}^{i}, \varepsilon_{t+1}\right) \\
A_{t}=\frac{-\left(w_{t}-c_{t}\right) E_{t} V_{w w}(\cdot)}{E_{t}\left[V_{w}(\cdot)\right]} \\
B_{t}=\frac{-\left(w_{t}-c_{t}\right) E_{t} V_{w w}(\cdot)-E_{t} V_{w z}(\cdot)}{E_{t}\left[V_{w}(\cdot)\right]}
\end{gathered}
$$

Note that the value function is a concave function of wealth, so the sign of $A_{t}$ is positive. However, there is no definite sign for $B_{t}$ since we are not certain about the sign of $V_{w z}(\cdot)$.

\footnotetext{
${ }^{36}$ Balvers (2004)
} 
Next, suppose there are two assets whose returns are perfectly correlated with permanent shock $\eta$ and transitory shock $\varepsilon$ respectively. Since $\eta_{t}$ and $\varepsilon_{t}$ are not correlated, we have:

$$
\begin{aligned}
\mu_{t+1}^{\eta}-r_{t+1}^{f} & =A_{t} \operatorname{Cov}_{t}\left(r_{t+1}^{\eta}, \eta_{t+1}\right)+B_{t} \operatorname{Cov}_{t}\left(r_{t+1}^{\eta}, \varepsilon_{t+1}\right) \\
& =A_{t} \operatorname{Var}\left(\eta_{t+1}\right) \\
\mu_{t+1}^{\varepsilon}-r_{t+1}^{f} & =A_{t} \operatorname{Cov}_{t}\left(r_{t+1}^{\varepsilon}, \eta_{t+1}\right)+B_{t} \operatorname{Cov}_{t}\left(r_{t+1}^{\varepsilon}, \varepsilon_{t+1}\right) \\
& =B_{t} \operatorname{Var}\left(\varepsilon_{t+1}\right)
\end{aligned}
$$

Then, solving $A$ and $B$, we derive a two-factor asset-pricing model:

$\mu_{t+1}^{i}-r_{t+1}^{f}=\frac{\operatorname{Cov}_{t}\left(r_{t+1}^{i}, \eta_{t+1}\right)}{\operatorname{Var}_{t}\left(\eta_{t+1}\right)}\left(\mu_{t+1}^{\eta}-r_{t+1}^{f}\right)+\frac{\operatorname{Cov}_{t}\left(r_{t+1}^{i}, \varepsilon_{t+1}\right)}{\operatorname{Var}_{t}\left(\varepsilon_{t+1}\right)}\left(\mu_{t+1}^{\varepsilon}-r_{t+1}^{f}\right)$

Let $\beta_{t}^{i \eta}=\frac{\operatorname{Cov}_{t}\left(r_{t+1}^{i}, \eta_{t+1}\right)}{\operatorname{Var}_{t}\left(\eta_{t+1}\right)}$ and $\beta_{t}^{i \varepsilon}=\frac{\operatorname{Cov}_{t}\left(r_{t+1}^{i}, \varepsilon_{t+1}\right)}{\operatorname{Var}_{t}\left(\varepsilon_{t+1}\right)}$, then

$\mu_{t+1}^{i}-r_{t+1}^{f}=\beta_{t}^{i \eta}\left(\mu_{t+1}^{\eta}-r_{t+1}^{f}\right)+\beta_{t}^{i \varepsilon}\left(\mu_{t+1}^{\varepsilon}-r_{t+1}^{f}\right)$

where the two factors - the permanent shock and the transitory shock can be obtained based on the previous section. In fact, as follows, there is a simple linear relationship between the two betas and the market beta in the CAPM.

$\operatorname{Cov}_{t}\left(r_{t+1}^{i}, r_{t+1}^{m}\right)=\operatorname{Cov}_{t}\left(r_{t+1}^{i}, \alpha+\eta_{t+1}+\left(\phi_{1}-1\right) z_{t}+\phi_{2} z_{t-1}+\varepsilon_{t+1}\right)=\operatorname{Cov}_{t}\left(r_{t+1}^{i}, \eta_{t+1}\right)+\operatorname{Cov}_{t}\left(r_{t+1}^{i}, \varepsilon_{t+1}\right)$

After dividing $\operatorname{Var}\left(r_{t+1}^{m}\right)$ on both sides, we get:

$$
\frac{\operatorname{Cov}_{t}\left(r_{t+1}^{i}, r_{t+1}^{m}\right)}{\operatorname{Var}_{t}\left(r_{t+1}^{m}\right)}=\frac{\operatorname{Var}_{t}\left(\eta_{t+1}\right)}{\operatorname{Var}_{t}\left(r_{t+1}^{m}\right)} \frac{\operatorname{Cov}_{t}\left(r_{t+1}^{i}, \eta_{t+1}\right)}{\operatorname{Var}_{t}\left(\eta_{t+1}\right)}+\frac{\operatorname{Var}_{t}\left(\varepsilon_{t+1}\right)}{\operatorname{Var}_{t}\left(r_{t+1}^{m}\right)} \frac{\operatorname{Cov}_{t}\left(r_{t+1}^{i}, \varepsilon_{t+1}\right)}{\operatorname{Var}_{t}\left(\varepsilon_{t+1}\right)}
$$

Conditionally, $\operatorname{Var}_{t}\left(r_{t+1}^{m}\right)=\operatorname{Var}_{t}\left(\eta_{t+1}\right)+\operatorname{Var}_{t}\left(\varepsilon_{t+1}\right)$, then $\frac{\operatorname{Var}_{t}\left(\eta_{t+1}\right)}{\operatorname{Var}_{t}\left(r_{t+1}^{m}\right)}+\frac{\operatorname{Var}_{t}\left(\varepsilon_{t+1}\right)}{\operatorname{Var}_{t}\left(r_{t+1}^{m}\right)}=1$. 
Let $\rho=\frac{\operatorname{Var}_{t}\left(\eta_{t+1}\right)}{\operatorname{Var}_{t}\left(r_{t+1}^{m}\right)}$, we have $\beta_{t}^{\text {im }}=\rho \beta_{t}^{i \eta}+(1-\rho) \beta_{t}^{i \varepsilon}$. According to this equation, market beta is a weighted sum of the permanent beta and the transitory beta. And the weight for each beta is the ratio of the conditional variance of its corresponding shock over the conditional variance of market return. If there is no transitory shock to market return, i.e. $\operatorname{Var}_{t}\left(\varepsilon_{t+1}\right)=0$, then $\rho=1$, therefore $\beta_{t}^{\text {im }}=\beta_{t}^{\text {in }}$, which means that our two-beta model is simply reduced to the CAPM.

\subsection{Evaluation of an asset-pricing model:}

From the theoretical derivation, the betas for permanent and transitory shocks are time-varying. We assume, however, in empirical analysis, that the betas are constant over time. Now, it is interesting to calculate $\beta_{\eta}^{i}$ and $\beta_{\varepsilon}^{i}$, and see how sensitive the different assets are to the permanent shock and the transitory shock. The assets examined are the Fama and French 25 size and book-to-market portfolios over the period 1926:07 2003:12 ${ }^{37}$. Based on the permanent and transitory shocks estimated in section II, we calculate $\beta_{\eta}^{i}$ and $\beta_{\varepsilon}^{i}$ according to the following formulae:

$$
\beta_{\eta}^{i}=\frac{\operatorname{Cov}\left(r^{i}, \eta\right)}{\operatorname{Var}(\eta)} \text { and } \beta_{\varepsilon}^{i}=\frac{\operatorname{Cov}\left(r^{i}, \varepsilon\right)}{\operatorname{Var}(\varepsilon)}
$$

Or simply regressing the asset returns on each shock will give the same results, since $\operatorname{Cov}(\eta, \varepsilon)=0$.

\footnotetext{
${ }^{37}$ The data are available from Kenneth French's website: http://mba.tuck.dartmouth.edu/pages/faculty/ken.french/data_library.html and quarterly and annual cases are also considered.
} 
Table 4.6 shows the estimates of the permanent-shock betas $\left(\hat{\beta}_{\eta}\right)$ and the transitoryshock betas $\left(\hat{\beta}_{\varepsilon}\right)$ for the Fama and French 25 size and book-to-market portfolios and the two shocks derived from the Hodrick-Prescott decomposition. The portfolios are organized with the growth portfolio at the left, the value portfolio at the upper right, the small-firm portfolio at the top and the large-firm portfolio at the bottom. In all the three Panels, controlling for the book-to-market ratio, $\hat{\beta}_{\eta}$ and $\hat{\beta}_{\varepsilon}$ tend to decrease from small stocks to large stocks except for $\hat{\beta}_{\eta}$ in Panel $\mathrm{C}$ which tends to increase from small to large stocks and $\hat{\beta}_{\eta}$ for the big value portfolios in Panel A and Panel B. When controlling for size, the permanent beta $\hat{\beta}_{\eta}$ does not seem to have a clear pattern from the growth stocks to the value stocks for any of the three Panels; as for the transitory beta $\hat{\beta}_{\varepsilon}$, there is no pronounced pattern, but the value stocks tend to have higher $\hat{\beta}_{\varepsilon}$ than the growth stocks.

Table 4.7 also shows the estimates of the permanent betas and the transitory betas based on the shocks obtained from the UC-MS approach. The test assets are the same 25 portfolios. Similar to Table 4.6, when controlling for book-to-market ratio, small stocks tend to have higher permanent beta $\hat{\beta}_{\eta}$ than big stocks except for the value stocks for monthly data. However, the transitory beta $\hat{\beta}_{\varepsilon}$ becomes negative and the absolute value of $\hat{\beta}_{\varepsilon}$ tends to decrease from small to big stocks. Besides, the value of $\hat{\beta}_{\varepsilon}$ becomes less significantly different from zero for quarterly and annual data, especially for big stocks. On the other hand, from growth stocks to value stocks, again similar to Table 4.5, neither $\hat{\beta}_{\eta}$ nor $\hat{\beta}_{\varepsilon}$ evinces any pattern, but value stocks seem to have higher $\hat{\beta}_{\eta}$ and lower $\hat{\beta}_{\varepsilon}$ (larger absolute value) than growth stocks. 
Now that we have the permanent beta and the transitory beta for the test assets, it seems natural to examine how these two betas are priced. The evaluation of the two-beta intertemporal asset pricing model (equation 14) can be conducted with a simple crosssectional regression ${ }^{38}$ :

$\bar{R}_{i}^{e}=\gamma_{0}+\gamma_{1} \hat{\beta}_{i, \eta}+\gamma_{2} \hat{\beta}_{i, \varepsilon}+e_{i}$

where $\bar{R}_{i}^{e}=\bar{R}_{i}-\bar{R}_{r f}$, the average excess returns of the 25 size and book-to-market portfolios.

For comparison purposes, we also examine the Capital Asset Pricing Model (CAPM) and the Fama-French three-factor model. The Fama-French three factors - market excess returns, the size factor (SMB) and the book-to-market (HML) factor are also available from Kenneth French’s website ${ }^{39}$.

Table 4.8 shows the estimated risk premiums for four different asset pricing models: the CAPM, the Fama and French's three-factor model, the two-beta intertemporal model based on the Hodrick-Prescott decomposition and the two-beta intertemporal model based on the unobserved components approach with Markov-switching variances. Panel A (monthly data) shows that the CAPM and the two-beta model with the UC-MS approach have the worst performance, for their adjusted $R^{2} \mathrm{~s}$ are negative. So, the market beta does not explain the cross-sectional variation in portfolios' average excess returns, neither does the permanent beta nor the transitory beta from the UC-MS approach. In contrast, the two-beta model with the HP approach performs the best with an adjusted $R^{2}(52.77 \%)$ even higher than that of the Fama and French three-factor model (49.67\%).

\footnotetext{
${ }^{38}$ See Black, Jensen, and Scholes(1972) and Fama and MacBeth (1973).

${ }^{39}$ The data, as well as the details about the portfolio construction can be obtained from http://mba.tuck.dartmouth.edu/pages/faculty/ken.french/
} 
As for the estimated price of risk, the Fama and French three-factor model produces a negative market risk premium, and significantly positive size and book-to-market risk premiums. However, the significant value of the constant term implies that there might be some other risk factors which contain information that Fama and French's three factors can not explain, since the constant in the cross-sectional regressions acts as a misspecification test. On the contrary, the constant term in the two-beta model with the $\mathrm{H}-\mathrm{P}$ approach is only significant at the $10 \%$ level. Besides, the price of permanent risk (HP-trend) is significantly negative and the price of transitory risk (HP-cycle) is significantly positive. For quarterly and annual data, the CAPM still performs poorly. And the Fama-French three-factor model performs the best with adjusted $R^{2}$ more than 76\%. Comparing the other two-beta models, the one with the HP approach performs worse than the one with the UC-MS approach. Moreover, the price of permanent and transitory risks for the UC-MS approach are both negative. Since from Table 4.6, the estimated transitory betas are negative, the portfolio with smaller transitory beta (larger absolute value, such as small stocks) will have higher expected excess returns than the one with larger transitory beta (smaller absolute value; such as big stocks). However, since the estimated permanent betas are positive, the negative price of permanent risk does not seem to explain the spread in expected excess returns between small stocks and big stocks or between growth stocks and value stocks. Note that small stocks have larger permanent betas than big stocks, and value stocks have larger permanent betas than growth stocks.

We also apply the Fama-Macbeth (FM) (1973) two-stage procedure to test these asset pricing models, since it has been widely used in asset pricing tests. By performing such 
tests, we can compare our results with those of previous studies ${ }^{40}$. The FM procedure is conducted in a rolling regression manner. Since the annual data only have 77 observations, we only examine the monthly and quarterly data. For illustration of the actual procedure conducted in the chapter, we take monthly data as an example; the same procedure is applied to quarterly data.

For monthly data, in the first stage, betas are estimated from time-series regressions of the returns of test assets on risk factors. We choose a 60-month time window to run the time-series regressions. In the second stage, at the $61^{\text {st }}$ month, we run a cross-sectional regression (CSR) of the excess returns of test assets on the estimated betas and save the estimated risk premiums. The same procedure is repeated with the 60-month time window moving one-month forward until the end of the sample period. Finally, from the CSR results, we perform hypothesis tests on the significance of the estimated risk premiums. However, as is well known, the estimated betas are measured with errors in the first stage. So, when they serve as independent variables in the CSR, they are subject to an errors-in-variables problem. To correct the problem, we adjust the standard errors from the second-stage regressions as proposed in Shanken (1992).

Table 4.9 reports the risk premium estimates for the competing models. Again, the CAPM performs worst, and its adjusted $R^{2}$ is $19.8 \%$ and $24.5 \%$ for monthly data and quarterly data respectively. Evidently, the Fama-French three-factor model has the best performance for both monthly data and quarterly data and its adjusted $R^{2}$ is $40 \%$ for monthly data and $46.8 \%$ for quarterly data. As for the two two-beta intertemporal models, the estimated risk premiums for the permanent beta and the transitory beta are not

\footnotetext{
${ }^{40}$ See for instance, Fama and French (1992), and Jagannathan and Wang (1996).
} 
significant and the adjusted $R^{2}$ s are only slightly higher than those of the CAPM for both monthly and quarterly cases. Since a model with more regressors generally has higher adjusted $R^{2}$ than a model with fewer regressors, the difference in the adjusted $R^{2}$ between the CAPM and the two-beta models is not considerable enough to argue that the two-beta models perform better than the CAPM. Although the two-beta models perform impressively in Table 4.9 in explaining the simple average excess returns of the test assets, the inconsistency evinced in Table 4.8 seems to leave some questions to be further investigated about the two-beta intertemporal asset pricing model.

\subsection{A conditional multivariable asset-pricing model}

In section III, from the derivation of the conditional two-beta asset pricing model, we find that there exists a stochastic discount factor. Specifically, from equation (4.20):

$\mu_{t+1}^{i}-r_{t+1}^{f}=A_{t} \operatorname{Cov}_{t}\left(r_{t+1}^{i}, \eta_{t+1}\right)+B_{t} \operatorname{Cov}_{t}\left(r_{t+1}^{i}, \varepsilon_{t+1}\right)$

Since $\operatorname{Cov}_{t}\left(r_{t+1}^{i}-r_{t+1}^{f}, 1-A_{t} \eta_{t+1}-B_{t} \varepsilon_{t+1}\right)$

$$
\begin{aligned}
& =\operatorname{Cov}_{t}\left(r_{t+1}^{i}-r_{t+1}^{f}, 1\right)-\operatorname{Cov}_{t}\left(r_{t+1}^{i}-r_{t+1}^{f}, A_{t} \eta_{t+1}\right)-\operatorname{Cov}_{t}\left(r_{t+1}^{i}-r_{t+1}^{f}, B_{t} \varepsilon_{t+1}\right) \\
& =A_{t} \operatorname{Cov}_{t}\left(r_{t+1}^{i}, \eta_{t+1}\right)-B_{t} \operatorname{Cov}_{t}\left(r_{t+1}^{i}, \varepsilon_{t+1}\right)
\end{aligned}
$$

also, $\operatorname{Cov}_{t}\left(r_{t+1}^{i}-r_{t+1}^{f}, 1-A_{t} \eta_{t+1}-B_{t} \varepsilon_{t+1}\right)$

$$
\begin{aligned}
& =E_{t}\left\{\left(r_{t+1}^{i}-r_{t+1}^{f}\right)\left(1-A_{t} \eta_{t+1}-B_{t} \varepsilon_{t+1}\right)\right\}-E_{t}\left(r_{t+1}^{i}-r_{t+1}^{f}\right) E_{t}\left(1-A_{t} \eta_{t+1}-B_{t} \varepsilon_{t+1}\right) \\
& =E_{t}\left\{\left(r_{t+1}^{i}-r_{t+1}^{f}\right)\left(1-A_{t} \eta_{t+1}-B_{t} \varepsilon_{t+1}\right)\right\}-E_{t}\left(r_{t+1}^{i}-r_{t+1}^{f}\right)
\end{aligned}
$$

then combine (4.25) and (4.26), we have:

$$
\begin{aligned}
E_{t}\left\{\left(r_{t+1}^{i}-r_{t+1}^{f}\right)\left(1-A_{t} \eta_{t+1}-B_{t} \varepsilon_{t+1}\right)\right\} & =\mu_{t+1}^{i}-r_{t+1}^{f}-A_{t} \operatorname{Cov}_{t}\left(r_{t+1}^{i}, \eta_{t+1}\right)-B_{t} \operatorname{Cov}_{t}\left(r_{t+1}^{i}, \varepsilon_{t+1}\right) \\
& =0
\end{aligned}
$$


$E_{t}\left\{\left(r_{t+1}^{i}-r_{t+1}^{f}\right)\left(1-A_{t} \eta_{t+1}-B_{t} \varepsilon_{t+1}\right)\right\}=0$ is a typical representation of stochastic discount factor equation ${ }^{41}$, where every asset's excess return $r_{t+1}^{i}-r_{t+1}^{f}$ can be priced by the same discount factor $m_{t}=1-A_{t} \eta_{t+1}-B_{t} \varepsilon_{t+1}$.

In addition, since

$$
A_{t}=\frac{-\left(w_{t}-c_{t}\right) E_{t} V_{w w}\left(w_{t+1}, z_{t+1}, z_{t}\right)}{E_{t}\left[V_{w}\left(w_{t+1}, z_{t+1}, z_{t}\right)\right]} \text {, it can be represented in an implicit function as }
$$

$A_{t}=f\left(w_{t}, z_{t}, z_{t-1}\right)$. When we assume that the value function has constant relative risk aversion, $w_{t}$ can be cancelled out from $A_{t}$. As a result, $A_{t}$ becomes a function of two state variables: $A_{t}=f\left(z_{t}, z_{t-1}\right)$. Similarly, $B_{t}$ can be represented as $B_{t}=g\left(z_{t}, z_{t-1}\right)$. Now, we need to find out the inherent factors in the stochastic discount factor. Since $A_{t}$ and $B_{t}$ are both implicit functions of $z_{t}$ and $z_{t-1}$, to simply the problem, we propose a first-order linear approximation of $A_{t}$ and $B_{t}$ :

$$
\begin{aligned}
& A_{t}=a_{0}+a_{1} z_{t}+a_{2} z_{t-1} \\
& B_{t}=b_{0}+b_{1} z_{t}+b_{1} z_{t-1}
\end{aligned}
$$

Substitute (4.27) and (4.28) into $m_{t}=1-A_{t} \eta_{t+1}-B_{t} \varepsilon_{t+1}$, we obtain a linear stochastic discount factor: $m_{t}=1-a_{0} \eta_{t+1}-a_{1} z_{t} \eta_{t+1}-a_{2} z_{t-1} \eta_{t+1}-b_{0} \varepsilon_{t+1}-b_{1} z_{t} \varepsilon_{t+1}-b_{2} z_{t-1} \varepsilon_{t+1}$.

As it is known ${ }^{42}$, a stochastic discount factor representation is equivalent to a betapricing representation, i.e. the factors in a stochastic discount factor are the same as the risk factors in a beta-pricing model. Therefore, we just derive an alternative multi-beta asset pricing model as follows:

\footnotetext{
${ }^{41}$ See Balvers (2004)

42 See Balvers (2004), and Cochrane (2001)
} 
$\mu_{t+1}^{i}-r_{t+1}^{f}=\beta_{t}^{i \eta} \mu_{t+1}^{\eta}+\beta_{t}^{i, z \eta 1} \mu_{t+1}^{z \eta 1}+\beta_{t}^{i, z \eta 2} \mu_{t+1}^{z \eta 2}+\beta_{t}^{i \varepsilon} \mu_{t+1}^{\varepsilon}+\beta_{t}^{i, z \varepsilon 1} \mu_{t+1}^{z \varepsilon 1}+\beta_{t}^{i, z \varepsilon 2} \mu_{t+1}^{z \varepsilon 2}$

In this model, besides the permanent shock $\eta_{t+1}$ and transitory shock $\varepsilon_{t+1}$ as those in the two-beta model, there are four additional factors: $z_{t} \eta_{t+1}, z_{t-1} \eta_{t+1}, z_{t} \varepsilon_{t+1}$ and $z_{t-1} \varepsilon_{t+1}$. $z_{t} \eta_{t+1}$ and $z_{t-1} \eta_{t+1}$ are the correlations between permanent shock $\eta_{t+1}$ and previous transitory component of market price, while $z_{t} \varepsilon_{t+1}$ and $Z_{t-1} \varepsilon_{t+1}$ are the correlations between $\varepsilon_{t+1}$ and previous transitory component of market price. So, this six-factor model claims that not only are the assets priced by current permanent and transitory shocks, but also priced by the correlations between those shocks and previous transitory component of market price.

To evaluate this model, we apply the Fama and MacBeth procedure on the quarterly data. Table 4.10 shows the test result. Also, in Table 4.10, we test another four-beta model:

$$
\mu_{t+1}^{i}-r_{t+1}^{f}=\beta_{t}^{i \eta} \mu_{t+1}^{\eta}+\beta_{t}^{i, z \eta 1} \mu_{t+1}^{z \eta 1}+\beta_{t}^{i \varepsilon} \mu_{t+1}^{\varepsilon}+\beta_{t}^{i, z \varepsilon 1} \mu_{t+1}^{z \varepsilon 1}
$$

This model is a parsimonious version of the six-beta model. The decision to ignore the other two factors is based on the concern that there is a potential multicollinearity problem between $z_{t} \eta_{t+1}$ and $z_{t-1} \eta_{t+1}$, and $z_{t} \varepsilon_{t+1}$ and $z_{t-1} \varepsilon_{t+1}$. As Table 4.10 shows, both the six-beta model and the four-beta model outperform the two-beta model, and their adjusted $R^{2}$ s (45.9\% and $41.2 \%$ respectively) are comparable with the adjusted $R^{2}$ (46.8\%) for the Fama and French three-factor model. Moreover, although neither the six-beta model nor the four-beta model have statistically significant risk premiums, the constant terms for both models are insignificant different from zero after Shanken's adjustment. In contrast, the constant term for the Fama and French three-factor model is 
significantly different from zero. Since the constant term indicates the information which can not be explained by the risk factors, our six-beta model and four-beta model get the better of the Fama and French three-factor model in this aspect.

\subsection{Conclusion}

Motivated by the findings that stock prices have a mean-reverting component as well as a fundamental growth component, this chapter derives a two-beta intertemporal asset pricing model to investigate how the two betas - permanent and transitory will be priced.

To acquire the permanent and transitory shocks, this chapter adopts two decomposition methodologies: the Hodrick-Prescott (HP) decomposition and the unobserved components approach with Markov-switching disturbances (UC-MS). The cyclical components derived from both decomposition approaches reflect the historical movement of the overall U.S. stock market. Based on Merton's (1973) intertemporal asset pricing model, a two-beta model is derived. In this model, one risk factor is perfectly correlated with the permanent shock and the other is perfectly correlated with the transitory shock. We examine the Fama and French 25 size and book-to-market portfolios and calculate the permanent beta and transitory beta for each test portfolio. We find that a regularity of some extent is exhibited in the value of the two betas among the portfolios: the small-firm stocks have larger permanent betas and also larger absolute values of transitory betas ${ }^{43}$ than the large-firm stocks; and though the tendency is not so distinct when controlling for size, the value stocks, in most cases, have larger permanent betas and also larger absolute values of transitory betas than the growth stocks. Next, in a

\footnotetext{
${ }^{43}$ The transitory beta is negative for the UC-MS approach.
} 
traditional two-pass framework, we evaluate the performance of our two-beta asset pricing model and compare it with those of the CAPM and the Fama and French threefactor model. When only one cross-sectional regression is conducted, our two-factor model displays a significant improvement in performance over the CAPM. Therefore, our model seems to show that the market return does contain different pieces of information which are viewed differently by the investors and are reflected in how the investors price the assets. However, the good performance is clouded when the classic rolling beta method of Fama and MacBeth (FM) (1973) is also applied. With the FM method, our two-beta model performs only slightly better than the CAPM and the Fama and French three-factor model still has the best performance. Finally, we derive a six-beta model from an embedded stochastic discount factor, and the Fama and MacBeth approach shows that this six-beta model and its alternative parsimonious four-beta model both perform comparatively with the Fama and French three-factor model.

The poor performance of the two-beta model could lie in the fact that so far there is no perfect decomposition method. The UC-MS approach already considers the switching regimes in the disturbances and the estimated components fit the data well. A more sophisticated model would probably only sacrifice the precision in estimation and computation time. A feasible further trial can divide the whole sample into different periods. As Campbell and Vuolteenaho (2003) split their sample at 1963:07, because that is when COMPUSTAT data become reliable and because most of the evidence on the book-to-market anomaly is obtained from the post-1963:07 period. Another possible break point is 1952:01, since Campbell (1991) and Hodrick (1992) found a structural change in the dividend process after this date. 
Figure 4.1: U.S. real stock market price and the Hodrick-Prescott trend Monthly, 1926:07-2003:12

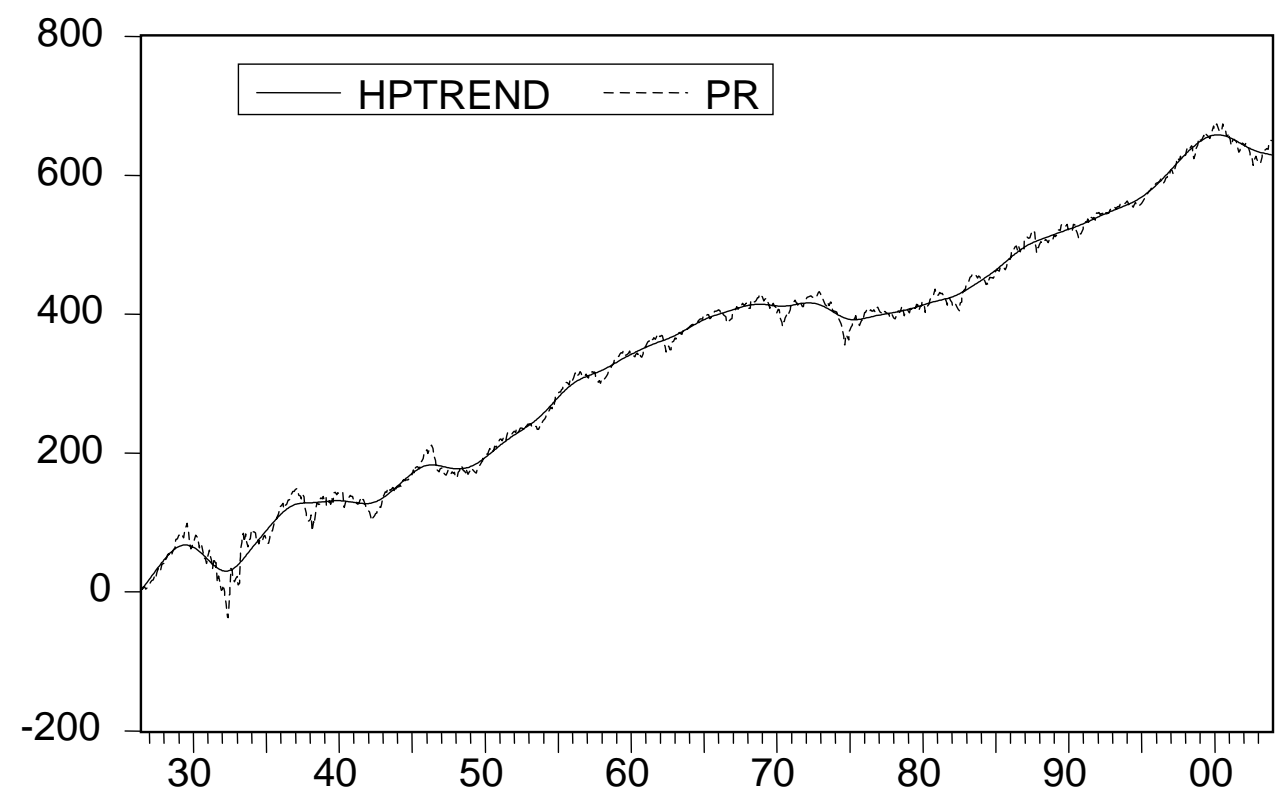

Figure 4.2: The Hodrick-Prescott cycle for the U.S. real stock market price Monthly, 1926:07-2003:12

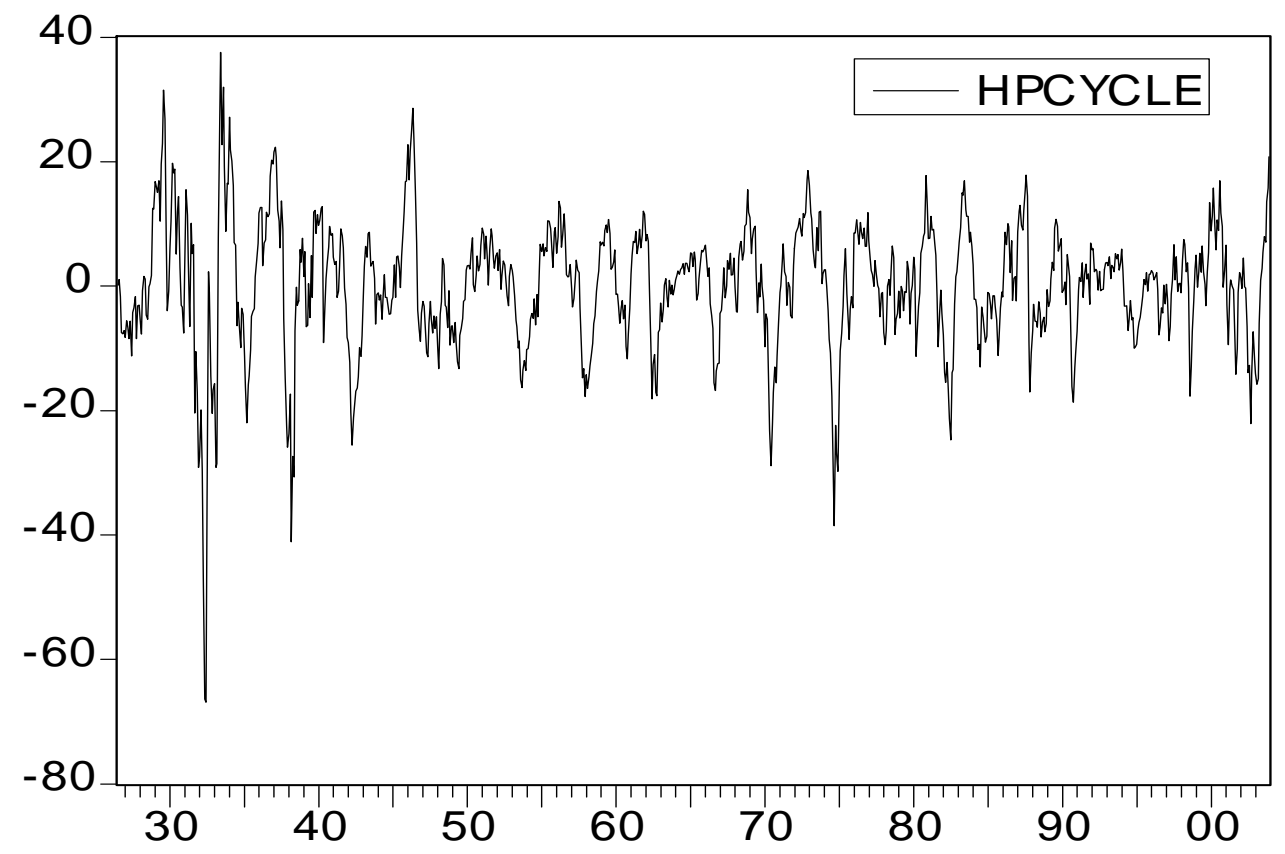


Figure 4.3: U.S. real stock market price and the Hodrick-Prescott trend Quarterly, 1926: III-2003: IV

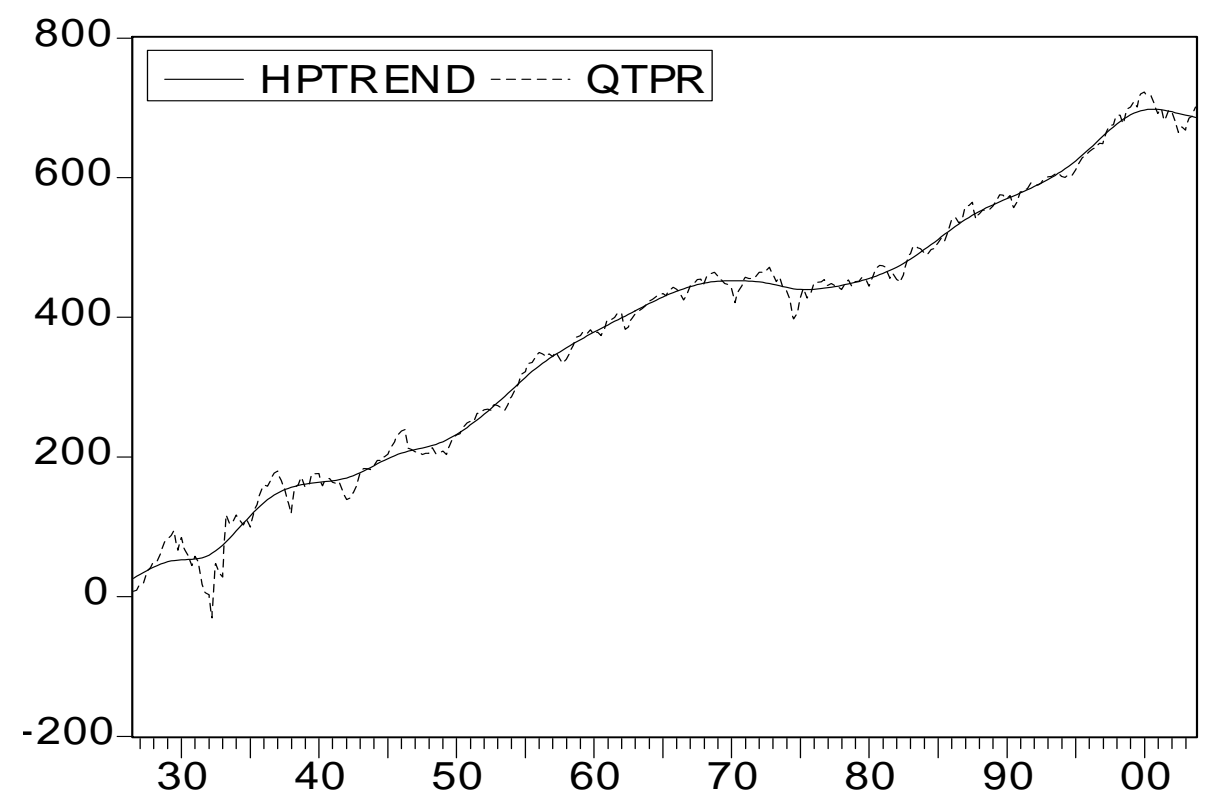

Figure 4.4: The Hodrick-Prescott cycle for the U.S. real stock market price Quarterly, 1926: III-2003: IV

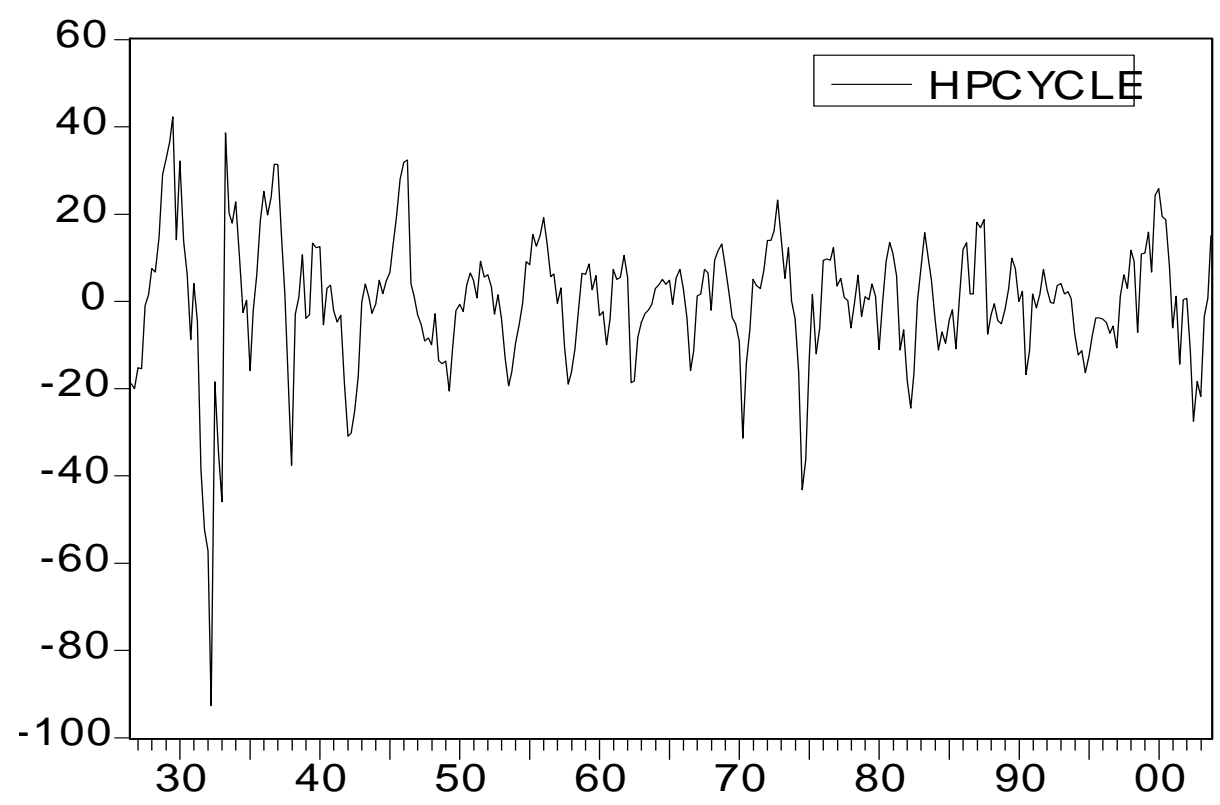


Figure 4.5: U.S. real stock market price and the Hodrick-Prescott trend Annually, 1926-2003

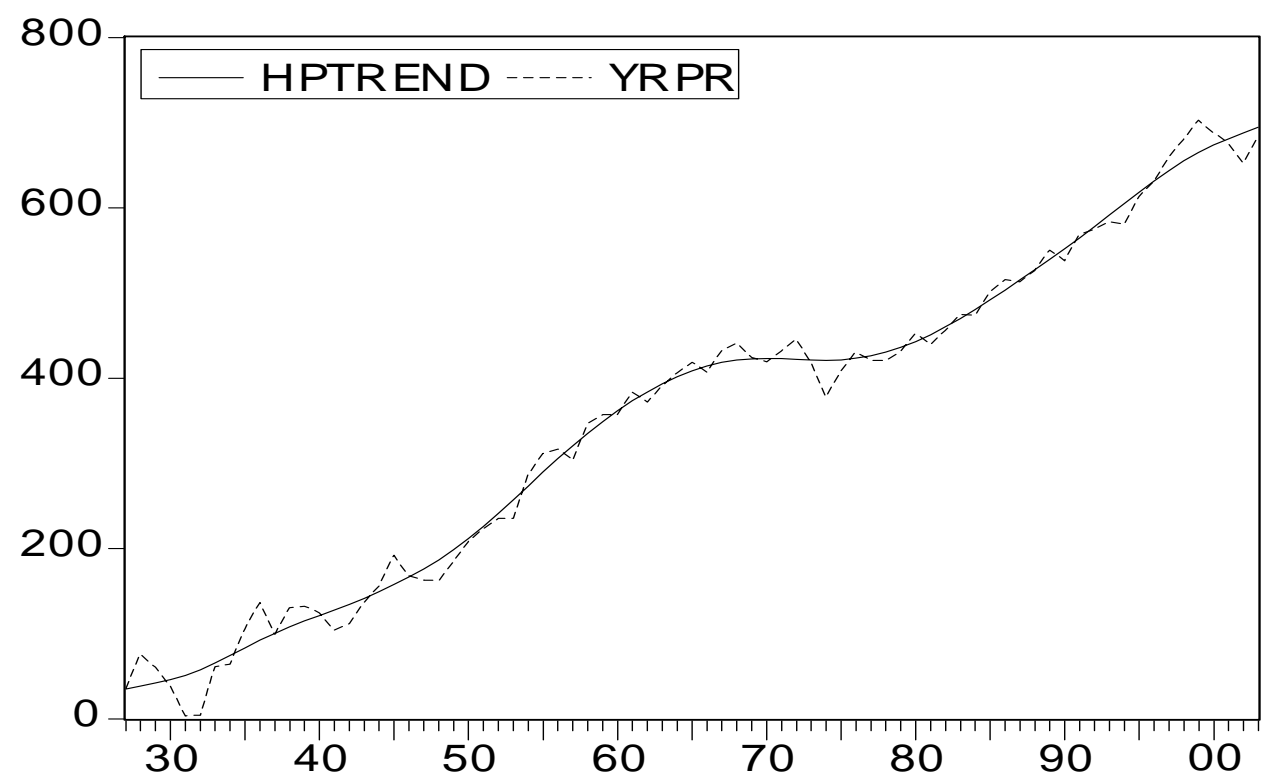

Figure 4.6: The Hodrick-Prescott cycle for the U.S. real stock market price Annually, 1926-2003

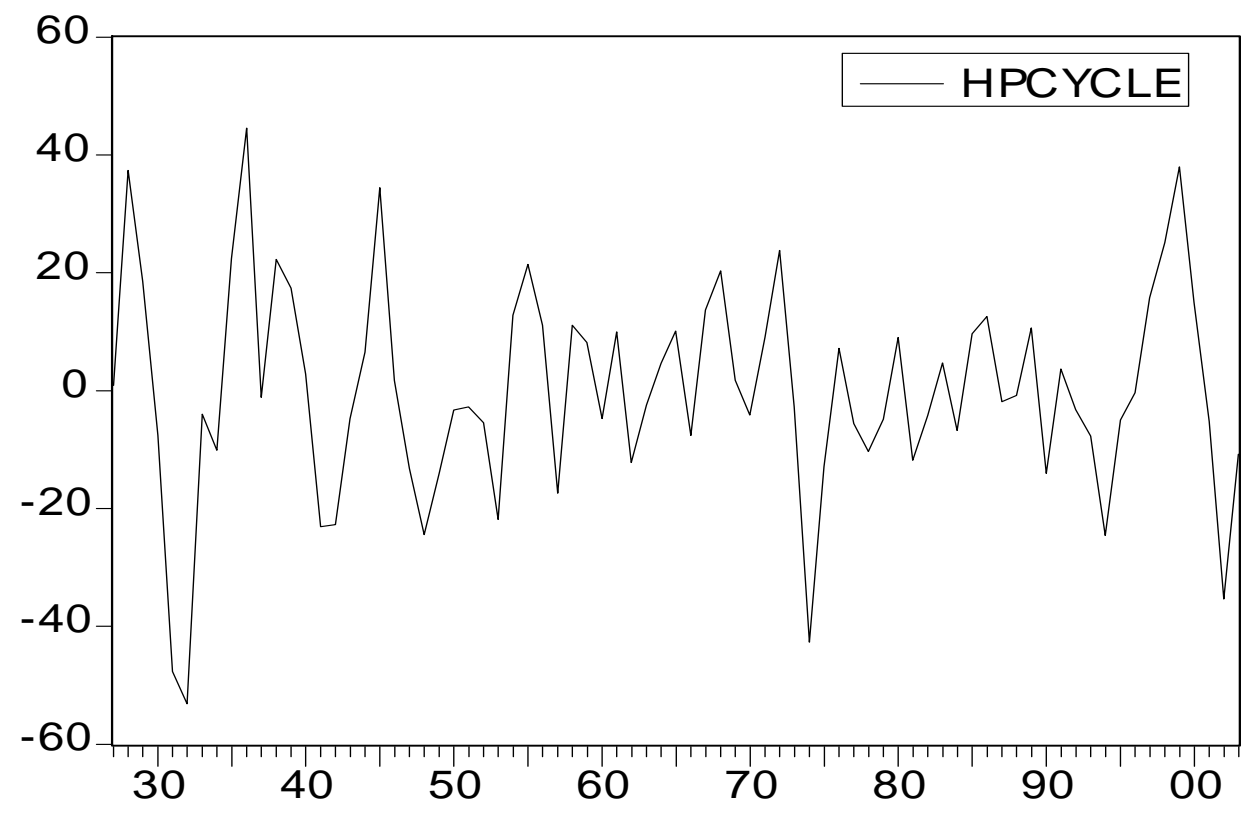


Table 4.1: Descriptive statistics for real stock market returns

This table shows the descriptive statistics for real stock market retrurns.The nominal market return over NYSE, AMEX, and NASDAQ stocks from July 1926 to December 2003 is obtained from the CRSP database, and the seasonally adjusted Consumer Price Index is obtained from the Bureau of Labor Statistics.

\begin{tabular}{|c|c|c|c|c|c|c|c|c|c|}
\hline & \multirow[b]{3}{*}{ mean } & \multirow[b]{3}{*}{ Std.Dev. } & \multirow[b]{3}{*}{ Min. } & \multirow[b]{3}{*}{ Max. } & \multirow{2}{*}{\multicolumn{5}{|c|}{ Autocorrelations }} \\
\hline & & & & & & & & & \\
\hline & & & & & $\rho_{1}$ & $\rho_{6}$ & $\rho_{12}$ & $\rho_{24}$ & $\rho_{36}$ \\
\hline \multirow[t]{4}{*}{ Monthly } & 0.70 & 5.53 & -28.32 & 38.27 & 0.110 & -0.020 & -0.003 & 0.030 & 0.020 \\
\hline & & & & & $(0.001)$ & $(0.000)$ & $(0.000)$ & $(0.000)$ & $(0.000)$ \\
\hline & & & & & \multicolumn{5}{|c|}{ Autocorrelations } \\
\hline & mean & Std.Dev. & Min. & Max. & $\rho_{1}$ & $\rho_{4}$ & $\rho_{8}$ & $\rho_{12}$ & $\rho_{16}$ \\
\hline \multirow[t]{4}{*}{ Quarterly } & 2.26 & 11.60 & -32.80 & 89.21 & -0.081 & -0.166 & -0.009 & -0.008 & -0.003 \\
\hline & & & & & $(0.151)$ & $(0.000)$ & $(0.000)$ & $(0.001)$ & $(0.004)$ \\
\hline & & & & & \multicolumn{5}{|c|}{ Autocorrelations } \\
\hline & mean & Std.Dev. & Min. & Max. & $\rho_{1}$ & $\rho_{2}$ & $\rho_{3}$ & $\rho_{4}$ & $\rho_{5}$ \\
\hline Annual & 8.87 & 21.08 & -40.28 & 56.96 & 0.000 & -0.180 & -0.092 & -0.064 & -0.012 \\
\hline & & & & & $(0.999)$ & $(0.270)$ & $(0.346)$ & $(0.454)$ & $(0.598)$ \\
\hline
\end{tabular}

Note: the P-values are in the parentheses.

Table 4.2: The correlation of permanent and transitory shocks for the market price from $\mathrm{H}-\mathrm{P}$ decomposition

The value-weighted real price index is backed out from the value-weighted real market return. The data is from July 1926 to December 2003.

\begin{tabular}{|c|c|c|c|c|c|c|}
\hline & Shock covariance & Trend & Cycle & Shock correlation & Trend & Cycle \\
\hline \multirow[t]{2}{*}{ Monthly } & Trend & 0.6838 & 0.2969 & Trend & 1.0000 & 0.0664 \\
\hline & Cycle & 0.2969 & 29.2593 & Cycle & 0.0664 & 1.0000 \\
\hline \multirow{4}{*}{ Quarterly } & Shock covariance & Trend & Cycle & Shock correlation & Trend & Cycle \\
\hline & Trend & 2.4986 & 1.4637 & Trend & 1.0000 & 0.0815 \\
\hline & Cycle & 1.4637 & 129.0479 & Cycle & 0.0815 & 1.0000 \\
\hline & Shock covariance & Trend & Cycle & Shock correlation & Trend & Cycle \\
\hline \multirow[t]{2}{*}{ Annually } & Trend & 19.9348 & 7.9889 & Trend & 1.0000 & 0.0896 \\
\hline & Cycle & 7.9889 & 398.7097 & Cycle & 0.0896 & 1.0000 \\
\hline
\end{tabular}


Table 4.3: Estimates of the state space model of real stock market returns

This table presents the estimation results for the following state space model with innovations following Gaussian processes. The data for real stock market returns is from July 1926 to December 2003 (standard errors are in parentheses).

$$
\begin{aligned}
& r_{t}=\alpha+\left[\begin{array}{ll}
1 & -1
\end{array}\right]\left[\begin{array}{c}
z_{t} \\
z_{t-1}
\end{array}\right]+\eta_{t}, \text { measurement equation } y_{t}=\mu+H \beta_{t}+e_{t} \\
& {\left[\begin{array}{c}
z_{t} \\
z_{t-1}
\end{array}\right]=\left[\begin{array}{cc}
\phi_{1} & \phi_{2} \\
1 & 0
\end{array}\right]\left[\begin{array}{c}
z_{t-1} \\
z_{t-2}
\end{array}\right]+\left[\begin{array}{c}
\varepsilon_{t} \\
0
\end{array}\right] \text {, transition equation } \beta_{t}=F \beta_{t-1}+v_{t}}
\end{aligned}
$$

\begin{tabular}{ccccccc}
\hline & $\sigma_{\eta}$ & $\sigma_{\varepsilon}$ & $\alpha(\%)$ & $\phi_{1}$ & $\phi_{2}$ & Log likelihood value \\
\hline \hline Monthly & 0.0165 & 5.4678 & 0.6784 & 1.101 & -0.1156 & 2900.6508 \\
& $(0.1302)$ & $(0.1268)$ & $(0.0381)$ & $(0.0326)$ & $(0.0326)$ & \\
Quarterly & 0.0234 & 11.4087 & 2.1643 & 0.8938 & 0.0575 & 1195.5878 \\
& $(0.339)$ & $(0.4583)$ & $(0.1237)$ & $(0.0568)$ & $(0.0569)$ & \\
\multirow{2}{*}{ Annual } & 0.0139 & 19.9162 & 8.7373 & 0.9064 & -0.0852 & 340.7188 \\
& $(0.6167)$ & $(1.6059)$ & $(0.483)$ & $(0.1148)$ & $(0.1147)$ & \\
\hline
\end{tabular}

Table 4.4: Estimates of the state space model of real stock market returns

This table presents the estimation results for a state space model with Markov-switching innovations. The

\begin{tabular}{|c|c|c|c|c|c|c|}
\hline \multirow{3}{*}{$\begin{array}{c}\text { Parameters } \\
\hat{p}_{\eta 1}\end{array}$} & \multicolumn{6}{|c|}{ Estimates } \\
\hline & \multicolumn{2}{|c|}{ Monthly } & \multicolumn{2}{|c|}{ Quarterly } & \multicolumn{2}{|c|}{ Annual } \\
\hline & 0.9602 & $(0.0225)$ & 0.9215 & $(0.0568)$ & 1.0000 & $(0.0002)$ \\
\hline$\hat{p}_{\eta 0}$ & 0.9883 & $(0.0091)$ & 0.9351 & $(0.0433)$ & 0.1743 & (2514) \\
\hline$\hat{p}_{\varepsilon 1}$ & 0.8779 & $(0.0746)$ & 0.9224 & $(0.0834)$ & 0.9568 & $(0.0682)$ \\
\hline$\hat{p}_{\varepsilon 0}$ & 0.9922 & $(0.0052)$ & 0.9937 & $(0.0062)$ & 0.9836 & $(0.0222)$ \\
\hline$\hat{\sigma}_{\eta 0}$ & 0.0364 & $(0.0025)$ & 0.0567 & $(0.0050)$ & 0.0480 & (497) \\
\hline$\hat{\sigma}_{\varepsilon 0}$ & 0.0000 & --- & 0.0000 & --- & 0.1010 & $(0.1149)$ \\
\hline$\hat{\sigma}_{\eta 1}$ & 0.0692 & $(0.0130)$ & 0.1168 & $(0.0106)$ & 0.1368 & $(0.0933)$ \\
\hline$\hat{\sigma}_{\varepsilon 1}$ & 0.1147 & $(0.0205)$ & 0.3259 & $(0.0774)$ & 0.2427 & $(0.0848)$ \\
\hline$\hat{\phi}_{1}$ & 1.0899 & $(0.1846)$ & 0.7585 & $(0.1276)$ & 0.7215 & $(0.2794)$ \\
\hline$\hat{\phi}_{2}$ & -0.2970 & (0.1006) & 0.1700 & $(0.0990)$ & -0.1302 & $(0.1008)$ \\
\hline$\hat{\alpha}$ & 0.0088 & $(0.0015)$ & 0.0285 & $(0.0045)$ & 0.0835 & $(0.0159)$ \\
\hline $\begin{array}{c}\text { Log } \\
\text { likelihood }\end{array}$ & \multicolumn{2}{|c|}{1529} & \multicolumn{2}{|c|}{302.15} & \multicolumn{2}{|c|}{14.31} \\
\hline
\end{tabular}
data for real stock market returns is from July 1926 to December 2003.

Note: standard errors are in the parentheses. 
Figure 4.7: U.S. real stock market price and the UC-MS ${ }^{44}$ trend Monthly, 1926:07-2003:12

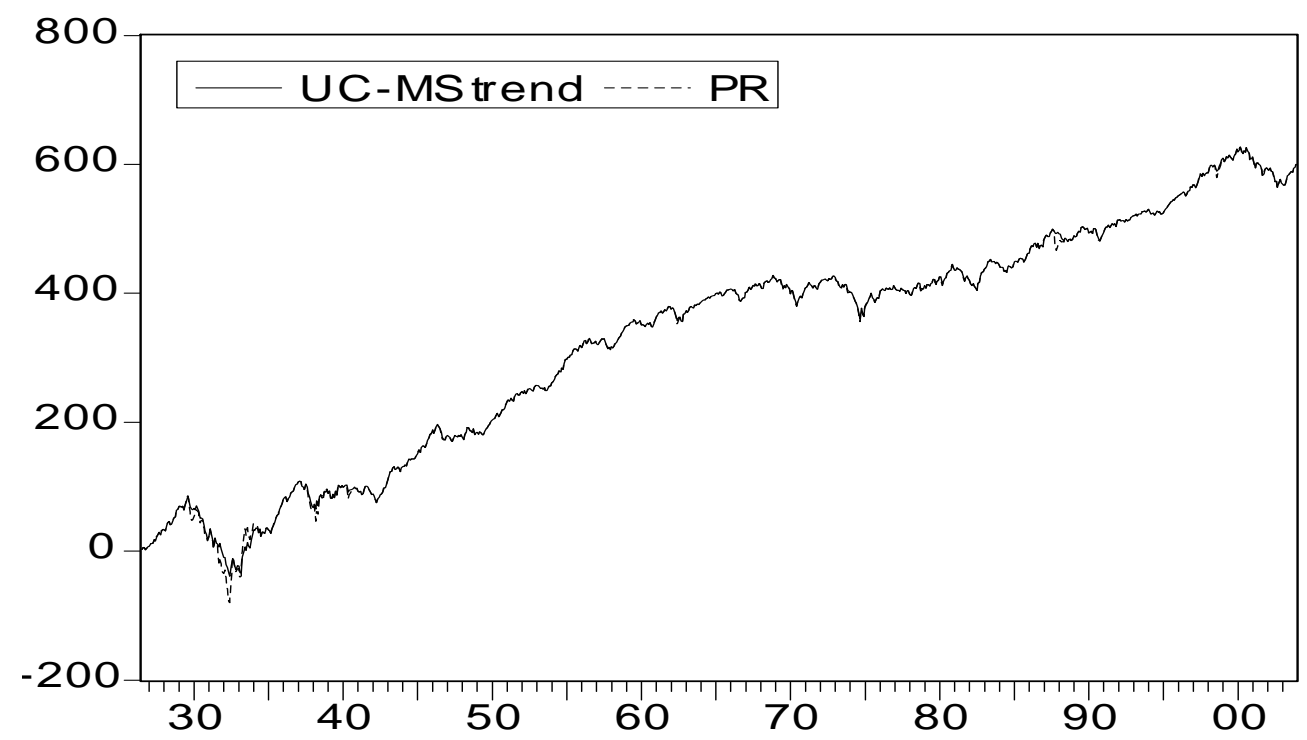

Figure 4.8: The UC-MS cycle for the U.S. real stock market price Monthly, 1926:07-2003:12

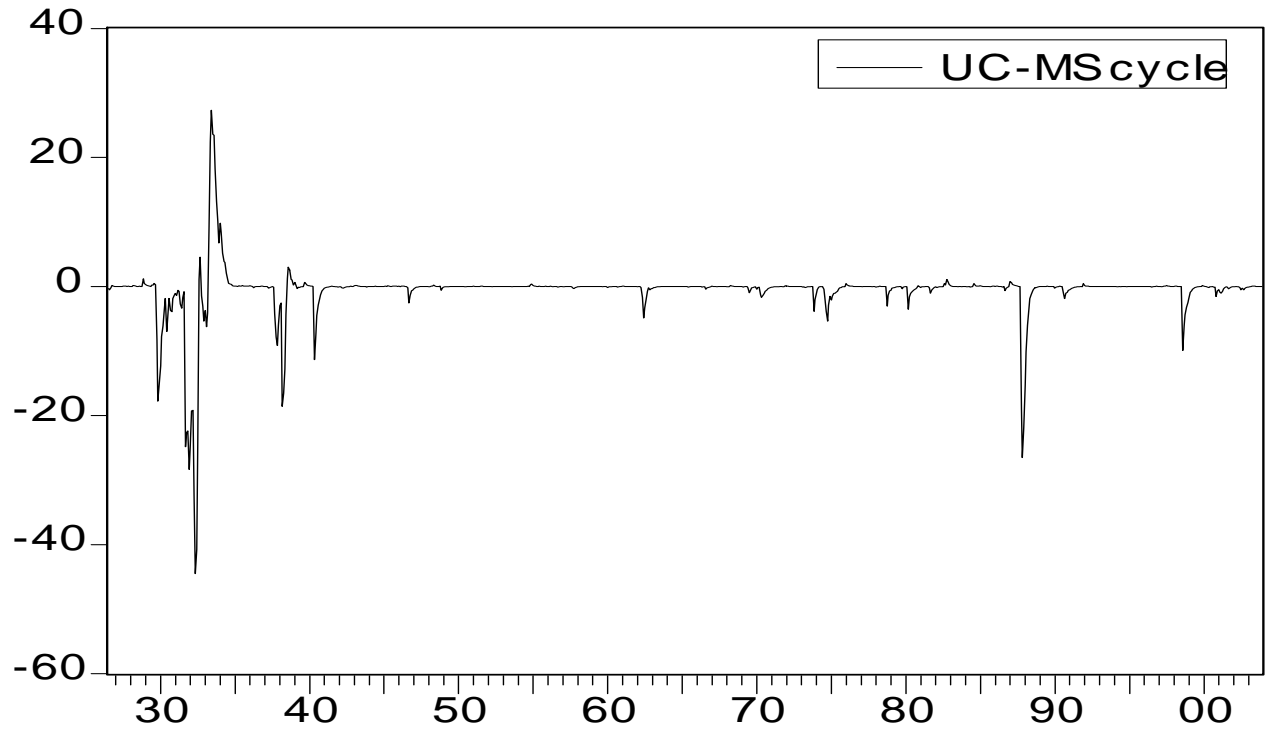

${ }^{44}$ US-MS means unobserved components model with Markov-switching variances. 
Figure 4.9: U.S. real stock market price and the UC-MS trend Quarterly, 1926: III-2003: IV

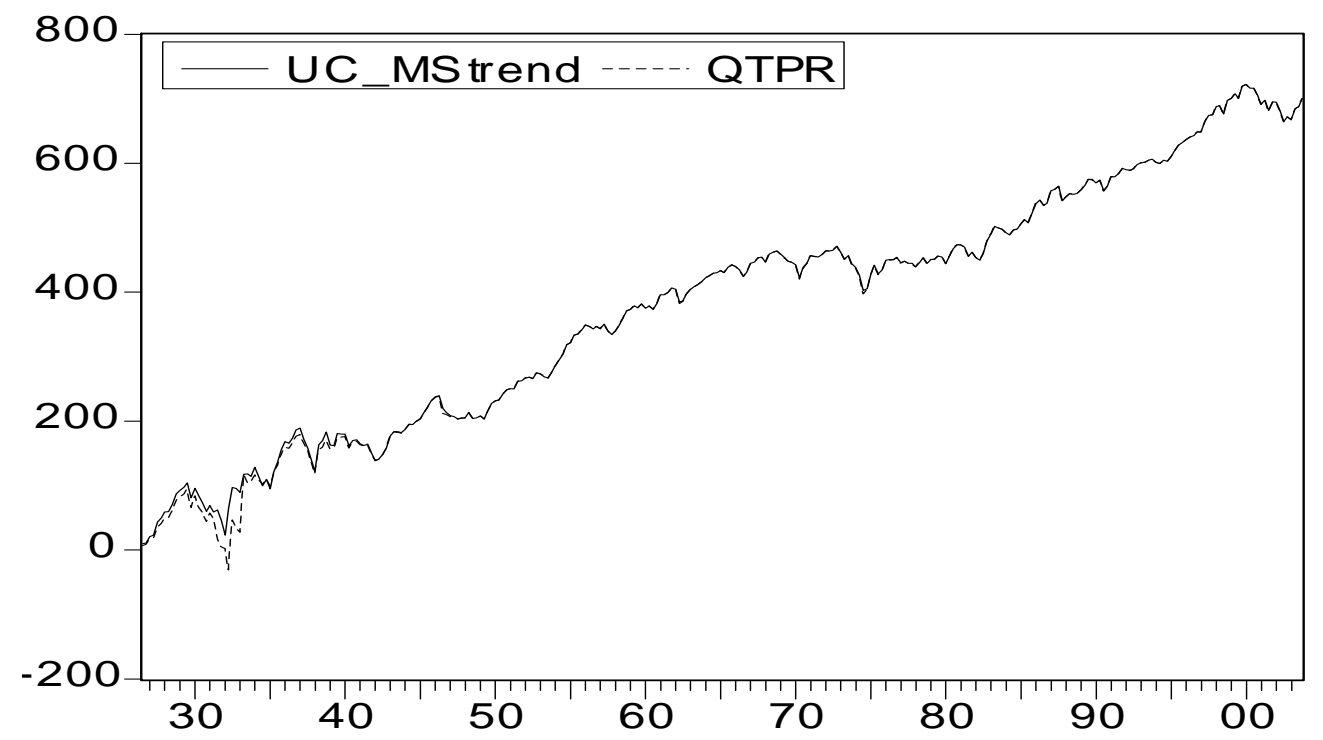

Figure 4.10: The UC-MS cycle for the U.S. real stock market price Quarterly, 1926: III-2003: IV

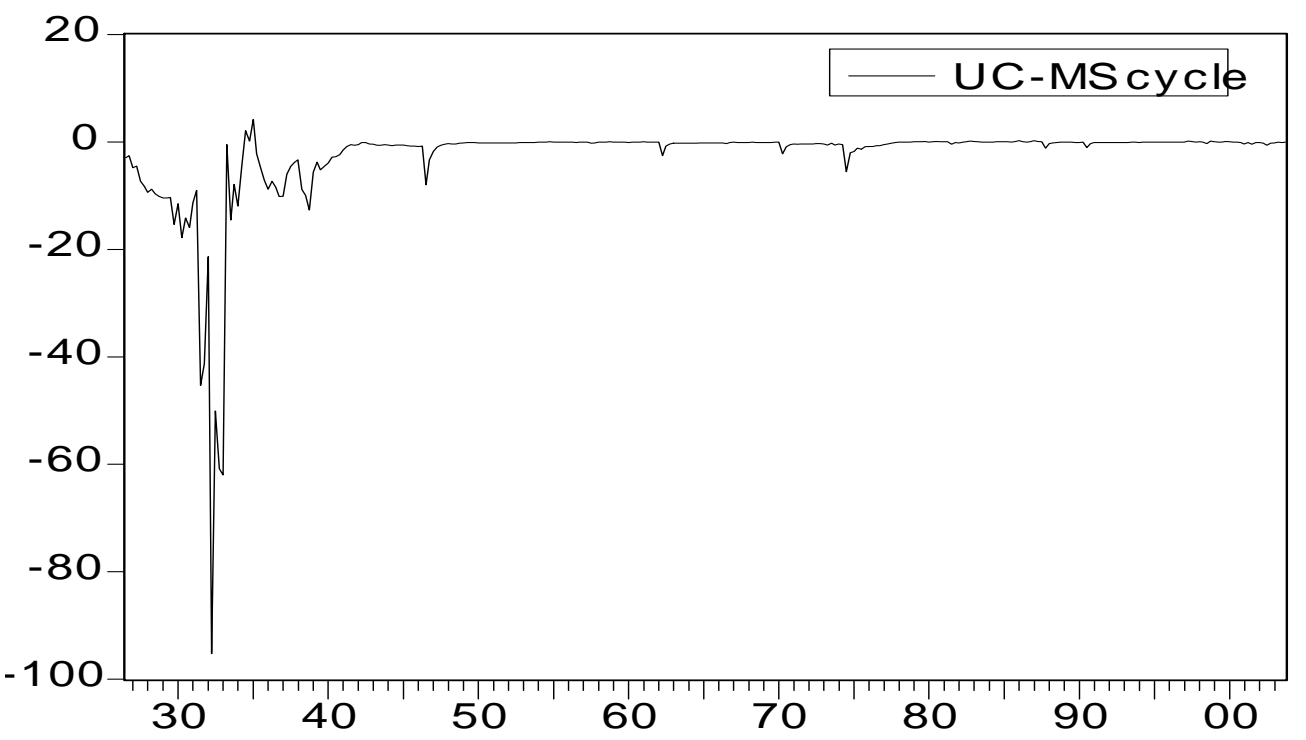


Figure 4.11: U.S. real stock market price and the UC-MS trend Annual, 1926-2003

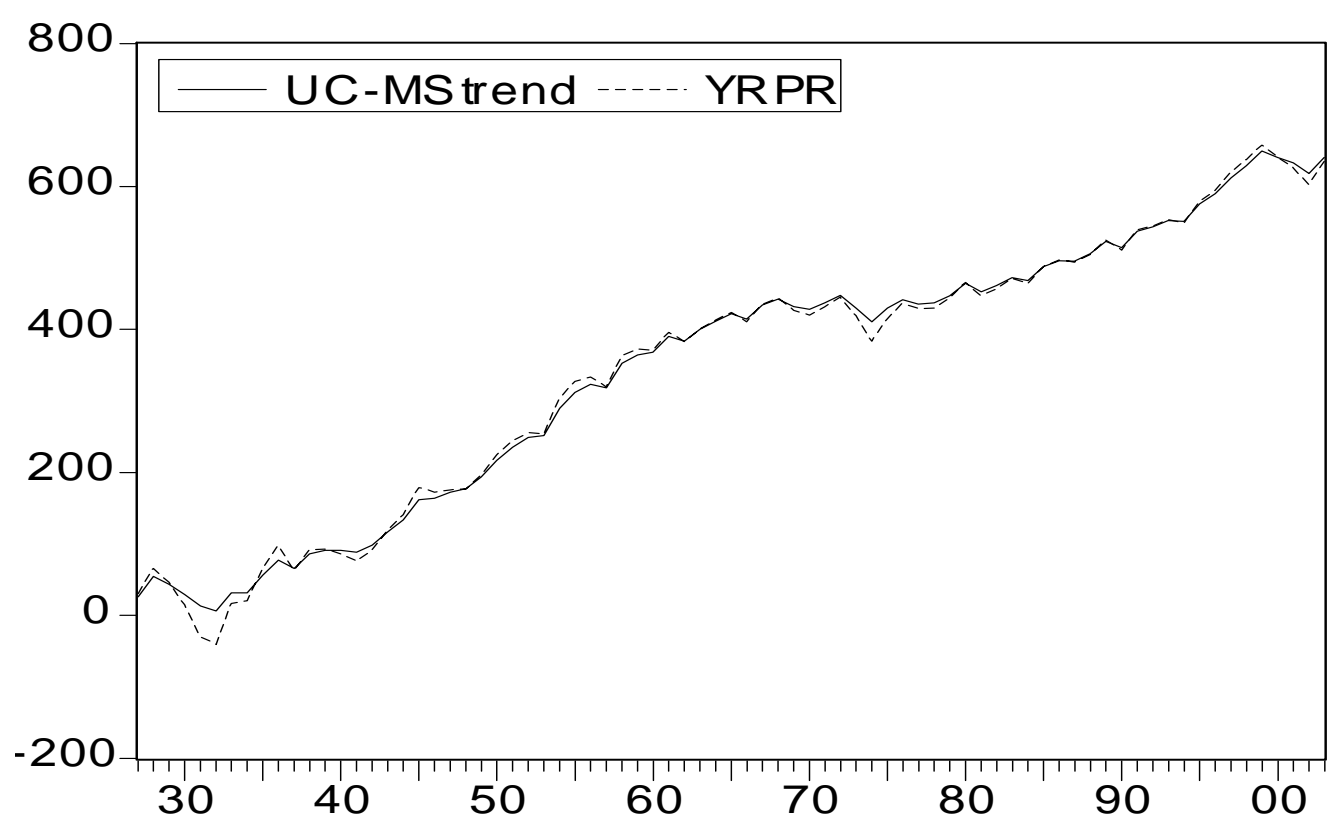

Figure 4.12: The UC-MS cycle for the U.S. real stock market price Annual, 1926-2003

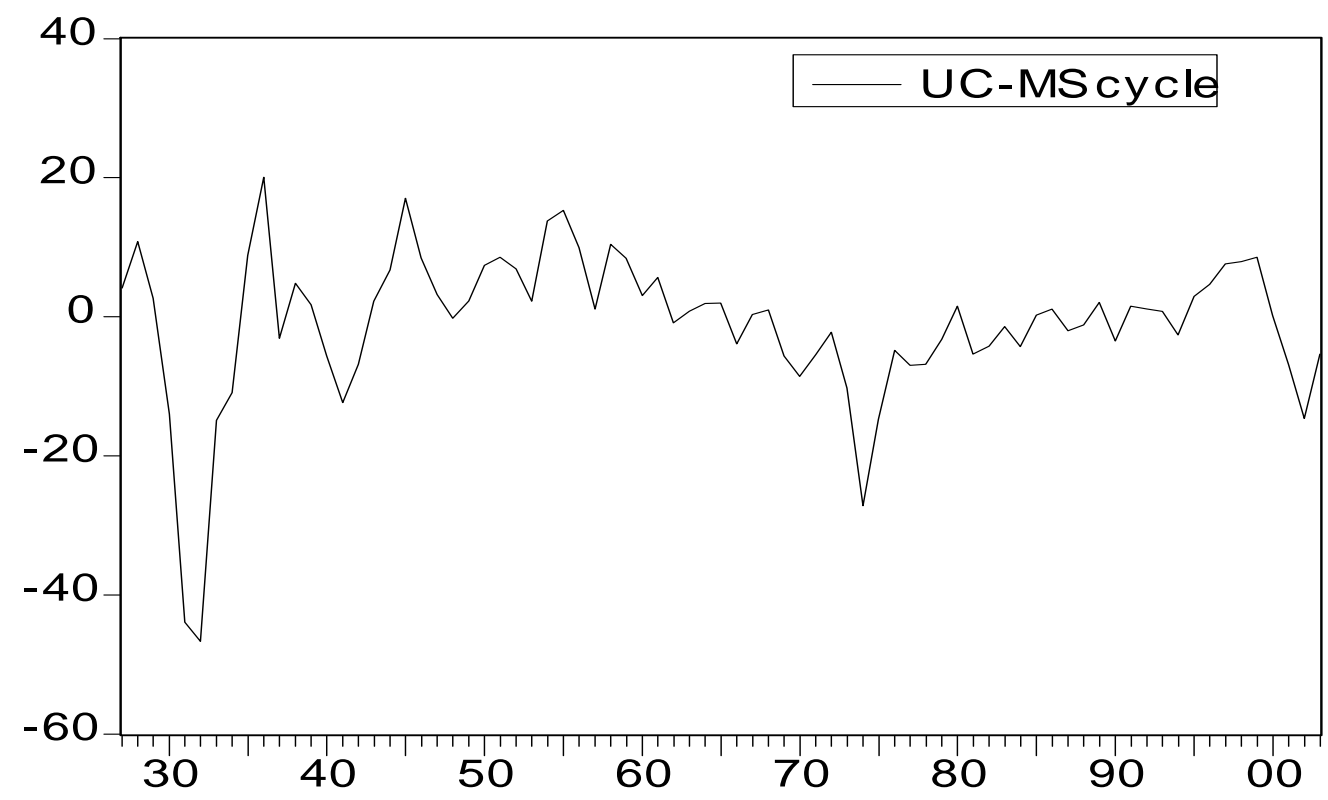


Table 4.5: The correlation of permanent and transitory shocks for the market price from the UC-MS decomposition

The value-weighted real price index is backed out from the value-weighted real market return. The data is from July 1926 to December 2003.

\begin{tabular}{cccc}
\cline { 1 - 1 } Monthly & Shock correlation & Trend & Cycle \\
\cline { 2 - 4 } & Trend & 1.0000 & 0.0513 \\
& Cycle & 0.0513 & 1.0000 \\
\cline { 2 - 4 } Quarterly & & & \\
\cline { 2 - 4 } & Shock correlation & Trend & Cycle \\
\cline { 2 - 4 } & Trend & 1.0000 & -0.0274 \\
& Cycle & -0.0274 & 1.0000 \\
\cline { 2 - 4 } Annually & & & \\
\cline { 2 - 4 } & Shock correlation & Trend & Cycle \\
\cline { 2 - 4 } & Trend & 1.0000 & -0.0655 \\
& Cycle & -0.0655 & 1.0000 \\
\cline { 2 - 4 } & & &
\end{tabular}

Table 4.6: Permanent and transitory $\beta$ s for the $25 \mathrm{ME}$ and BE/ME portfolios

The table shows the estimates of the permanent betas $\left(\hat{\beta}_{\eta}\right)$ and the transitory betas $\left(\hat{\beta}_{\varepsilon}\right)$ for the Fama and French 25 size and book-to-market portfolios. The betas are calculated using formulae (a) and (b) with shocks estimated from the H-P approach. 'Growth' denotes the lowest BE/ME ratio, 'Value' the highest BE/ME ratio, 'Small' the lowest ME, and 'Big' the highest ME. The standard errors are in the parentheses.

Panel A: 1926:07 - 2003:12

\begin{tabular}{|c|c|c|c|c|c|c|c|c|c|c|}
\hline$\hat{\beta}_{\eta}$ & \multicolumn{2}{|c|}{ Growth } & \multicolumn{2}{|c|}{2} & \multicolumn{2}{|c|}{3} & \multicolumn{2}{|c|}{4} & \multicolumn{2}{|c|}{ Value } \\
\hline Small & 2.00 & $(0.50)$ & 1.83 & $(0.42)$ & 1.73 & $(0.37)$ & 1.76 & $(0.35)$ & 1.70 & $(0.38)$ \\
\hline 2 & 1.63 & $(0.32)$ & 1.57 & $(0.31)$ & 1.47 & $(0.29)$ & 1.52 & $(0.30)$ & 1.53 & $(0.34)$ \\
\hline 3 & 1.69 & $(0.30)$ & 1.48 & $(0.26)$ & 1.41 & $(0.27)$ & 1.35 & $(0.27)$ & 1.47 & $(0.34)$ \\
\hline 4 & 1.41 & $(0.25)$ & 1.42 & $(0.25)$ & 1.41 & $(0.25)$ & 1.31 & $(0.28)$ & 1.45 & (0.36) \\
\hline Big & 1.49 & $(0.22)$ & 1.30 & $(0.21)$ & 1.40 & $(0.23)$ & 1.42 & $(0.27)$ & 5.69 & $(0.53)$ \\
\hline$\hat{\beta}_{\varepsilon}$ & \multicolumn{2}{|c|}{ Growth } & \multicolumn{2}{|c|}{2} & \multicolumn{2}{|c|}{3} & \multicolumn{2}{|c|}{4} & \multicolumn{2}{|c|}{ Value } \\
\hline Small & 1.66 & $(0.05)$ & 1.53 & $(0.04)$ & 1.39 & $(0.03)$ & 1.30 & $(0.03)$ & 1.39 & $(0.04)$ \\
\hline 2 & 1.24 & $(0.03)$ & 1.25 & $(0.02)$ & 1.19 & $(0.02)$ & 1.22 & $(0.02)$ & 1.35 & (0.03) \\
\hline 3 & 1.28 & $(0.02)$ & 1.14 & $(0.02)$ & 1.15 & $(0.02)$ & 1.13 & $(0.02)$ & 1.39 & (0.03) \\
\hline 4 & 1.08 & $(0.01)$ & 1.10 & $(0.01)$ & 1.09 & $(0.02)$ & 1.18 & $(0.02)$ & 1.46 & (0.03) \\
\hline Big & 0.98 & $(0.01)$ & 0.93 & $(0.01)$ & 0.98 & $(0.02)$ & 1.12 & $(0.02)$ & 1.22 & $(0.08)$ \\
\hline
\end{tabular}


Panel B: 1926: III - 2003: IV

\begin{tabular}{|c|c|c|c|c|c|c|c|c|c|c|}
\hline b1 & \multicolumn{2}{|c|}{ Growth } & \multicolumn{2}{|c|}{2} & \multicolumn{2}{|c|}{3} & \multicolumn{2}{|c|}{4} & \multicolumn{2}{|c|}{$\begin{array}{l}\text { Value } \\
\end{array}$} \\
\hline Small & 1.82 & $(0.89)$ & 2.15 & $(1.00)$ & 2.08 & $(0.86)$ & 2.21 & $(0.87)$ & 1.82 & $(0.86)$ \\
\hline 2 & 1.47 & $(0.62)$ & 1.76 & $(0.64)$ & 1.78 & $(0.69)$ & 1.78 & $(0.70)$ & 1.60 & $(0.72)$ \\
\hline 3 & 1.94 & $(0.66)$ & 1.45 & $(0.51)$ & 1.61 & $(0.57)$ & 1.40 & (0.57) & 1.61 & $(0.78)$ \\
\hline 4 & 1.35 & $(0.46)$ & 1.56 & $(0.50)$ & 1.51 & $(0.50)$ & 1.36 & $(0.60)$ & 1.60 & $(0.80)$ \\
\hline Big & 1.63 & $(0.40)$ & 1.32 & $(0.37)$ & 1.49 & $(0.44)$ & 1.62 & $(0.57)$ & 2.65 & $(0.86)$ \\
\hline b2 & \multicolumn{2}{|c|}{ Growth } & \multicolumn{2}{|c|}{2} & \multicolumn{2}{|c|}{3} & \multicolumn{2}{|c|}{4} & \multicolumn{2}{|c|}{ Value } \\
\hline Small & 1.87 & $(0.07)$ & 2.06 & $(0.08)$ & 1.82 & $(0.06)$ & 1.80 & $(0.07)$ & 1.77 & $(0.06)$ \\
\hline 2 & 1.34 & $(0.04)$ & 1.44 & $(0.04)$ & 1.51 & $(0.04)$ & 1.50 & $(0.05)$ & 1.55 & $(0.05)$ \\
\hline 3 & 1.49 & $(0.04)$ & 1.18 & $(0.03)$ & 1.30 & $(0.03)$ & 1.27 & $(0.03)$ & 1.68 & $(0.05)$ \\
\hline 4 & 1.06 & $(0.02)$ & 1.16 & $(0.02)$ & 1.16 & $(0.02)$ & 1.33 & $(0.04)$ & 1.72 & $(0.05)$ \\
\hline Big & 0.96 & $(0.02)$ & 0.87 & $(0.02)$ & 0.99 & $(0.02)$ & 1.26 & $(0.04)$ & 1.49 & $(0.09)$ \\
\hline
\end{tabular}

Panel C: 1927 - 2003

\begin{tabular}{|c|c|c|c|c|c|c|c|c|c|c|}
\hline b1 & \multicolumn{2}{|c|}{ Growth } & \multicolumn{2}{|c|}{2} & \multicolumn{2}{|c|}{3} & \multicolumn{2}{|c|}{4} & \multicolumn{2}{|c|}{$\begin{array}{l}\text { Value } \\
\end{array}$} \\
\hline Small & 0.58 & $(0.99)$ & 0.95 & $(0.98)$ & 0.86 & $(0.92)$ & 0.77 & $(1.13)$ & 0.60 & $(0.99)$ \\
\hline 2 & 0.87 & $(0.84)$ & 0.95 & $(0.79)$ & 0.96 & $(0.79)$ & 0.79 & $(0.85)$ & 1.03 & (0.85) \\
\hline 3 & 1.23 & $(0.79)$ & 0.88 & $(0.72)$ & 1.00 & $(0.69)$ & 0.99 & $(0.71)$ & 1.14 & $(0.84)$ \\
\hline 4 & 1.23 & $(0.60)$ & 1.29 & $(0.64)$ & 1.25 & $(0.66)$ & 0.71 & $(0.70)$ & 1.11 & (0.88) \\
\hline Big & 1.54 & (0.52) & 1.27 & $(0.48)$ & 1.48 & $(0.54)$ & 1.32 & $(0.64)$ & 1.42 & $(0.86)$ \\
\hline b2 & \multicolumn{2}{|c|}{ Growth } & \multicolumn{2}{|c|}{2} & \multicolumn{2}{|c|}{3} & \multicolumn{2}{|c|}{4} & \multicolumn{2}{|c|}{ Value } \\
\hline Small & 1.46 & $(0.14)$ & 1.58 & $(0.12)$ & 1.50 & $(0.11)$ & 1.66 & $(0.17)$ & 1.57 & $(0.13)$ \\
\hline 2 & 1.36 & $(0.10)$ & 1.33 & $(0.09)$ & 1.32 & $(0.09)$ & 1.41 & $(0.10)$ & 1.36 & (0.11) \\
\hline 3 & 1.35 & (0.09) & 1.25 & $(0.07)$ & 1.19 & $(0.07)$ & 1.19 & (0.08) & 1.29 & (0.12) \\
\hline 4 & 1.07 & $(0.06)$ & 1.10 & $(0.08)$ & 1.14 & $(0.07)$ & 1.19 & (0.08) & 1.38 & $(0.12)$ \\
\hline Big & 0.96 & $(0.05)$ & 0.89 & $(0.05)$ & 0.93 & $(0.07)$ & 1.05 & (0.08) & 1.21 & $(0.13)$ \\
\hline
\end{tabular}


Table 4.7: Permanent and transitory $\beta$ s for the $25 \mathrm{ME}$ and $\mathrm{BE} / \mathrm{ME}$ portfolios

The table shows the estimates of the permanent betas $\left(\hat{\beta}_{\eta}\right)$ and the transitory betas $\left(\hat{\beta}_{\varepsilon}\right)$ for the Fama and French 25 size and book-to-market portfolios. The betas are calculated using formulae (a) and (b) with shocks estimated from the UC-MS model. 'Growth' denotes the lowest BE/ME ratio, 'Value' the highest $\mathrm{BE} / \mathrm{ME}$ ratio, 'Small' the lowest ME, and 'Big' the highest ME. The standard errors are in the parentheses.

Panel A: 1926:07 - 2003:12

\begin{tabular}{lcccccccccc}
\hline \multicolumn{1}{c}{$\hat{\beta}_{\eta}$} & \multicolumn{2}{c}{ Growth } & \multicolumn{2}{c}{2} & \multicolumn{2}{c}{3} & \multicolumn{2}{c}{4} & \multicolumn{2}{c}{ Value } \\
\hline \hline Small & 1.81 & $(0.07)$ & 1.63 & $(0.06)$ & 1.52 & $(0.05)$ & 1.39 & $(0.04)$ & 1.49 & $(0.05)$ \\
2 & 1.43 & $(0.03)$ & 1.37 & $(0.03)$ & 1.29 & $(0.03)$ & 1.32 & $(0.03)$ & 1.46 & $(0.04)$ \\
3 & 1.42 & $(0.03)$ & 1.28 & $(0.02)$ & 1.25 & $(0.03)$ & 1.22 & $(0.03)$ & 1.49 & $(0.04)$ \\
4 & 1.25 & $(0.02)$ & 1.21 & $(0.02)$ & 1.2 & $(0.02)$ & 1.28 & $(0.03)$ & 1.55 & $(0.04)$ \\
Big & 1.11 & $(0.02)$ & 1.05 & $(0.02)$ & 1.06 & $(0.02)$ & 1.21 & $(0.03)$ & 1.49 & $(0.09)$ \\
\hline
\end{tabular}

\begin{tabular}{llllllllllll}
\hline \multicolumn{1}{c}{$\hat{\beta}_{\varepsilon}$} & \multicolumn{2}{c}{ Growth } & \multicolumn{2}{c}{2} & \multicolumn{2}{c}{3} & \multicolumn{2}{c}{4} & \multicolumn{2}{c}{ Value } \\
\hline \hline Small & -0.44 & $(0.10)$ & -0.31 & $(0.08)$ & -0.29 & $(0.07)$ & -0.24 & $(0.07)$ & -0.36 & $(0.07)$ \\
2 & -0.12 & $(0.06)$ & -0.24 & $(0.06)$ & -0.25 & $(0.06)$ & -0.27 & $(0.06)$ & -0.3 & $(0.07)$ \\
3 & -0.21 & $(0.06)$ & -0.15 & $(0.05)$ & -0.21 & $(0.05)$ & -0.26 & $(0.05)$ & -0.37 & $(0.07)$ \\
4 & -0.13 & $(0.05)$ & -0.19 & $(0.05)$ & -0.18 & $(0.05)$ & -0.34 & $(0.05)$ & -0.37 & $(0.07)$ \\
Big & -0.12 & $(0.04)$ & -0.09 & $(0.04)$ & -0.14 & $(0.05)$ & -0.23 & $(0.05)$ & -0.38 & $(0.11)$ \\
\hline
\end{tabular}

Panel B: 1926: III - 2003: IV

\begin{tabular}{|c|c|c|c|c|c|c|c|c|c|c|}
\hline b1 & \multicolumn{2}{|c|}{ Growth } & \multicolumn{2}{|c|}{2} & \multicolumn{2}{|c|}{3} & \multicolumn{2}{|c|}{4} & \multicolumn{2}{|c|}{ Value } \\
\hline Small & 1.74 & $(0.11)$ & 1.66 & $(0.13)$ & 1.57 & $(0.11)$ & 1.48 & $(0.11)$ & 1.53 & (0.11) \\
\hline 2 & 1.35 & $(0.06)$ & 1.3 & $(0.07)$ & 1.29 & $(0.08)$ & 1.27 & $(0.09)$ & 1.39 & (0.09) \\
\hline 3 & 1.33 & $(0.08)$ & 1.14 & $(0.05)$ & 1.13 & $(0.07)$ & 1.11 & $(0.07)$ & 1.39 & $(0.10)$ \\
\hline 4 & 1.07 & $(0.04)$ & 1.06 & $(0.05)$ & 1.04 & $(0.06)$ & 1.18 & $(0.07)$ & 1.4 & $(0.10)$ \\
\hline Big & 0.92 & $(0.04)$ & 0.84 & $(0.04)$ & 0.85 & $(0.50)$ & 1.03 & $(0.07)$ & 1.38 & $(0.12)$ \\
\hline b2 & \multicolumn{2}{|c|}{ Growth } & \multicolumn{2}{|c|}{2} & \multicolumn{2}{|c|}{3} & \multicolumn{2}{|c|}{4} & \multicolumn{2}{|c|}{ Value } \\
\hline Small & $\begin{array}{c}-0.23 \\
\end{array}$ & $\begin{array}{l}(0.16) \\
\end{array}$ & $\begin{array}{l}-0.45 \\
\end{array}$ & $(0.18)$ & $\begin{array}{c}-0.34 \\
\end{array}$ & $\begin{array}{l}(0.15) \\
\end{array}$ & -0.43 & $\begin{array}{l}(0.15) \\
\end{array}$ & $\begin{array}{l}-0.35 \\
\end{array}$ & $\begin{array}{c}(0.15) \\
\end{array}$ \\
\hline 2 & -0.07 & $(0.11)$ & -0.07 & $(0.11)$ & -0.29 & $(0.12)$ & -0.29 & $(0.12)$ & -0.17 & (0.13) \\
\hline 3 & -0.26 & $(0.12)$ & -0.10 & $(0.09)$ & -0.15 & $(0.10)$ & -0.12 & $(0.10)$ & -0.20 & $(0.14)$ \\
\hline 4 & -0.07 & $(0.08)$ & -0.13 & $(0.09)$ & -0.07 & $(0.09)$ & -0.14 & (0.11) & -0.26 & (0.14) \\
\hline Big & 0.00 & $(0.07)$ & 0.00 & $(0.07)$ & -0.02 & $(0.08)$ & -0.11 & (0.10) & 0.04 & $(0.15)$ \\
\hline
\end{tabular}


Panel C: 1927 - 2003

\begin{tabular}{|c|c|c|c|c|c|c|c|c|c|c|}
\hline $\mathrm{b} 1$ & \multicolumn{2}{|c|}{ Growth } & \multicolumn{2}{|c|}{2} & \multicolumn{2}{|c|}{3} & \multicolumn{2}{|c|}{4} & \multicolumn{2}{|c|}{ Value } \\
\hline Small & 2.17 & $(0.22)$ & 2.26 & $(0.20)$ & 2.08 & $(0.20)$ & 2.15 & $(0.29)$ & 2.16 & $(0.22)$ \\
\hline 2 & 2.01 & $(0.16)$ & 1.88 & $(0.15)$ & 1.82 & $(0.16)$ & 1.90 & $(0.18)$ & 1.94 & $(0.18)$ \\
\hline 3 & 1.94 & $(0.15)$ & 1.75 & (0.13) & 1.69 & $(0.13)$ & 1.69 & $(0.14)$ & 1.83 & (0.19) \\
\hline 4 & 1.60 & $(0.09)$ & 1.57 & $(0.13)$ & 1.63 & $(0.13)$ & 1.63 & $(0.14)$ & 1.94 & $(0.20)$ \\
\hline Big & 1.49 & $(0.07)$ & 1.34 & $(0.07)$ & 1.42 & $(0.10)$ & 1.55 & $(0.13)$ & 1.70 & $(0.22)$ \\
\hline b2 & \multicolumn{2}{|c|}{ Growth } & \multicolumn{2}{|c|}{2} & \multicolumn{2}{|c|}{3} & \multicolumn{2}{|c|}{4} & \multicolumn{2}{|c|}{ Value } \\
\hline Small & -0.69 & $(0.41)$ & -1.18 & (0.39) & -1.22 & $(0.36)$ & -2.13 & $(0.41)$ & -1.56 & (0.37) \\
\hline 2 & -1.04 & $(0.34)$ & -1.16 & (0.31) & -1.11 & $(0.31)$ & -1.28 & $(0.32)$ & -1.13 & (0.34) \\
\hline 3 & -1.17 & $(0.31)$ & -0.96 & $(0.28)$ & -0.88 & $(0.27)$ & -0.93 & $(0.29)$ & -0.96 & $(0.34)$ \\
\hline 4 & -0.54 & $(0.25)$ & -0.90 & $(0.26)$ & -0.85 & $(0.27)$ & -0.85 & $(0.28)$ & -0.94 & $(0.36)$ \\
\hline Big & -0.31 & $(0.23)$ & -0.41 & $(0.21)$ & -0.51 & $(0.23)$ & -0.62 & $(0.27)$ & -0.76 & $(0.35)$ \\
\hline
\end{tabular}


Table 4.8: Asset pricing tests with a cross-sectional regression on mean return This table shows the estimated risk premiums for four different asset pricing models: CAPM, Fama and French's three-factor model, two-beta intertemporal model based on Hodrick-Prescott decomposition and two-beta intertemporal model based on unobserved components approach with Markov-switching variances. The following cross-sectional regression is applied:

$$
{\overline{R_{i}}}^{e}=\gamma_{0}+\sum_{j=1}^{n} \gamma_{j} \hat{\beta}_{i, j}+e_{i}
$$

where $\bar{R}_{i}^{e}=\bar{R}_{i}-\bar{R}_{r f}$, the average excess returns of the 25 size and book-to-market portfolios. $\hat{\beta}_{i, j}$ is the estimated coefficient from the time-series regression of each of the 25 portfolios on the risk factors which vary with different asset pricing models. The t-statistics, corrected for heteroskedasticity and serial correclation, is based on Newey-West (1987) efficient estimator of standard errors.

\begin{tabular}{|c|c|c|c|c|c|}
\hline \multicolumn{6}{|c|}{ Monthly: 1926:07 - 2003:12 } \\
\hline $\begin{array}{l}\text { Risk Premium } \\
\text { t-value }\end{array}$ & $\begin{array}{c}\text { Constant } \\
0.5955 \\
1.2626 \\
\end{array}$ & $\begin{array}{l}\text { Exmkt } \\
0.2096 \\
0.5064 \\
\end{array}$ & & & $\begin{array}{c}R_{a d j}^{2} \\
-0.0303\end{array}$ \\
\hline $\begin{array}{l}\text { Risk Premium } \\
\text { t-value }\end{array}$ & $\begin{array}{c}\text { Constant } \\
2.6860 \\
3.7670 \\
\end{array}$ & $\begin{array}{c}\text { Exmkt } \\
-1.9971 \\
-2.7475 \\
\end{array}$ & $\begin{array}{c}\mathrm{HML} \\
0.2871 \\
1.8945 \\
\end{array}$ & $\begin{array}{c}\mathrm{SMB} \\
0.3149 \\
2.5002 \\
\end{array}$ & $\begin{array}{c}R_{a d j}^{2} \\
0.4967\end{array}$ \\
\hline $\begin{array}{l}\text { Risk Premium } \\
\text { t-value }\end{array}$ & $\begin{array}{c}\text { Constant } \\
0.5862 \\
1.1475 \\
\end{array}$ & $\begin{array}{l}\text { HP-trend } \\
-0.2765 \\
-20.3970 \\
\end{array}$ & $\begin{array}{c}\text { HP-cycle } \\
0.4844 \\
1.1161 \\
\end{array}$ & & $\begin{array}{c}R_{a d j}^{2} \\
0.5277\end{array}$ \\
\hline $\begin{array}{l}\text { Risk Premium } \\
\text { t-value }\end{array}$ & $\begin{array}{c}\text { Constant } \\
1.0499 \\
2.3065 \\
\end{array}$ & $\begin{array}{c}\text { UC-MS-trend } \\
-0.3726 \\
-0.7400\end{array}$ & $\begin{array}{c}\text { UC-MS-cycle } \\
-0.9697 \\
-0.7258\end{array}$ & & $\begin{array}{c}R_{a d j}^{2} \\
-0.0567\end{array}$ \\
\hline
\end{tabular}




\begin{tabular}{|c|c|c|c|c|c|}
\hline \multicolumn{6}{|c|}{ Quarterly: 1926:III - 2003:IV } \\
\hline \multirow{3}{*}{$\begin{array}{l}\text { Risk Premium } \\
\text { t-value }\end{array}$} & Constant & Exmkt & & & $R_{a d j}^{2}$ \\
\hline & 0.7742 & 1.6251 & & & \multirow[t]{2}{*}{0.2941} \\
\hline & 0.8679 & 2.2908 & & & \\
\hline \multirow{3}{*}{$\begin{array}{l}\text { Risk Premium } \\
\text { t-value }\end{array}$} & Constant & Exmkt & HML & SMB & $R_{a d j}^{2}$ \\
\hline & 5.4066 & -3.2257 & 1.6470 & 0.8450 & \multirow[t]{2}{*}{0.7643} \\
\hline & 5.1128 & -2.9644 & 5.3735 & 5.4994 & \\
\hline \multirow{3}{*}{$\begin{array}{l}\text { Risk Premium } \\
\text { t-value }\end{array}$} & Constant & HP-trend & HP-cycle & & $R_{a d j}^{2}$ \\
\hline & 1.3396 & -0.6914 & 1.6555 & & \multirow[t]{2}{*}{0.3100} \\
\hline & 1.4898 & -1.5343 & 2.2393 & & \\
\hline \multirow{3}{*}{$\begin{array}{l}\text { Risk Premium } \\
\text { t-value }\end{array}$} & Constant & UC-MS-trend & UC-MS-cycle & & \multirow{3}{*}{$\begin{array}{c}R_{a d j}^{2} \\
0.4607\end{array}$} \\
\hline & 2.9068 & -0.4625 & -5.4439 & & \\
\hline & 2.4695 & -0.4292 & -3.9945 & & \\
\hline \multicolumn{6}{|c|}{ Annual: $1927-2003$} \\
\hline \multirow{3}{*}{$\begin{array}{l}\text { Risk Premium } \\
\text { t-value }\end{array}$} & Constant & Exmkt & & & \multirow{3}{*}{$\begin{array}{c}R_{a d j}^{2} \\
0.2528\end{array}$} \\
\hline & -0.6335 & 10.0164 & & & \\
\hline & -0.1419 & 2.5222 & & & \\
\hline \multirow{3}{*}{$\begin{array}{l}\text { Risk Premium } \\
\text { t-value }\end{array}$} & Constant & Exmkt & HML & SMB & $R_{a d j}^{2}$ \\
\hline & 15.8721 & -7.9566 & 5.8207 & 3.4317 & \multirow{2}{*}{0.7660} \\
\hline & 2.7194 & -1.2867 & 4.5927 & 4.0176 & \\
\hline \multirow{3}{*}{$\begin{array}{l}\text { Risk Premium } \\
\text { t-value }\end{array}$} & Constant & HP-trend & HP-cycle & & $R_{a d j}^{2}$ \\
\hline & -0.0061 & 0.1528 & 9.3260 & & \multirow[t]{2}{*}{0.2396} \\
\hline & -0.0009 & 0.0429 & 2.4416 & & \\
\hline \multirow{3}{*}{$\begin{array}{l}\text { Risk Premium } \\
\text { t-value }\end{array}$} & Constant & UC-MS-trend & UC-MS-cycle & & \multirow{3}{*}{$\begin{array}{c}R_{a d j}^{2} \\
0.6195\end{array}$} \\
\hline & 12.1661 & -4.4871 & -9.3347 & & \\
\hline & 3.6362 & -1.7572 & -5.8531 & & \\
\hline
\end{tabular}


Table 4.9: Asset pricing tests with Fama-MacBeth procedure

This table shows the estimated risk premiums by way of Fama-MacBeth two-stage procedure. Assessed are four different asset pricing models: CAPM, Fama and French's three-factor model, two-beta intertemporal model based on Hodrick-Prescott decomposition and two-beta intertemporal model based on unobserved components approach with Markov-switching variances.

\begin{tabular}{|c|c|c|c|c|c|}
\hline \multicolumn{6}{|c|}{ Monthly: 1926:07 - 2003:12 } \\
\hline \multirow{3}{*}{$\begin{array}{l}\text { Risk Premium } \\
\text { t-value }\end{array}$} & \multirow{4}{*}{$\begin{array}{c}\text { Constant } \\
0.736 \\
2.746 \\
2.744 \\
\end{array}$} & \multirow{2}{*}{$\begin{array}{l}\text { Exmkt } \\
0.162\end{array}$} & & & $R_{\text {adj }}^{2}$ \\
\hline & & & & & 0.198 \\
\hline & & 0.509 & & & \\
\hline \multirow[t]{2}{*}{ Shanken -adj t-value } & & 0.508 & & & \\
\hline & Constant & Exmkt & HML & SMB & \\
\hline Risk Premium & 1.167 & -0.418 & 0.413 & 0.195 & 0.400 \\
\hline t-value & 4.732 & -1.615 & 3.457 & 1.711 & \\
\hline \multirow[t]{2}{*}{ Shanken -adj t-value } & 4.660 & -1.603 & 3.460 & 1.711 & \\
\hline & Constant & HP-trend & HP-cycle & & \\
\hline Risk Premium & 0.697 & -0.015 & 0.136 & & 0.256 \\
\hline t-value & 2.681 & -0.318 & 0.463 & & \\
\hline \multirow{2}{*}{ Shanken -adj t-value } & 2.679 & -0.318 & 0.463 & & \\
\hline & Constant & UC-MS-trend & UC-MS-cycle & & \\
\hline \multirow{2}{*}{$\begin{array}{l}\text { Risk Premium } \\
\text { t-value }\end{array}$} & 0.874 & 0.018 & 0.334 & & 0.263 \\
\hline & 3.538 & 0.068 & 1.238 & & \\
\hline \multirow[t]{2}{*}{ Shanken -adj t-value } & 3.527 & 0.067 & 1.236 & & \\
\hline & \multicolumn{3}{|c|}{ Quarterly: 1926: III - 2003:IV } & & \\
\hline & Constant & Exmkt & & & 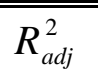 \\
\hline Risk Premium & 2.379 & 0.339 & & & 0.245 \\
\hline t-value & 3.224 & 0.398 & & & \\
\hline \multirow[t]{2}{*}{ Shanken -adj t-value } & 3.221 & 0.398 & & & \\
\hline & Constant & Exmkt & HML & SMB & \\
\hline Risk Premium & 3.596 & -1.418 & 1.427 & 0.496 & 0.468 \\
\hline t-value & 4.425 & -1.797 & 3.853 & 1.480 & \\
\hline \multirow[t]{2}{*}{ Shanken -adj t-value } & 4.205 & -1.744 & 3.829 & 1.480 & \\
\hline & Constant & HP-trend & HP-cycle & & \\
\hline Risk Premium & 2.858 & 0.220 & -0.479 & & 0.308 \\
\hline t-value & 3.523 & 1.013 & -0.560 & & \\
\hline \multirow[t]{2}{*}{ Shanken -adj t-value } & 3.480 & 1.003 & -0.556 & & \\
\hline & Constant & UC-MS-trend & UC-MS-cycle & & \\
\hline Risk Premium & 1.732 & 0.789 & -0.181 & & 0.338 \\
\hline t-value & 2.218 & 0.920 & -0.601 & & \\
\hline Shanken -adj t-value & 2.144 & 0.900 & -0.582 & & \\
\hline
\end{tabular}


Table 4.10: Evaluation of a six-beta asset-pricing model

This table shows the estimated risk premiums by way of Fama-MacBeth two-stage procedure. Assessed are six different asset pricing models: CAPM, Fama and French's three-factor model, two-beta intertemporal model based on Hodrick-Prescott (H-P) decomposition, two-beta intertemporal model based on unobserved components approach with Markov-switching variances (UC-MS), six-beta model based on UC-MS and four-beta model based on UC-MS.

\begin{tabular}{|c|c|c|c|c|c|c|c|c|}
\hline \multicolumn{9}{|c|}{ Quarterly: 1926: III - 2003:IV } \\
\hline & Constant & Exmkt & & & $R_{a d j}^{2}$ & & & \\
\hline Risk Premium & 2.379 & 0.339 & & & 0.245 & & & \\
\hline t-value & 3.224 & 0.398 & & & & & & \\
\hline \multirow[t]{2}{*}{ Shanken -adj t-value } & 3.221 & 0.398 & & & & & & \\
\hline & Constant & Exmkt & HML & SMB & $R_{a d j}^{2}$ & & & \\
\hline Risk Premium & 3.596 & -1.418 & 1.427 & 0.496 & 0.468 & & & \\
\hline t-value & 4.425 & -1.797 & 3.853 & 1.480 & & & & \\
\hline \multirow[t]{2}{*}{ Shanken -adj t-value } & 4.205 & -1.744 & 3.829 & 1.480 & & & & \\
\hline & Constant & HP-trend & HP-cycle & & $R_{a d j}^{2}$ & & & \\
\hline Risk Premium & 2.858 & 0.220 & -0.479 & & 0.308 & & & \\
\hline t-value & 3.523 & 1.013 & -0.560 & & & & & \\
\hline \multirow[t]{2}{*}{ Shanken -adj t-value } & 3.480 & 1.003 & -0.556 & & & & & \\
\hline & Constant & UC-MS-trend & UC-MS-cycle & & $R_{a d j}^{2}$ & & & \\
\hline Risk Premium & 1.732 & 0.789 & -0.181 & & 0.338 & & & \\
\hline t-value & 2.218 & 0.920 & -0.601 & & & & & \\
\hline \multirow[t]{2}{*}{ Shanken -adj t-value } & 2.144 & 0.900 & -0.582 & & & & & \\
\hline & Constant & UC-MS-trend & UC-MS-cycle & tr_zlag1 & tr_zlag2 & cy_zlag1 & cy_zlag2 & $R_{a d j}^{2}$ \\
\hline Risk Premium & 2.449 & -0.020 & -0.110 & $\overline{4} .058$ & -2.432 & -0.496 & -13.600 & 0.459 \\
\hline t-value & 3.579 & -0.025 & -0.266 & 0.936 & -0.536 & -1.114 & -0.493 & \\
\hline \multirow[t]{2}{*}{ Shanken -adj t-value } & 0.486 & -0.004 & -0.036 & 0.128 & -0.074 & -0.152 & -0.067 & \\
\hline & Constant & UC-MS-trend & UC-MS-cycle & tr_zlag1 & cy_zlag1 & & $R_{a d j}^{2}$ & \\
\hline Risk Premium & 1.866 & 0.537 & -0.548 & $\overline{3.798}$ & -0.864 & & 0.412 & \\
\hline t-value & 2.558 & 0.613 & -1.263 & 0.811 & -1.719 & & & \\
\hline Shanken -adj t-value & 1.500 & 0.408 & -0.743 & 0.477 & -1.011 & & & \\
\hline
\end{tabular}




\section{APPENDIX}




\section{Appendix:}

\section{State-space model and Kalman Filter estimation procedure:}

A state-space model consists of two equations (or two equation systems): a measurement equation and a transition equation. Measurement equation describes the relation between observed variables and unobserved state variables, while transition equation describes the dynamics of the state variables. A general form for state-space model can be written as follows:

Measurement equation: $y_{t}=A z_{t}+H \xi_{t}+e_{t}, e_{t} \sim$ i.i.d.N $(0, R)$

Transition equation: $\xi_{t}=\mu+F \xi_{t-1}+v_{t}, v_{t} \sim$ i.i.d.N $(0, Q)$

Where $e_{t}$ and $v_{t}$ are uncorrelated at any lags, i.e. $E\left(e_{t} v_{\tau}^{\prime}\right)=0$, for all $t$ and $\tau$.

Once a state-space model is set up, the Kalman filter is readily available for inferences on the unobserved state vector $\xi_{t}$. Basically, Kalman filter algorithm consists of prediction and updating equations. Let $\xi_{t \mid \tau}$ be the estimate of $\xi_{t}$ based on the information up to time $\tau$ and $P_{t \mid \tau}$ be the MSE of the estimate and defined as $P_{t \mid \tau}=E\left[\left(\xi_{t}-\xi_{t \mid \tau}\right)\left(\xi_{t}-\xi_{t \mid \tau}\right)^{\prime}\right]$. So, the prediction equations are:

$$
\begin{aligned}
\xi_{t \mid t-1} & =\mu+F \xi_{t-1 \mid t-1}, \\
P_{t \mid t-1} & =F P_{t-1 \mid t-1} F^{\prime}+Q, \\
\eta_{t \mid t-1} & =y_{t}-y_{t \mid t-1}=y_{t}-H \xi_{t \mid t-1}-A z_{t}, \\
f_{t \mid t-1} & =H P_{t \mid t-1} H^{\prime}+R,
\end{aligned}
$$

Updating equations are:

$$
\begin{aligned}
& \xi_{t \mid t}=\xi_{t \mid t-1}+K_{t} \eta_{t \mid t-1}, \\
& P_{t \mid t}=P_{t \mid t-1}-K_{t} H P_{t \mid t-1},
\end{aligned}
$$

where $K_{t}=P_{t \mid t-1} H^{\prime} f_{t \mid t-1}^{-1}$ is called the Kalman gain.

And the associated Gaussian log likelihood function is represented by:

$$
\ln L=-\frac{1}{2} \sum_{t=\tau+1}^{T} \ln \left(2 \pi f_{t \mid t-1}\right)-\frac{1}{2} \sum_{t=\tau+1}^{T} \eta_{t \mid t-1}^{\prime} f_{t \mid t-1}^{-1} \eta_{t \mid t-1}
$$


As stated in Kim and Nelson (1999), for nonstationary $\xi_{t}$, the log likelihood function is evaluated from observation $\tau+1(\tau>>1)$ to minimize the effect of the arbitrary initial value of $\xi_{0 \mid 0}$ on the log likelihood value.

For example, in section III, to control the actual cointegration relationship, I use this state-space model:

Measurement equation: $P_{t}^{i}-P_{t}^{w}=\alpha^{i}+\theta^{i} * P_{t}^{w}+x_{t}^{i}$;

Transition equation: $x_{t}^{i}=\delta^{i} * x_{t-1}^{i}+v_{t}^{i}$

In this case, $y_{t}=P_{t}^{i}-P_{t}^{w} ; \quad A=\left[\alpha^{i}, \theta^{i}\right] ; \quad z_{t}=\left[1, P_{t}^{w}\right] ; \quad H=1 ; \quad \mu=0 ; \quad F=\delta^{i} ; \quad R=0$; $Q=\sigma_{v i}^{2}$, and the state variable is $x_{t}^{i}$.

As for the general dynamic factor model in section IV:

$$
\begin{aligned}
& \text { Measurement equation --- } p_{t}^{w}=p_{t}^{w t}+p_{t}^{w s} \\
& p_{t}^{i}=p_{t}^{i t}+p_{t}^{i s}, i=1,2, \ldots 7 \\
& \text { Transition equations --- } p_{t}^{w t}=\mu+p_{t-1}^{w t}+\varepsilon_{t}, \varepsilon_{t} \sim \text { i.i.d.N }\left(0, \sigma_{\varepsilon}^{2}\right) \\
& p_{t}^{w s}=\varphi^{*} p_{t-1}^{w s}+\eta_{t}, \eta_{t} \sim \text { i.i.d. } . N\left(0, \sigma_{\eta}^{2}\right) \\
& p_{t}^{i t}=\mu^{i}+p_{t-1}^{i t}+v_{t}^{i}, v_{t}^{i} \sim \text { i.i.d.N } N\left(0, \sigma_{v i}^{2}\right) \\
& p_{t}^{i s}=\varphi^{i *} p_{t-1}^{i s}+w_{t}^{i}, w_{t}^{i} \sim \text { i.i.d. } N\left(0, \sigma_{w i}^{2}\right) \\
& y_{t}=\left[\begin{array}{llllllll}
p_{t}^{w} & p_{t}^{1} & p_{t}^{2} & p_{t}^{3} & p_{t}^{4} & p_{t}^{5} & p_{t}^{6} & p_{t}^{7}
\end{array}\right]^{\prime} \text {, and state variables are: } \\
& {\left[\begin{array}{llllllllllll}
p_{t}^{w t} & p_{t}^{1 t} & p_{t}^{2 t} & . & . & p_{t}^{7 t} & p_{t}^{w s} & p_{t}^{1 s} & p_{t}^{2 s} & . & . & p_{t}^{7 s}
\end{array}\right]^{1 \times 16}} \\
& A=0 \text {, and } z_{t}=0 \text {, }
\end{aligned}
$$




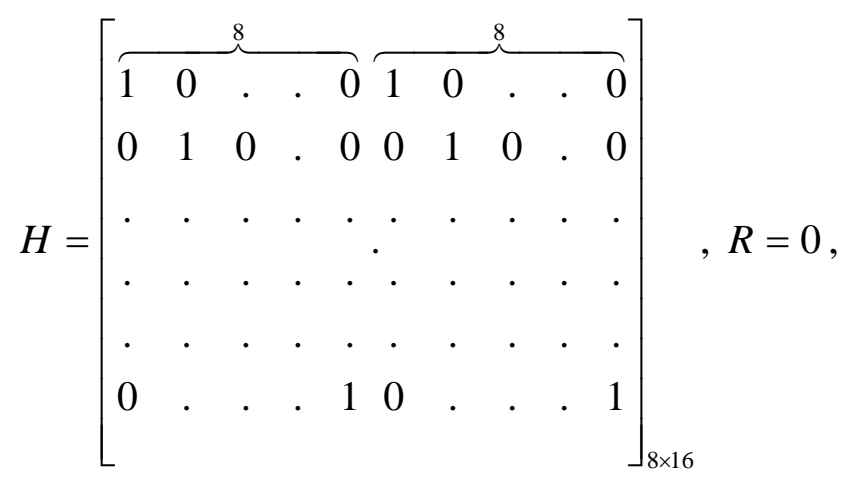

$\mu=\left[\begin{array}{lllllllll}\beta & \beta^{1} & \beta^{2} & . & \beta^{7} & 0 & . & . & 0\end{array}\right]_{1 \times 16}$,

$$
F=\left[\begin{array}{cccccccccc}
\overbrace{1} & 0 & \cdot & \cdot & 0 & 0 & 0 & \cdot & \cdot & 0 \\
\cdot & 1 & \cdot & \cdot & 0 & \cdot & \cdot & \cdot & \cdot & \cdot \\
\cdot & \cdot & \cdot & \cdot & \cdot & \cdot & \cdot & \cdot & \cdot & \cdot \\
\cdot & \cdot & \cdot & \cdot & \cdot & \cdot & \cdot & \cdot & \cdot & \cdot \\
\cdot & \cdot & \cdot & \cdot & 1 & \cdot & \cdot & \cdot & \cdot & \cdot \\
\cdot & \cdot & \cdot & \cdot & \cdot & \delta & \cdot & \cdot & \cdot & \cdot \\
\cdot & \cdot & \cdot & \cdot & \cdot & \cdot & \delta^{1} & \cdot & \cdot & \cdot \\
\cdot & \cdot & \cdot & \cdot & \cdot & \cdot & \cdot & \cdot & \cdot & \cdot \\
\cdot & \cdot & \cdot & \cdot & \cdot & \cdot & \cdot & \cdot & \cdot & \cdot \\
0 . & \cdot & \cdot & \cdot & \cdot & 0 & \cdot & \cdot & \cdot & \delta^{7}
\end{array}\right]_{16 \times 16}
$$




$$
Q=\left[\begin{array}{cccccccccc}
\overbrace{\sigma_{\varepsilon}^{2}} & \sigma_{\varepsilon, v 1} & \sigma_{\varepsilon, v 2} & \cdot & 0 & 0 & \cdot & \cdot & \cdot & 0 \\
\sigma_{\varepsilon, v 1} & \sigma_{v 1}^{2} & \sigma_{v 1, v 2} & \cdot & \cdot & \cdot & \cdot & \cdot & \cdot & \cdot \\
\sigma_{\varepsilon, v 2} & \sigma_{v 1, v 2} & \sigma_{v 2}^{2} & \cdot & \cdot & \cdot & \cdot & \cdot & \cdot & \cdot \\
\cdot & \cdot & \cdot & \cdot & \cdot & \cdot & \cdot & \cdot & \cdot & \cdot \\
\cdot & \cdot & \cdot & \cdot & \sigma_{v 7}^{2} & 0 & \cdot & \cdot & \cdot & 0 \\
0 & \cdot & \cdot & \cdot & 0 & \sigma_{\eta}^{2} & \sigma_{\eta, w 1} & \sigma_{\eta, w 2} & \cdot & 0 \\
\cdot & \cdot & \cdot & \cdot & \cdot & \sigma_{\eta, w 1} & \sigma_{w 1}^{2} & \sigma_{w 1, w 2} & \cdot & \cdot \\
\cdot & \cdot & \cdot & \cdot & \cdot & \sigma_{\eta, w 2} & \sigma_{w 1, w 2} & \sigma_{w 2}^{2} & \cdot & \cdot \\
\cdot & \cdot & \cdot & \cdot & \cdot & \cdot & \cdot & \cdot & \cdot & \cdot \\
0 & \cdot & \cdot & \cdot & 0 & 0 & \cdot & \cdot & \cdot & \sigma_{w 7}^{2}
\end{array}\right]
$$




\section{REFERENCES}




\section{References}

Angas, L.L.B., 1936, Investment for appreciation-Forecasting movements in security prices, Technique of Trading in Shares for Profit (Macmillan, London).

Balvers, Ronald J., T.F. Cosimano, and B. McDonald, 1990, Predicting stock returns in an efficient market, Journal of Finance 45, 1109-1128.

Balvers, Ronald J., Yangru Wu, and Erik Gilliland, 2000, Mean reversion across national stock markets and parametric contrarian investment strategies, Journal of Finance 55, 745-772.

Balvers, Ronald J., 2004, Foundations of Asset Pricing, Lecture notes.

Baxter, M. and R.G. King, 1999, Measuring business cycles: approximate band-pass filters for economic time series, Review of Economics and Statistics 81, 575 - 593.

Beveridge, S. and Nelson, Charles, 1981, A new approach to the decomposition of Economic time series into permanent and transitory components with particular attention to the measurement of business cycle, Journal of Monetary Economics 7, $151-174$.

Black, Fischer, 1993, Beta and return, Journal of Portfolio Management 20, 8-18.

Blanchard, O. J., 1993, Movements in the equity premium, Brookings Papers on Economic Activity, Macroeconomics (2), 75-118.

Boschan, C. and W.W. Ebanks, 1978, The phase-average trend: a new way of measuring growth, in 1978 Proceedings of the Business and Economic Statistics Section, American Statistical Association, Washington, D.C.

Breen, William J. and Robert Korajczyk, 1995, On selection biases in book-to-market tests of asset pricing models, Working paper, Kellogg Graduate School of Management.

Campbell, J.Y., 1987, Stock returns and the term structure, Journal of Financial Economics 18, 373-399

Campbell, John Y., 1991, A variance decomposition for stock returns, Economic Journal 101, $157-179$.

Campbell, John Y., 1993, Intertemporal asset pricing without consumption data, American Economic Review 83, 487 - 512. 
Campbell John Y., 2000, Asset Pricing at the Millennium, Journal of Finance 55, 15151567.

Campbell, John Y. and Tuomo Vuolteenaho, 2003, Bad beta, good beta, NBER paper No. 9509.

Clark, Peter K., 1987, The cyclical component of U.S. economic activity, Quarterly Journal of Economics 102, 797 - 814.

Chan, Louis K.C., Jason Karceski and Josef Lakonishok, 1999, On portfolio optimization: forecasting covariances and choosing the risk model, Review of Financial Studies 12, 937-974.

Chow, K. Victor, 2001, Marginal conditional stochastic dominance, statistical inference, and measuring portfolio performance, Journal of Financial Research vol. XXIV, 289-307.

Chow, K. Victor and Ou Hu, Conditional mean dominance: testing for the sufficiency of anomalies, working paper.

Cochrane, John H., 1988, How big is the random walk in GNP?, Journal of Political Economy 96, $893-920$.

Cochrane, J.H., 1991, Production-based asset pricing and the link between stock returns and economic fluctuations, Journal of Finance 46, 209-238.

Cochrane, John H., 2001, Asset Pricing, Princeton NJ: Princeton University Press.

Cooper, Michael, Huseyin Gulen, and Maria Vassalou, 2001, Investing in size and bookto-market portfolio using information about the macroeconomy: some new trading rules, Working paper.

DeBondt, Werner and Richard Thaler, 1985, Does the Market Overreact?, Journal of Finance 40, 793-805.

DeBondt, Werner and Richard Thaler, 1987, Further Evidence on Investor Overreaction and Stock Market Seasonality, Journal of Finance 42, 557-581.

DeBondt, Werner and Richard Thaler, 1990, Do Security Analysts Overreact?, American Economic Review 80, 52 - 57.

Elton, Edwin J., 1999, Expected return, realized return, and asset pricing tests, Journal of Finance 54, 1199-1220.

Fama, Eugene F. and Kenneth R. French, 1988, Permanent and temporary components of stock prices, Journal of Political Economy 96, 246 - 273. 
Fama, Eugene F. and Kenneth R. French, 1992, The cross-section of expected stock returns, Journal of Finance 47, 427-465.

Fama, Eugene F. and Kenneth R. French, 1993, Common risk factors in the returns on stocks and bonds, Journal of Financial Economics 33, 3-56.

Fama, Eugene F. and Kenneth R. French, 1995, Size and book-to-market factors in earnings and returns, Journal of Finance 50, 131-155.

Fama, Eugene F. and Kenneth R. French, 1996, Multifactor explanations of asset pricing anomalies, Journal of Finance 51, 55-84.

Fama, Eugene F. and Kenneth R. French, 1997, Industry costs of equity, Journal of Financial Economics 43, 153-193.

Fama, Eugene F. and Kenneth R. French, 1998, Value versus growth: the international evidence, Journal of Finance 53, 1975-1999.

Fama, Eugene F. and Kenneth R. French, 2002, The equity premium, Journal of Finance 57, 637-659.

Fama, Eugene F. and J. MacBeth, 1973, Risk, return, and equilibrium: empirical tests, Journal of Political Economy 71, 607-636.

Fama, Eugene F. and G. Schwert, 1977, Asset returns and inflation, Journal of Financial Economics 5, 115-146.

Ferson, Wayne E. and C.R. Harvey, 1993, The risk and predictability of international equity returns, Review of Financial Studies 6, 527-566.

Ferson, Wayne E. and Dennis H. Locke, 1998, Cost of Capital Estimation without CAPM: Analysis of Sources of Error, Management Science 44, 485-500.

Forster, F.D., T. Smith, and R. Whaley, 1997, Assessing the goodness-of-fit of asset pricing models: The distribution of the maximal $\mathrm{R}^{2}$, Journal of Finance 52, 591607.

Hamilton, James D., Time Series Analysis, Princeton University Press.

Hansen, Lars Peter and Robert J. Hodrick, 1980, Forward exchange rates as optimal predictors of future spot rates: an econometric analysis, Journal of Political Economy 88, 829-853. 
Harvey, A.C., 1985, Trends and cycles in macroeconomic time series, Journal of Business and Economic Statistics 3, 216 - 227.

Harvey, A.C., 1989, Forecasting, structural time series models and the Kalman Filter, Cambridge University Press, Cambridge, New York and Melbourne.

Harvey, A.C., 2000, Trend analysis, University of Cambridge, Faculty of Economics and Politics, Manuscript.

Harvey, A.C. and A. Jaeger, 1993, Detrending, stylized facts and the business cycle, Journal of Applied Econometrics 8, 231 - 247.

Hodrick, Robert J., 1992, Dividend yields and expected stock returns: alternative procedures for inference and measurement, Review of Financial Studies 5, 357 386.

Hodrick, R.J. and E.C. Prescott, 1997, Postwar U.S. business cycles: an empirical investigation, Journal of Money Credit and Banking 29, 1 - 16.

Jagannathan, R., E. R. McGrattan and A. Scherbian, 2001, The declining U.S. equity premium, Quarterly Review, Federal Reserve Bank of Minneapolis.

Jagannathan, R. and Iwan Meier, 2002, Do we need CAPM for capital budgeting?, NBER working paper 8719 .

Jegadeesh, Narasimhan, 1990, Evidence of predictable behavior of security returns, Journal of Finance 45, 881-898.

Jagannathan, Ravi and Z. Wang, 1996, The conditional CAPM and the cross-section of expected returns, Journal of Finance 51, 3-53.

Kasa, Kenneth, 1992, Common stochastic trends in international stock markets, Journal of Monetary Economics 29, $95-124$.

Kim, Chang-Jin, and Charles R. Nelson, State-space models with regime switching Classical and Gibbs-Sampling approaches with applications, The MIT Press.

Kim, Chang-Jin, and Myung-Jig Kim, 1996, Transient fads and the crash of '87', Journal of Applied Econometrics 11, $41-58$.

Koopman, S.J., Exact initial Kalman Filter and smoother for non-stationary time series models, Journal of the American Statistical Association 92, 1630 - 1638.

Kothari, S.P., Jay Shanken and Richard G. Sloan, 1995, Another look at the cross-section of expected stock returns, Journal of Finance 50, 185-224. 
Lakonishok, Josef, Andrei Shleifer, and Robert W. Vishny, 1994, Contrarian investment, extrapolation, and risk, Journal of Finance 49, 1541 - 1578.

Liew, Jimmy and Maria Vassalou, 2000, Can book-to-market, size and momentum be risk factors that predict economic growth?, Journal of Financial Economics 57, 221-245.

Lo, Andrew W. and A. Craig MacKinlay, 1988, Stock market prices do not follow random walks: Evidence from a simple specification test, Review of Financial Studies 1, $41-66$.

Lo, Andrew W. and A. Craig MacKinlay, 1990b, Data-snooping biases in tests of financial asset pricing models, Review of Financial studies 3, 431-467.

Lucas, Robert E., Jr., 1980, Methods and problems in business cycle theory, Journal of Money, Credit, and Banking 12, 696 - 715.

Merton, Robert C., 1969, Lifetime portfolio selection under uncertainty: The continuous time case, Review of Economics and Statistics 51, 247-257.

Merton, Robert C., 1971, Optimum consumption and portfolio rules in a continuous-time model, Journal of Economic Theory 3, 373-413.

Merton, Robert C., 1973, An intertemporal capital asset pricing model, Econometrica 41, 867-887.

Merton, Robert C., 1980, On estimating the expected return on the market, Journal of Financial Economics 8, 323-361.

Mitchell, Wesley C., 1913, Business Cycles, Berkeley, California: University of California Press.

Moskowitz, T.J. and Mark Grinblatt, 1999, Do industries explain momentum?, Journal of Finance, 1249-1290.

Nelson, Charles and Charles I. Plosser, 1982, Trends and random walks in macroeconomic time series: some evidence and implications, Journal of Monetary Economics 10, 139 - 162.

Pastor, Lubos and Robert F. Stambaugh, 1999, Costs of Equity Capital and Model Mispricing, Journal of Finance 54, 67-121.

Pesaran, M. H. and A. Timmermann, 1995, Predictability of stock returns: Robustness and economic significance, Journal of Finance 50, 1201-1228. 
Pesaran, M. H. and A. Timmermann, 2000, A recursive modeling approach to predicting stock returns, Economic Journal 110, 159-191.

Poterba, James M. and Lawrence H. Summers, 1988, Mean reversion in stock prices: evidence and implications, Journal of Financial Economics 22, 27 - 59.

Proietti, T., 2002, Forecasting with structural time series models, in A Companion to Economic Forecasting, M.P. Clements and D.F.Hendry editors, Oxford: Blackwell Publishers.

Richards, A.J., 1995, Comovements in national stock market returns: Evidence of predictability, but not cointegration, Journal of Monetary Economics 36, 631 - 654.

Rotemberg, J.J., 1999, A heuristic method for extracting smooth trends from economics time series, NBER working paper No. 7439.

Siegel, Jeremy, 1999, Stocks for the long run, $2^{\text {nd }}$ edition. (Irwin).

Shanken, Jay, 1992, On the estimation of beta-pricing models, Review of Financial Studies 5, $1-33$.

Summers, Lawrence, 1986, Does the stock market rationality reflect fundatmental values?, Journal of Finance 41, $591-601$.

Wadhwani, S. B., 1999, The US stock market and the global economic crisis, National Institute Economic Review, 86-105.

Watson, Mark W. 1986, Univariate detrending methods with stochastic trends, Journal of Monetary Economics 18, 49 - 75.

Zarnowitz, Victor and Ataman Ozyildirim, 2002, Time series decomposition and measurement of business cycles, trends and growth cycles, NBER working paper No. 8736. 